\title{
Constricted migration is associated with stable 3D genome structure differences in melanoma cells
}

Rosela Golloshi ${ }^{1}$, Trevor F. Freeman ${ }^{1}$, Priyojit Das ${ }^{2}$, Thomas Isaac Raines ${ }^{1}$, Rebeca San Martin ${ }^{1}$, Christopher Playter ${ }^{1}$, Delaney Thurston ${ }^{1}$, Rachel Patton McCord ${ }^{1,3, *}$

${ }^{1}$ Biochemistry \& Cellular and Molecular Biology Department, University of Tennessee, Knoxville, TN ${ }^{2}$ UT-ORNL Graduate School of Genome Science and Technology, University of Tennessee, Knoxville, TN ${ }^{3}$ Lead Contact

*Correspondence: rmccord@utk.edu (R.P.M.)

Running Title: Constricted migration genome structure

\begin{abstract}
To spread from a localized tumor, metastatic cancer cells must squeeze through constrictions that cause major nuclear deformations. Since chromosome structure affects nucleus stiffness, gene regulation and DNA repair, here we investigate how confined migration affects or is affected by 3D genome structure. Using melanoma (A375) cells, we identify phenotypic differences in cells that have undergone multiple rounds of constricted migration. These cells display a stably higher migration efficiency, elongated morphology, and differences in the distribution of Lamin A/C and heterochromatin. Using Hi-C, we observe differences in chromosome spatial compartmentalization specific to cells that have passed through constrictions and related alterations in expression of genes associated with migration and metastasis. These sequentially constricted cells also show more nuclear deformations and altered behavior in a 3D collagen matrix. Our observations reveal a relationship between chromosome structure changes, metastatic gene signatures, and the altered nuclear appearance of aggressive melanoma.
\end{abstract}

\section{Introduction}

Despite significant improvements in the diagnosis and treatment of cancer, most patients with advanced metastatic disease face a terminal illness incurable by current therapeutic methods. The dissemination of cancer cells from the primary tumor and the formation of new tumor colonies at distant sites involves a complex multi-step invasion-metastasis cascade (Lambert et al., 2017, Gupta and Massague, 2006, Chambers et al., 2002, Fidler, 2003). To metastasize, cancer cells must squeeze through constrictions of the extracellular matrix or endothelial lining that are much smaller than their nucleus, causing major nuclear deformations. While the cell membrane and cytoplasm are quite elastic, the ability of the cell's nucleus to withstand large deformations and squeeze through these small spaces is limited by its size and stiffness, posing challenges to confined migration (Davidson et al., 2014, Fu et al., 2012, Wolf et al., 2013, Friedl et al., 2011). Nuclear stiffness and deformability depend on two major components: lamin proteins (Lamin A/C and Lamin B) and the chromatin (Stephens et al., 2017, Harada et al., 2014, Davidson et al., 2014).

Lamin A/C expression and its stoichiometric relation to Lamin B contributes to nuclear mechanical properties (Harada et al., 2014, Swift et al., 2013). Low expression levels of Lamin 
A/C lead to decreased nuclear stiffness and increased deformability (Lammerding et al., 2006). Likely resulting from increased nuclear flexibility, decreased expression of Lamin A/C has been shown to promote the ability of mouse embryonic fibroblasts (MEFs) to undergo constricted migration (Davidson et al., 2014). Conversely, neutrophils show decreased constricted migration ability when expression of Lamin A/C is increased (Davidson et al., 2014, Rowat et al., 2013). Given this relation between lamin content and confined migration, it is not surprising that low levels of Lamin A/C are correlated with the increased aggressiveness of some cancers (Broers et al., 1993, Wazir et al., 2013). However, not all invasive cancers downregulate their Lamin A/C expression; in fact, an increase in Lamin A/C expression is associated with progression of aggressive cancers such as colorectal and skin basal cell carcinoma (Willis et al., 2008, Venables et al., 2001) and lower levels of Lamin A/C can decrease cell migration speed (Lee et al., 2007). Decreased lamin content during confined migration can even be deleterious as it jeopardizes the integrity of the nuclear envelope and increases the probability of nuclear rupture events as the nucleus passes through a constriction. Such nuclear rupture can lead to DNA damage, DNA loss, and genomic aberrations (Denais et al., 2016, Irianto et al., 2017a, Raab et al., 2016).

In addition to the complex role of lamin content, recent work emphasizes the role of chromatin in mechano-sensing, nuclear stiffness, and invasiveness (Miroshnikova et al., 2017, Stephens et al., 2017). The two-meter chromatin fiber is packaged into the nucleus in a complex 3D architecture that informs DNA replication, repair, and gene regulation (Marchal et al., 2019, Krijger and de Laat, 2016, Spielmann et al., 2018). Regions of the genome are marked with different histone modifications and become spatially compartmentalized into heterochromatin and euchromatin through different mechanisms, such as tethering to nuclear structures like the lamina, or due to phase separation (van Steensel and Belmont, 2017, Strom et al., 2017, Larson et al., 2017). Genes within less-accessible heterochromatin tend to be inactive while those localized to more accessible euchromatin tend to be active or poised for quick transcriptional activation (GasparMaia et al., 2011, van Steensel and Belmont, 2017). Chromatin state has also been shown to influence nuclear physical properties: increasing heterochromatin increases nuclear stiffness while increasing euchromatin decreases stiffness and increases nuclear deformability (Stephens et al., 2017, Stephens et al., 2018). Such global changes in chromatin state can also influence confined migration. For example, increasing euchromatin or decreasing heterochromatin inhibits mouse melanoma cell migration (Gerlitz and Bustin, 2010, Maizels et al., 2017, Segal et al., 2018, Panagiotakopoulou et al., 2016, Krause et al., 2019). Mounting evidence also points to the effect that extracellular physical forces have on nuclear mechanics and chromosome structure. Nuclei aspirated into narrow micropipettes exhibit stretching of chromatin domains that is sometimes irreversible (Irianto et al., 2017b). External cellular forces can also affect gene expression through direct chromatin deformations (Tajik et al., 2016). Despite such connections between chromatin structure, nucleus deformation, and nucleus mechanics, it is not fully understood whether the 3D organization of the genome affects or is affected by confined migration.

Ever-improving microscopic techniques and the development of chromosome conformation capture approaches have revolutionized our understanding of 3D genome architecture in the past decade (Dekker et al., 2002, Bickmore and van Steensel, 2013, Rowley and Corces, 2018, Pombo and Dillon, 2015, Abbas et al., 2019). Chromosomes are folded at different length scales into loops, topologically associating domains (TADs), active and inactive (A/B) compartments, 
and chromosomal territories. How these layers of structure are affected by physical nucleus shape changes such as the kind experienced during constricted migration remains unknown. Previous work has shown that 3D chromosome organization changes correlate with the progression of cancer (Taberlay et al., 2016, Barutcu et al., 2015, Zhou et al., 2019) and that both the formation and downstream effect of chromosomal translocations in cancer progression is influenced by 3D genome structure (Zhang et al., 2012, Hnisz et al., 2016). In addition, some changes have been noted in the 3D genome structures of neutrophils that have undergone constricted migration (Jacobson et al., 2018). Taken together, previous evidence leads us to hypothesize that chromosome structure may influence a cancer cell's ability to undergo confined migration, that changes in chromosome structure could be caused by nuclear deformation, and that such chromosome structure changes could influence gene regulation and cancer cell phenotype. In this study, we seek to unite these previous ideas and investigate whether certain 3D genome structures of cancer cells facilitate or are changed by constricted migration.

Here, we use invasive human melanoma cells (A375) to investigate the properties of the nucleus and 3D chromosome structure that accompany confined migration. We find that A375 cells that have migrated numerous times through tight constrictions show increased migration efficiency and are phenotypically distinct from cells that do not pass through constrictions. These repeatedly constricted cells exhibit specific and stable differences in 3D genome organization, particularly at the level of A/B compartmentalization, lamin localization, and gene expression patterns. Our results suggest that 3D genome architecture correlates with the ability of cancer cells to undergo constricted migration. Our experimental data and modeling suggest that 3D genome and nucleus differences could arise from both initial heterogeneity in the melanoma cell population and changes induced by constricted migration itself.

\section{Keywords}

Constricted migration, Hi-C, 3D genome, melanoma, genome compartments, metastasis, heterochromatin, lamin, nucleus structure

\section{Glossary}

Control Cells that have not undergone constricted migration but have been grown in a $2 \mathrm{D}$ culture dish.

Top-5 Cells that have not undergone constricted migration through $5 \mu \mathrm{m}$ pores even after 10 chances to do so.

Bottom-5 Cells that have undergone constricted migration through $5 \mu \mathrm{m}$ pores for 10 rounds.

Top20-5 Cells that have not undergone constricted migration through $5 \mu \mathrm{m}$ pores even after 20 chances to do so.

Bottom 20-5 Cells that have undergone constricted migration through $5 \mu \mathrm{m}$ pores for 20 rounds. 
Top-12

Bottom-12
Cells that have not undergone migration through $12 \mu \mathrm{m}$ pores even after 10 chances to do so.

\section{Results}

\section{Melanoma cells exhibit an increased migration efficiency and cell morphology differences after multiple rounds of constricted migration}

To investigate the relationship between 3D genome organization and constricted migration, we performed sequential rounds of migration of A375 cells through $5 \mu \mathrm{m}$ transwell filters (Figure 1A, see Methods for a detailed experimental design). The diameter of A375 nuclei ranges from 8-16 $\mu \mathrm{m}$ (Figure S1A), so passing through these $5 \mu \mathrm{m}$ pores requires nuclear constriction and leads to nuclear deformations. Interestingly, cells that successfully undergo constricted migration through $5 \mu \mathrm{m}$ pores in each round migrate more efficiently in subsequent rounds of the same Transwell assay. The population of cells that have passed through the $5 \mu \mathrm{m}$ pores for 10 consecutive rounds (Bottom-5) migrate at high efficiency $(\sim 70 \%)$ as compared to the initial population (20\%) (Figure 1B and Figure S1B). In contrast, the population of cells that failed to undergo constricted migration through $5 \mu \mathrm{m}$ pores in the first round, shows a progressive decrease in migratory efficiency, approaching $0 \%$ migration after 10 consecutive rounds (Top-5) (Figures 1B and S1B).

These differences in migration efficiency correspond to other notable differences in cell phenotype. Phase contrast imaging of the A375 subpopulations shows that Bottom-5 cells exhibit a decrease in cell-cell adhesions and an elongated cell body (suggesting a more mesenchymal phenotype) when compared to Top-5 cells (Figures 1C, S1C and S1D). We extended the sequential transwell assay up to 20 rounds and observe similar elongated cell bodies in A375 cells that have undergone 20 rounds of $5 \mu \mathrm{m}$ transwell migration (Bottom20-5) (Figures S1C and S1D). These morphological characteristics and migration efficiency differences are maintained even after continuous culture (5 passages) or multiple freeze-thaw cycles, indicating stable phenotypes among Top-5 and Bottom-5 cells (Figure S1E). Live cell imaging of Top-5 and Bottom- 5 cells migrating on a 2D surface shows that Bottom-5 cells maintain their elongated shapes and display lobopodia/lamellipodia-like migration, while Top-5 cells display amoeboidlike migration over a 13-hr migration period (Figure 1D and Movie S1 and S2). We then investigated whether loss of cell-cell adhesion in Bottom-5 cells corresponded to differences in focal adhesions by phalloidin stain (Figure S1F). Bottom-5 cells exhibit a decrease in the area covered by bright F-actin stain compared to Control and Top cells (Top-5 and Top20-5) (Figure $\mathrm{S} 1 \mathrm{~F}$, Focal adhesion area quantification). This suggests a decrease in focal adhesion size, which has been previously reported to correlate with increase in migration speed and cell motility (Kim and Wirtz, 2013). These results indicate that the morphological and/or genetic differences associated with passing through constrictions could promote migration in consecutive rounds. These phenotypes are consistent with previous studies showing that the degree of invasiveness is often correlated with an increase of cell shape irregularity (Lyons et al., 2016, Machesky, 2008). 
It has been previously reported that A375 cells are heterogeneous in their metastatic ability (Kozlowski et al., 1984), so it is possible that the differences we observe are associated only with ability to migrate and are not specific to passing through a constriction. We repeated the sequential migration experiment using transwell filters with $12 \mu \mathrm{m}$ pores (Figures $1 \mathrm{E}$ and $\mathrm{S} 1 \mathrm{G}$ ). Migration through $12 \mu \mathrm{m}$ pores does not pose a major spatial barrier for the nucleus since the minimum diameter of the majority of A375 cells is smaller than the $12 \mu \mathrm{m}$ diameter of the pore (Figure S1A). Accordingly, A375 cells migrate at a much higher rate ( 55-70\%) in the first round of the $12 \mu \mathrm{m}$ transwell assay (Figures $1 \mathrm{E}$ and $\mathrm{S} 1 \mathrm{G}$ ).

Cells that were successful at migrating through $12 \mu \mathrm{m}$ pores for 10 rounds (Bottom-12) displayed only a minimal increase in migratory efficiency as compared to the more dramatic increase shown by Bottom-5 cells after each consecutive round (Figures $1 \mathrm{E}$ and S1G). In contrast, cells that failed to migrate through the $12 \mu \mathrm{m}$ pores (Top-12), displayed a significant decrease in migration efficiency after 10 sequential rounds of migration (Figures $1 \mathrm{E}$ and S1G). Phase contrast imaging revealed that Top-12 cells display high cell-cell adhesion and more epithelial like phenotypes ( similar to Top-5) when compared to Bottom-12 cells, which show a decrease in cell-cell adhesion and more elongated phenotypes (Figure 1F and Figure S1H). However, when quantifying solidity or aspect ratio (Figure 1G) for all A375 sub-populations, it becomes clear that Bottom-5 cells exhibit more dramatic elongated phenotypes ( $65 \%$ of cells with solidity < $0.8125)$ compared to Bottom- 12 cells $(\sim 45 \%$ of cells with solidity $<0.8125)$ which show no significant difference compared to the Control, Top-5 and Top-12 cells (Figure 1G). When challenged to migrate through 5 - $\mu$ m pores, Bottom-12 cells showed a migration efficiency similar to the control population $(\sim 3-20 \%)$. These unconstricted migration results indicate that there is heterogeneity in the initial A375 population, with some cells unable to migrate even through large pores (Top-12). But, simply being able to migrate is not enough to guarantee efficient migration through constricted spaces, indicating that additional features are associated with constricted migration. Given the large degree of nuclear squeezing necessary to undergo constricted migration, we next turned to investigating the organization of the nucleus and chromosome structure of these different subgroups of A375 cells. 

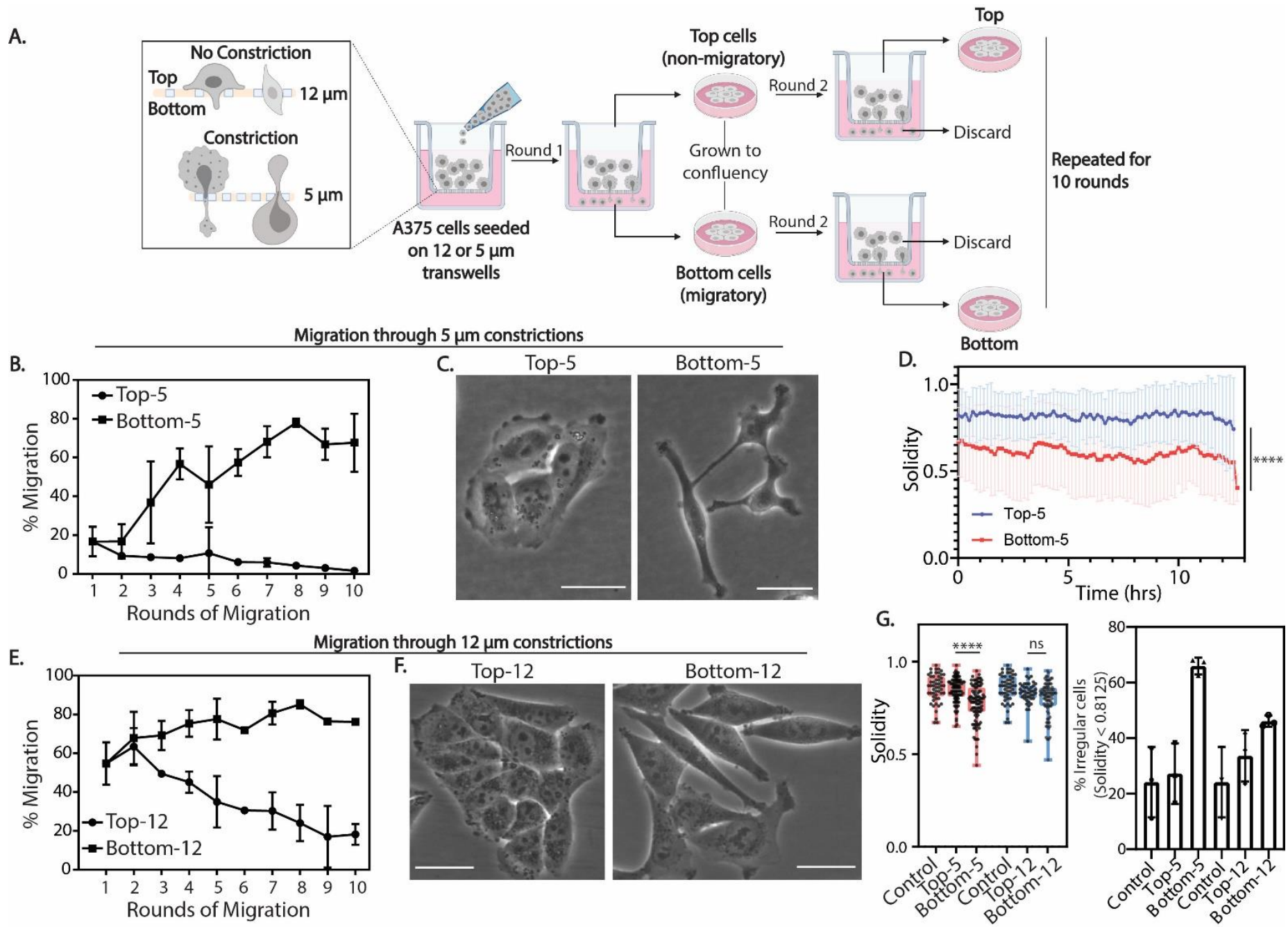

Figure 1. A375 cells exhibit morphological differences and increase in migration efficiency after sequential rounds of constricted migration. (A) Layout of sequential transwell migration experiment with A375 cells. (B) Migration efficiency (\% of cells that migrated through filter pores in each round) of A375 cells during $5 \mu \mathrm{m}$ constricted migration. Error bars $=$ mean \pm SD for $\mathrm{n}=3$ biological replicates. (C) Phase contrast imaging of A375 cells that have not (Top-5) or have (Bottom-5) undergone $5 \mu \mathrm{m}$ constricted migration. (D) Solidity measurements of A375 cells undergoing live-cell migration for 13 hours on a 2D surface (1 indicates ideally round cell shapes and lower values indicate more irregularities and protrusions). Error bars $=$ mean \pm SD for $n=76$ Top -5 cells and $n=77$ Bottom -5 cells $(p<0.0001$, twotailed t-test). (E) Migration efficiency of A375 cells undergoing $12 \mu \mathrm{m}$ transwell migration. (F) Phase contrast imaging of A375 cells that have not (Top-12) or have (Bottom-12) undergone $12 \mu \mathrm{m}$ transwell migration. (G) (Left panel) Quantification of solidity measurements between A375 cells that have undergone migration through $5 \mu \mathrm{m}$ and $12 \mu \mathrm{m}$ pores. Box and whiskers plot showing all data points in Control ( $\mathrm{n}=52$ cells), Top-5 ( $\mathrm{n}=99$ cells), Bottom-5 ( $\mathrm{n}=98$ cells), Top-12 ( $\mathrm{n}=43$ cells) and Bottom-12 $(\mathrm{n}=82$ cells) $(* * * * \mathrm{p}<0.0001, \mathrm{~ns} \mathrm{p}=0.0726$, two-tailed $\mathrm{t}$-test). (Right panel) \% of A375 cells displaying irregular morphology (Solidity $<0.8125$, first quartile of Control). Scale bars (white) indicate a length of $25 \mu \mathrm{m}$. 
A.

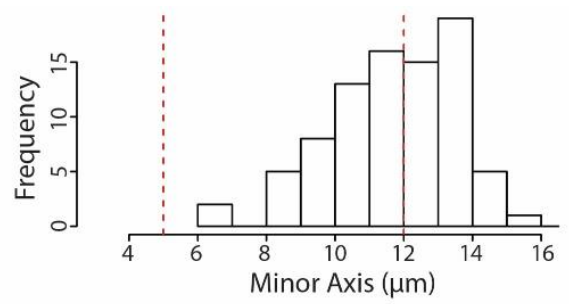

c.

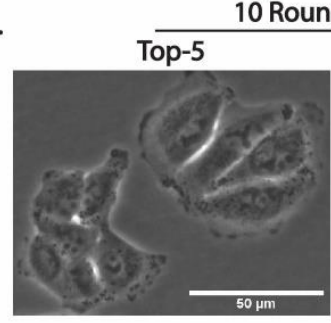

E.
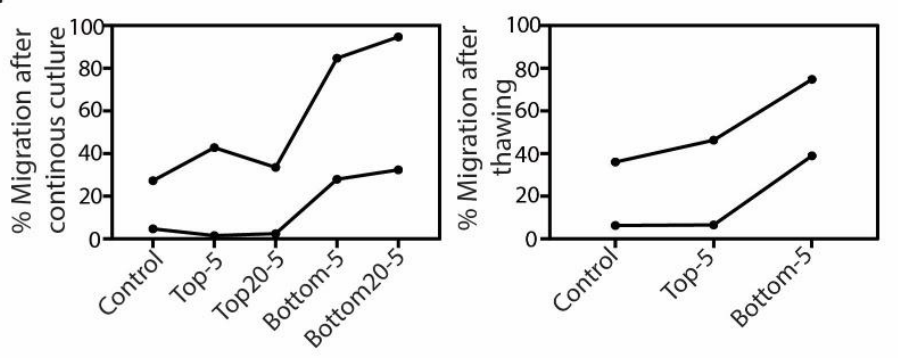

G.

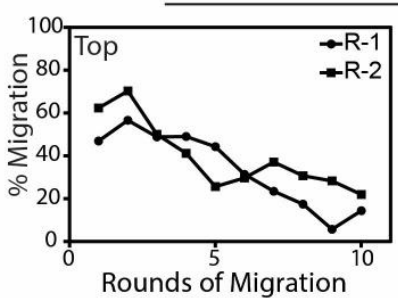

$12 \mu \mathrm{m}$

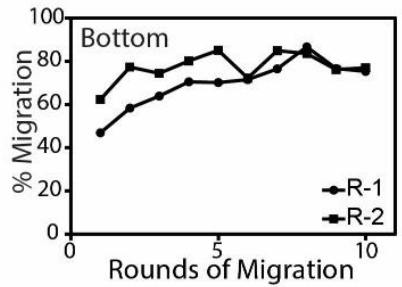

H.
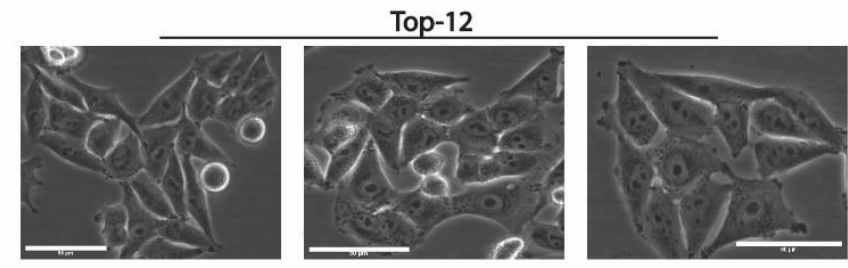

Bottom-12
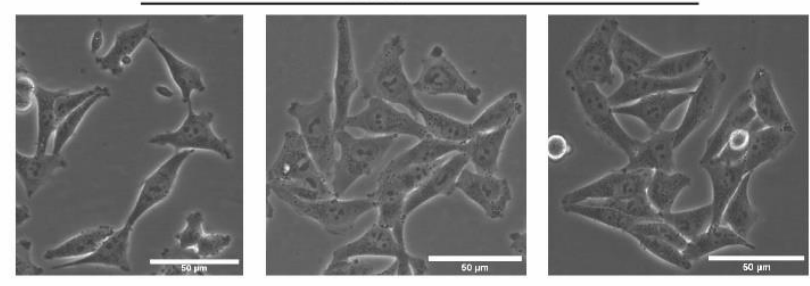

B.

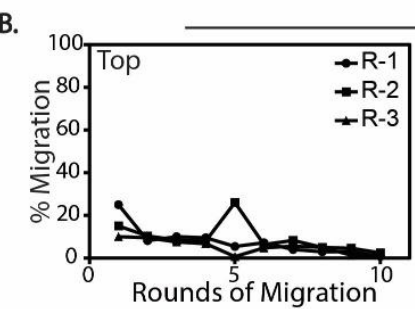

$5 \mu \mathrm{m}$

D.
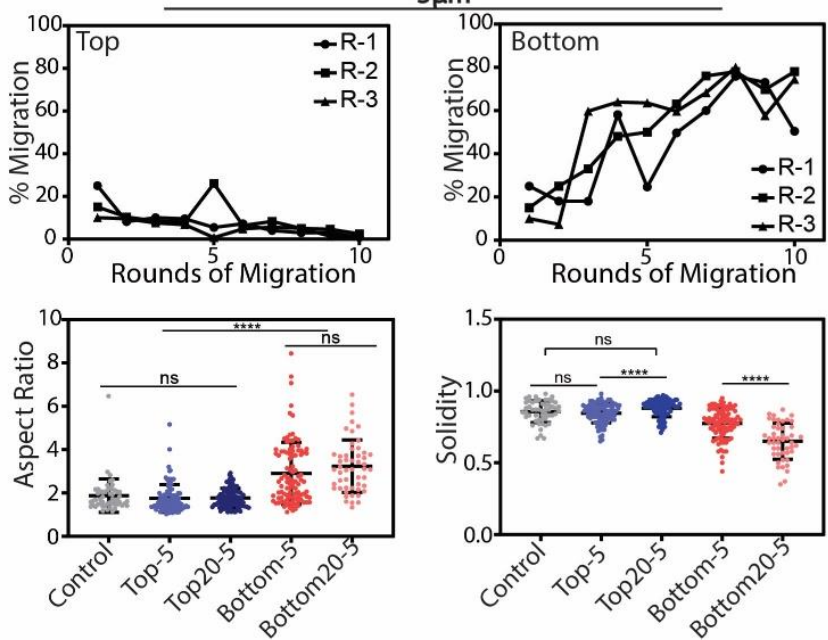

F.

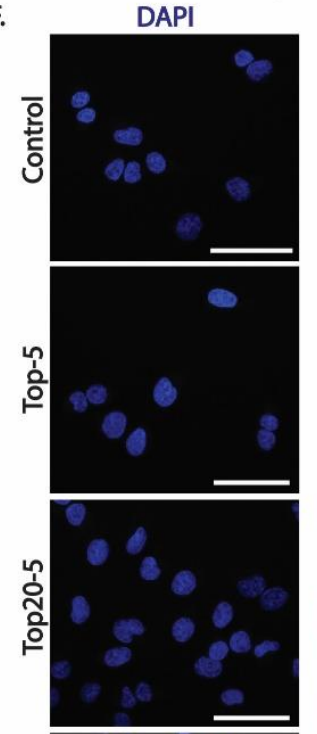

Phalloidin
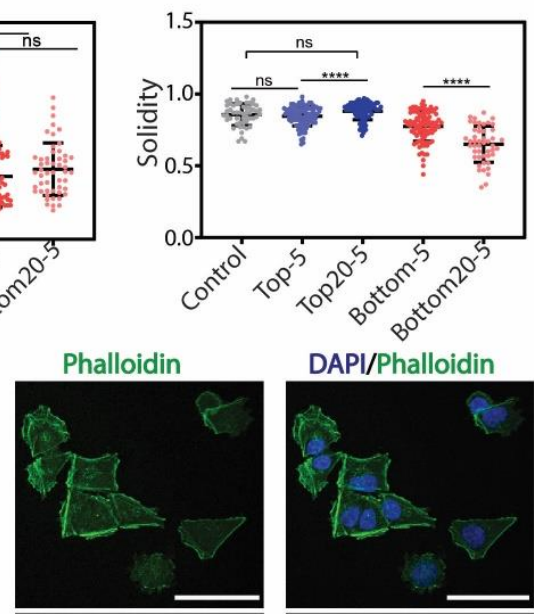

DAPI/Phalloidin
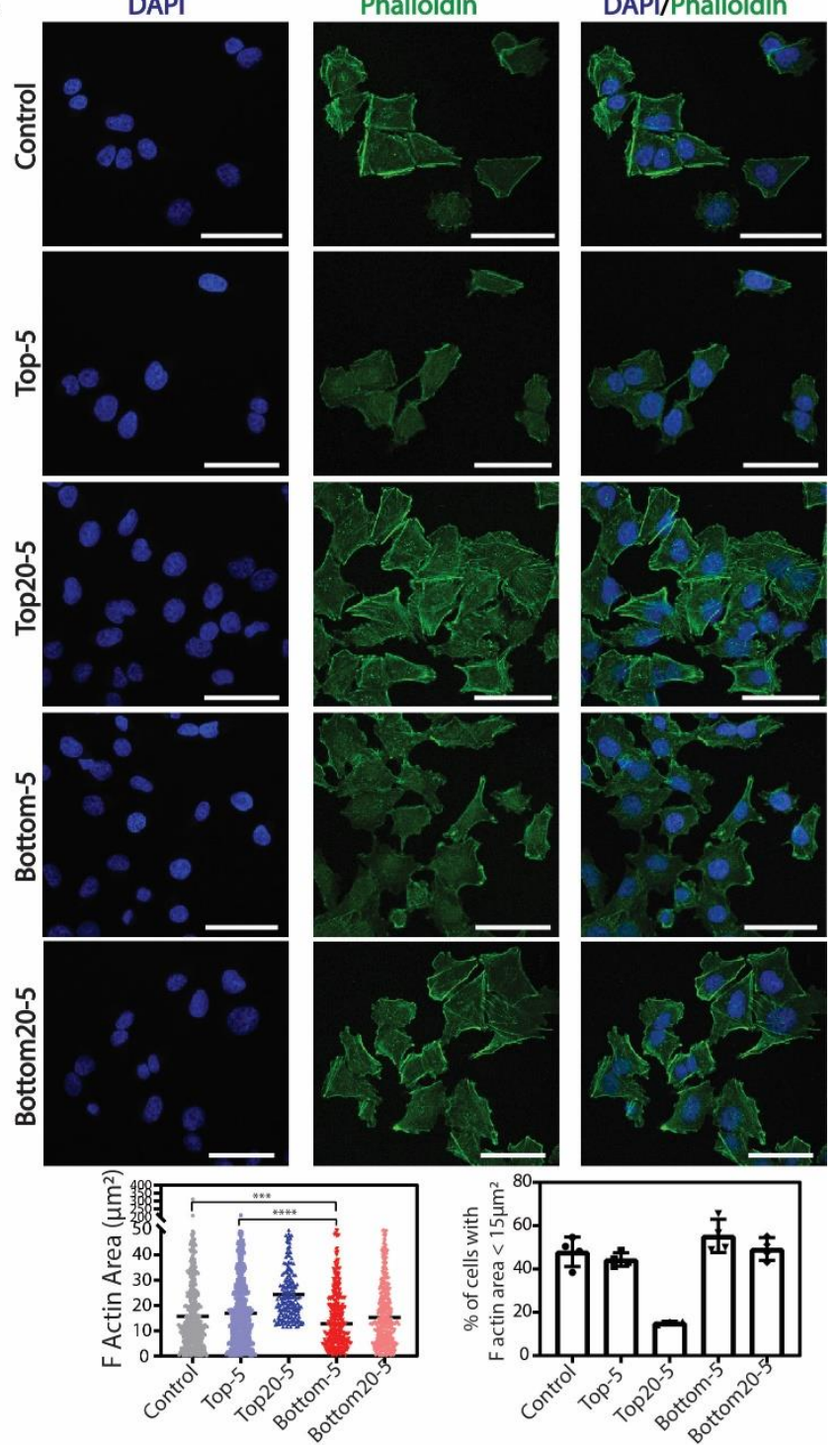

Supplementary Figure 1. A375 cells exhibit persistent increase in migration efficiency and morphological changes after $5 \mu \mathrm{m}$ constricted migration. (A) Minor axis (minimum diameter) measurements of A375 cell nuclei based on confocal z-stacks. $\mathrm{N}=85$. (B) Migration efficiency of each biological replicate for 10 rounds of $5 \mu \mathrm{m}$ transwell migration 
in Top (left) and Bottom (right) cells. (C) Phase contrast images of A375 cells exposed to $5 \mu \mathrm{m}$ transwell migration for 10 and 20 rounds. (D) Aspect ratio (left graph) and solidity (right graph) measurements of cells in A375 subpopulations that have undergone 10 rounds (Top-5 and Bottom-5) and 20 rounds (Top20-5 and Bottom20-5) of migration through $5 \mu$ m constrictions $(* * * * \mathrm{p}<0.0001$; Control $(\mathrm{n}=52)$, Top-5 $(\mathrm{n}=99)$, Top20-5 $(\mathrm{n}=93)$, Bottom-5 $(\mathrm{n}=98)$, Bottom205 ( $n=48)$; two - tailed t-test). (E) Migration efficiency of A375 cells after 5 passages of continuous culture (left graph) and after one cycle of freeze - thawing (right graph) in two replicates. (F) Confocal images of Phalloidin (green) and DAPI (blue) immunostained cells that have undergone constricted migration. Graphs represent area of the cell with phalloidin staining passing a threshold $(* * * \mathrm{p}=0.0003$, $* * * * \mathrm{p}<0.0001$; two-tailed t-test $)$ and fraction of cells that display phalloidin staining area $<15 \mu \mathrm{m}^{2}$. (G) Migration efficiency of each replicate for 10 rounds of $12-\mu \mathrm{m}$ transwell migration. (H) Phase contrast images of A375 cells exposed to $12 \mu \mathrm{m}$ transwell migration. Scale bars (white) indicate a length of $50 \mu \mathrm{m}$.

\section{Irregular distribution of Lamin $\mathrm{A} / \mathrm{C}$ and peripheral localization of heterochromatin correlate with an increased constricted migration proficiency}

Changes in nuclear morphology are consistently used as a diagnostic tool in cancer progression (Kadota et al., 2012) and previous studies report nuclear envelope rupture and blebbing as a result of constricted migration (Denais et al., 2016, Raab et al., 2016) (Irianto et al., 2017a, Davidson and Lammerding, 2014). Thus, we next investigated whether nuclear morphology changes accompany the phenotype differences we observed among cell populations after sequential constricted migration. We used immunofluorescence imaging to observe nucleus morphology, heterochromatin distribution (H3K9me3), and Lamin A/C levels and distribution 18 hours after sequential constricted migration. Analyzing maximum projected images, we find that Bottom-5 nuclei more often exhibit elongated morphologies ( $40 \%$ of population) than Control (25\%), Top$5(20 \%)$ and Bottom-12 nuclei ( 15\%) (Figure S2A). When statistically comparing these cell populations, only Bottom-12 has a significantly different mean aspect ratio compared to Bottom5. This observation indicates the inherent variability in nuclear morphology that already exists in the original population and that variation is still seen in each subpopulation after migration. The differences after constricted migration lie in the extreme tail of the distribution rather than being observed in the average. We also investigated nuclear morphology features of 3D projections (sphericity and elongation). These also show no significant differences in mean, but, again, there are a larger number of Bottom-5 cells that are outliers from the central tendency with more elongated nuclei (Figure S2B). These results are in agreement with previous reports showing that the morphological changes with constriction are reversible (Irianto et al., 2017a), but indicate that outliers with elongated nuclei are more likely to be observed among the cell population that has gone through constricted migration.

Given their previously reported roles in mechanosensing and modulating nucleus stiffness, we next investigated whether differences in Lamin $\mathrm{A} / \mathrm{C}$ and constitutive heterochromatin (H3K9me3) levels or distribution exist among A375 subpopulations with different migratory ability (Figure 2A). High resolution confocal microscopy of immunostained nuclei showed no difference in the overall level of Lamin $\mathrm{A} / \mathrm{C}$ in the cell subpopulations that had undergone constricted migration vs. those that had not (Figure S2C). The lack of difference in Lamin A/C protein levels was confirmed by western blot (Figure S2G). These unchanged Lamin A/C levels echo recent observations reported in mechanically stretched cells (Nava et al., 2020) and are in contrast to other reports that 
show an association between lower levels of Lamin $\mathrm{A} / \mathrm{C}$ and increased constricted migration ability (Harada et al., 2014). We find that, like total Lamin A/C levels, Lamin B1 protein levels and $\mathrm{H} 3 \mathrm{~K} 9$ me3 levels do not change across the subpopulations (Figure $\mathrm{S} 2 \mathrm{H}$ and J). Lamin A/C can be regulated not only in abundance, but also by phosphorylation, which can affect its solubility and distribution (Torvaldson et al., 2015). But we also see no difference in levels of Lamin A/C phosphorylated at Ser22 (Figure S2L).

Though total levels of Lamin A/C were unchanged, we noted that the distribution of Lamin A/C appeared to be different after constricted migration. A375 Control, Top-5 and Bottom-12 nuclei showed a uniform distribution of Lamin A/C throughout the nuclear envelope (Figure 2A, middle panel). In contrast, Bottom-5 nuclei display an altered distribution of Lamin A/C with certain regions of the nuclear envelope devoid of it (Figures $2 \mathrm{~A}$ and $2 \mathrm{~B}$, indicated by white arrows, Movie S3 and S4). By visual inspection, we found that $~ 50 \%$ of Bottom-5 nuclei show an abnormal distribution of Lamin A/C when compared to 25\% of Bottom-12 nuclei (Figure 2C) suggesting that differences in Lamin $\mathrm{A} / \mathrm{C}$ distribution are specific to constricted migration. To quantify this difference more systematically, we compared the coefficient of variance of the Lamin A/C signal across each nucleus between the A375 subpopulations. We find that Bottom-5 nuclei exhibit higher Lamin A/C coefficient of variance when compared to Control, Top-5 and Bottom-12 cells (Figure 2D). This variation in Lamin A/C pixel intensity could arise due to an increase in nuclear envelope invaginations and wrinkling in Bottom-5 nuclei as observed from central orthogonal slices of Lamin A/C stained nuclei (Figure 2E).

Like Lamin A/C, we find that the distribution of heterochromatin is altered in A375 cells that have undergone constricted migration. Heterochromatic foci are randomly distributed throughout the nucleus in Control, Top-5, and Bottom-12 cells (Figure 2A) with some foci localized to the nuclear periphery. In contrast, heterochromatin foci in Bottom-5 nuclei are more dispersed and the majority of $\mathrm{H} 3 \mathrm{~K} 9 \mathrm{me} 3$ signal is localized to the nuclear periphery (Figures $2 \mathrm{~A}$ and $2 \mathrm{~F}$ ). Indeed, quantifying the radial distribution of $\mathrm{H} 3 \mathrm{~K} 9 \mathrm{me} 3$ signal in the nucleus reveals that Bottom-5 nuclei display a lower $\mathrm{H} 3 \mathrm{~K} 9 \mathrm{me} 3$ intensity in the interior of the nucleus when compared to Control and Top-5 nuclei (Figure 2G, top graph). These differences are very evident when compared to Bottom-12 cells which display a random distribution of $\mathrm{H} 3 \mathrm{~K} 9 \mathrm{me} 3$ foci across the nucleus (Figure $2 \mathrm{G}$, bottom graph). Alterations in $\mathrm{H} 3 \mathrm{~K} 9 \mathrm{me} 3$ and Lamin $\mathrm{A} / \mathrm{C}$ distributions are also evident in line scans across central slices of the nucleus (Figure 2H). Bottom-5 cells exhibit a significant increase in heterochromatin localization to the nuclear periphery when compared to Control and Top-5 cells along both the major and minor axes. Interestingly, this analysis also reveals a lower intensity of Lamin $\mathrm{A} / \mathrm{C}$ at the nuclear periphery of Control and Bottom-5 cells as compared to Top-5 cells, specifically across the minor (narrower) axis of the nucleus.

All effects on nuclear morphology and Lamin A/C distribution discussed thus far are observed persisting 18 hours after the final round of constricted migration. To determine whether transient effects of constricted migration on nuclear morphology and Lamin A/C distribution were different or more dramatic, we performed transwell migration of Bottom-12 and Bottom-5 cells for 3 and 5 hours after seeding on the transwell chambers (pore sizes $12 \mu \mathrm{m}$ and $5 \mu \mathrm{m}$ respectively). After 3 hours of migration, there is no difference in the average nucleus sphericity and elongation between constricted $(5 \mu \mathrm{m})$ and unconstricted $(12 \mu \mathrm{m})$ migrating cells (Figure S2D, top panel). In contrast, at 5 hours, the nuclei of Bottom- 5 cells are on average more elongated compared to Bottom-12 
nuclei (Figure S2D, bottom panel). The Lamin A/C distribution of Bottom-5 cells is more variable than Bottom-12 at both 3 and 5 hours (Figure S2E). While we see no difference in overall Lamin $\mathrm{A} / \mathrm{C}$ levels among the subpopulations 18 hours after migration, there could be a minor transient difference in Lamin A/C- we observe a lower Lamin A/C intensity in Bottom-5 cells that have undergone migration for 3 hours as compared to Bottom-12 cells, but this difference is no longer present at 5 hours into the transwell migration experiment (Figure S2F).

A.
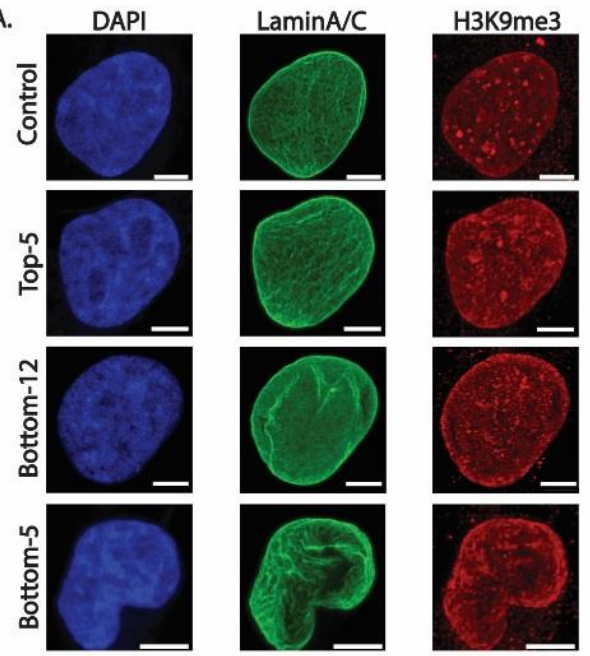

F.

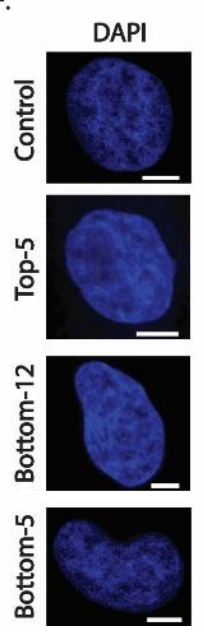

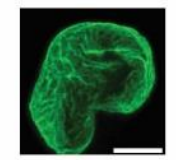

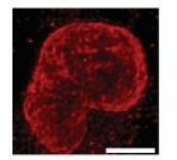

H3K9me3
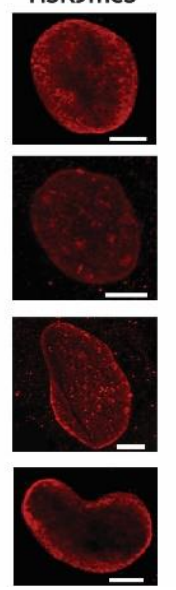

DAPV/H3K9me3
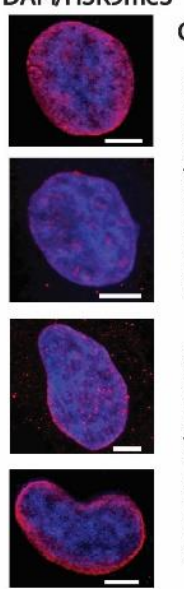

D.
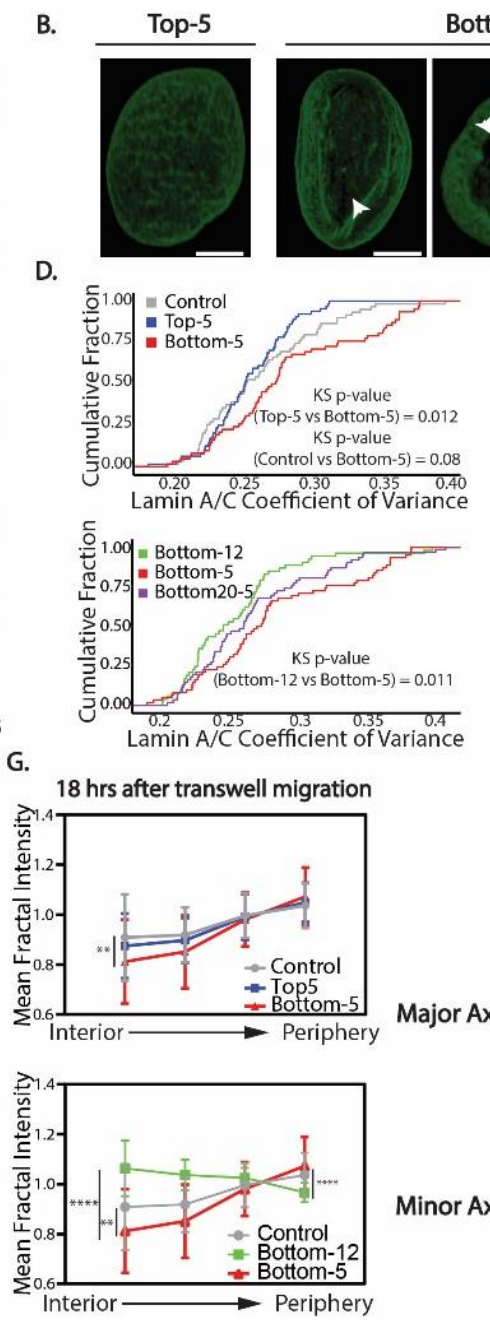

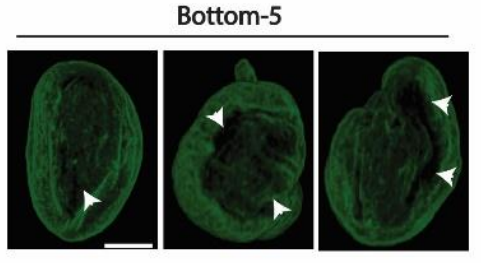

E.

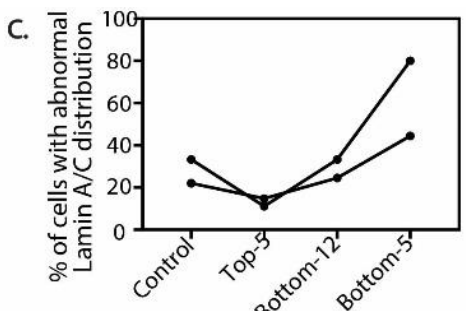

Central Slice of LaminA/C $\mathrm{B}^{\mathrm{O}}$
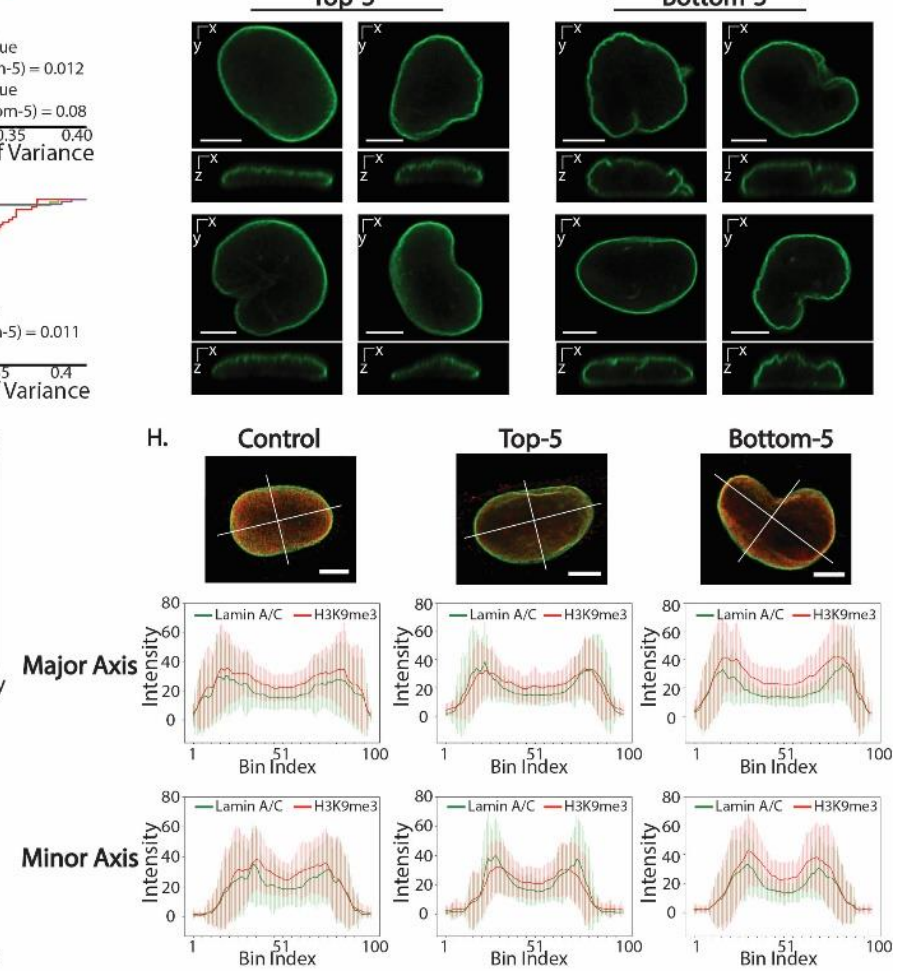

Figure 2. Irregular distribution of Lamin $\mathrm{A} / \mathrm{C}$ and heterochromatin upon constricted migration. (A) A375 nuclei stained with DAPI (blue), Lamin A/C (green) and $\mathrm{H} 3 \mathrm{~K} 9 \mathrm{me} 3$ (red) in the indicated migration conditions. Images shown represent a maximum projection of z-stacks. (B) Snapshots of 3D reconstructed z-stacks of A375 nuclei stained with Lamin A/C. For full 3D visualization see Movie S3 and S4. White arrows indicate areas devoid of Lamin A/C. (C) Fraction of A375 cells displaying irregular patterns of Lamin A/C, defined by visual inspection, in Control $(n=59)$, Top-5 ( $n=63)$, Bottom-12 ( $=80)$ and Bottom-5 $(\mathrm{n}=64)$ cells. Two replicates shown in the figure; lines connect A375 conditions within the same replicate. (D) Cumulative distribution plots of Lamin A/C coefficient of variance in all indicated A375 subpopulations. Kolmogorov-Smirnov test p-values indicated in each plot. (E) Central orthogonal slices of Lamin A/C stained nuclei in Top-5 and Bottom-5 cells. (F) A375 nuclei stained with DAPI (blue) and H3K9me3 (red) for indicated A375 cell subpopulations. Images represent maximum projection of z-stacks. (G) Radial intensity distribution of $\mathrm{H} 3 \mathrm{~K} 9 \mathrm{me} 3$ signal in the maximum projected nuclei of A375 subpopulations. Top graph: H3K9me3 radial intensity distribution in Control ( $\mathrm{n}=$ 59), Top-5 ( $\mathrm{n}=63)$ and Bottom-5 $(\mathrm{n}=64)$ nuclei $(* * \mathrm{p}=0.0069$, two-tailed t-test). Bottom graph: H3K9me3 radial intensity distribution in Control $(\mathrm{n}=59)$, Bottom-12 $(\mathrm{n}=80)$ and Bottom-5 $(\mathrm{n}=64)$ nuclei $(* * * * \mathrm{p}<0.0001$, ** $\mathrm{p}=0.0069$; two- 
tailed t-test). Error bars $=$ mean $\pm \mathrm{SD}$. $(\mathrm{H})$ Intensity line scans across major and minor axes of Lamin $\mathrm{A} / \mathrm{C}$ and $\mathrm{H} 3 \mathrm{~K} 9 \mathrm{me} 3$ central slices in A375 Control $(n=59)$, Top-5 $(n=63)$ and Bottom-5 $(n=64)$ nuclei. Error bars $=$ mean \pm SD. All scale bars (white) in this figure $=5 \mu \mathrm{m}$.
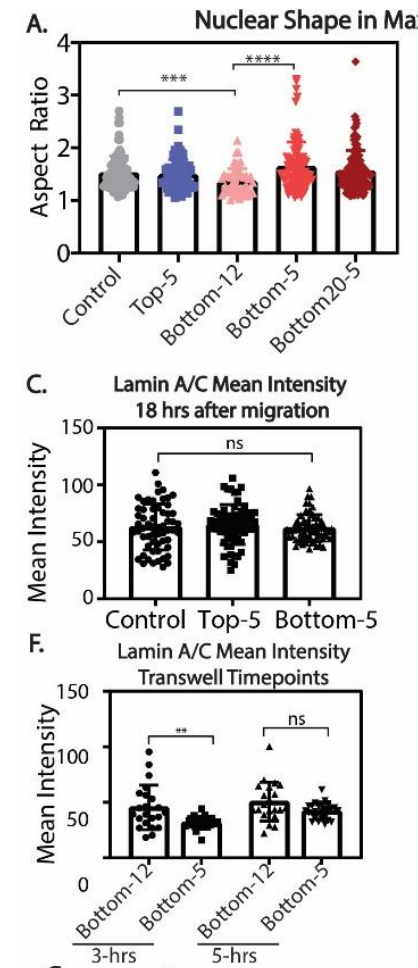

G.
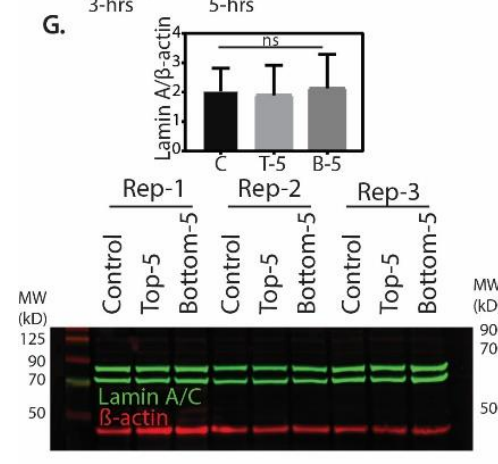

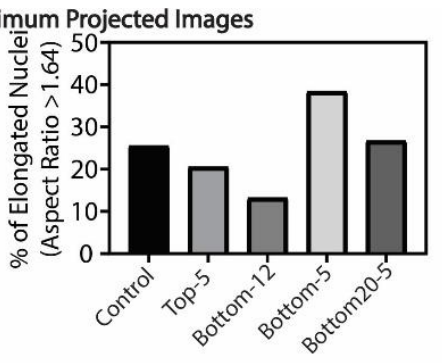

D.
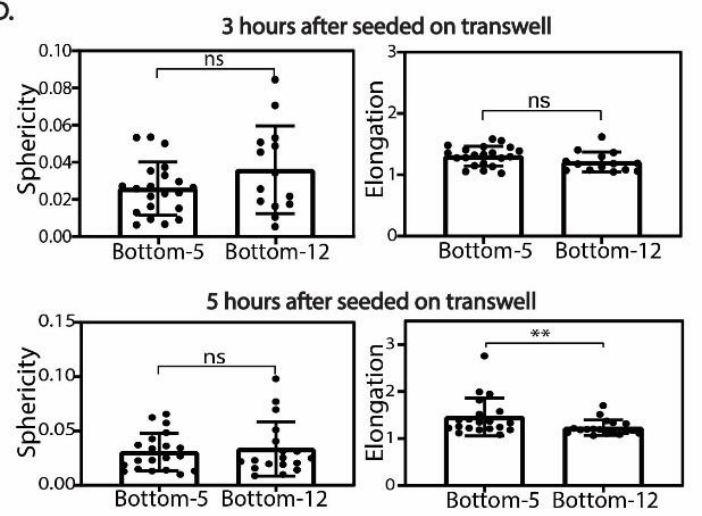

B. $0.20 \quad$ Nuclear Shape in 3D Projegcted Images

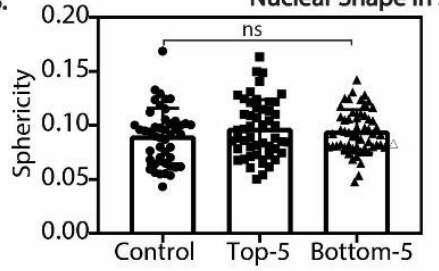

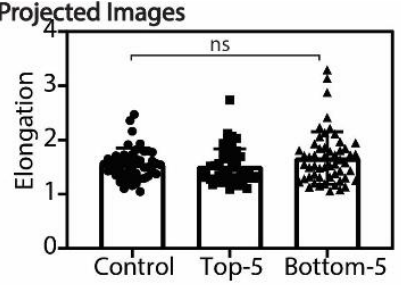

E.
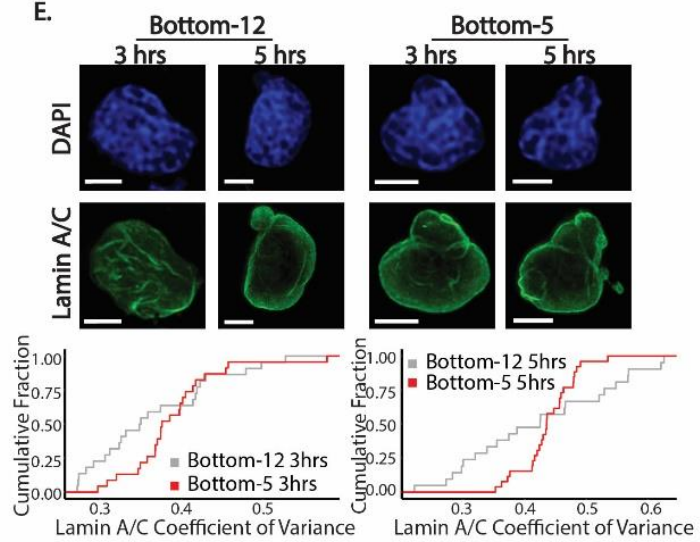

H.

I.

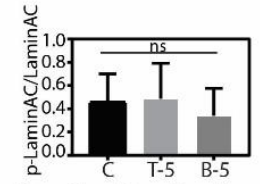

J.
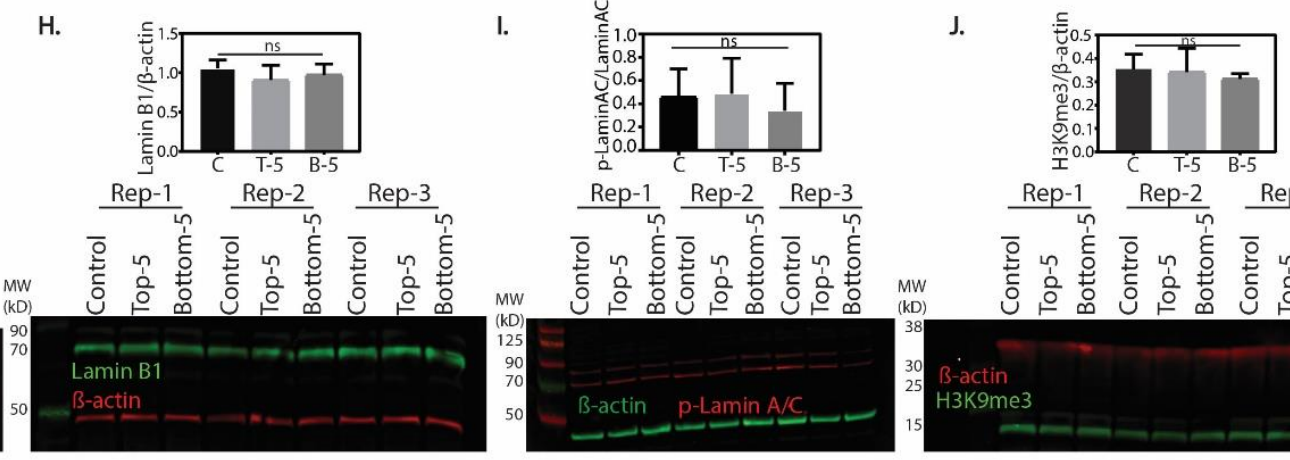

Rep-1 Rep-2 Rep-3
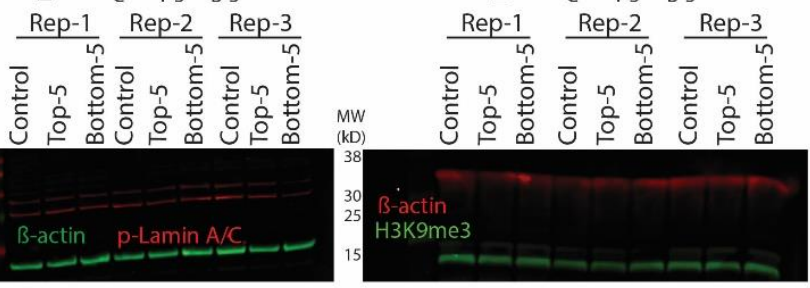

Supplementary Figure 2. Changes in nuclear morphology after constricted migration are not dependent on Lamin A/C or $\mathrm{H} 3 \mathrm{~K} 9 \mathrm{me} 3$ protein levels. (A) Aspect ratio quantification of A375 maximum projected nuclei exposed to transwell migration $(* * * \mathrm{p}=0.0002, * * * * \mathrm{p}<0.0001$, two-tailed t-test; Control $=59$, Top-5 = 63, Bottom- $12=80$, Bottom-5 = 64, Bottom20-5 = 52 nuclei). (B) Nuclear shape measurements of 3D reconstructed A375 nuclei. The number of nuclei quantified remains the same as in A. (C) Lamin A/C mean intensity in A375 cells 18 hrs after migrating through $5 \mu \mathrm{m}$ transwell chambers. Number of nuclei quantified remains the same as in A. (D) Nuclear shape measurements of 3D reconstructed nuclei at 3 and $5 \mathrm{hrs}$ after migrating through $5 \mu \mathrm{m}$ (Bottom-5; $\mathrm{n}=23$ for $3 \mathrm{hrs}$ and $\mathrm{n}=26$ for $5 \mathrm{hrs}$ ) and $12 \mu \mathrm{m}$ (Bottom-12; $\mathrm{n}=19$ for $3 \mathrm{hrs}$ and $\mathrm{n}=22$ for 5hrs) transwell pores. ${ }^{* *} \mathrm{p}=0.0043$; two-tailed t-test. (E) Top Panel: DAPI (blue) and Lamin A/C (green) immunostained nuclei of A375 cells that have migrated through 5 and $12 \mu$ m transwell pores for 3 and 5 hrs. Bottom Panel: Cumulative distribution plots of Lamin A/C coefficient of variance in maximum projected nuclei. Number of nuclei remains the same as in D. (F) Lamin A/C mean intensity of A375 cells that have undergone migration through 5 and $12 \mu \mathrm{m}$ transwell chambers for 3 and 5 hours. Number of nuclei quantified is the same 
as D. ${ }^{* *} \mathrm{p}=0.0058$; two-tailed t-test. (G-J) Western blot analysis of A375-Control, Top-5 and Bottom-5 cells probing for Lamin A/C, Lamin B1, phospho-Lamin A/C (Ser22) and H3K9me3. Quantification shown above each blot. No significant differences found in pairwise comparisons by two-tailed t-test. All scale bars (white) in this figure $=5 \mu \mathrm{m}$.
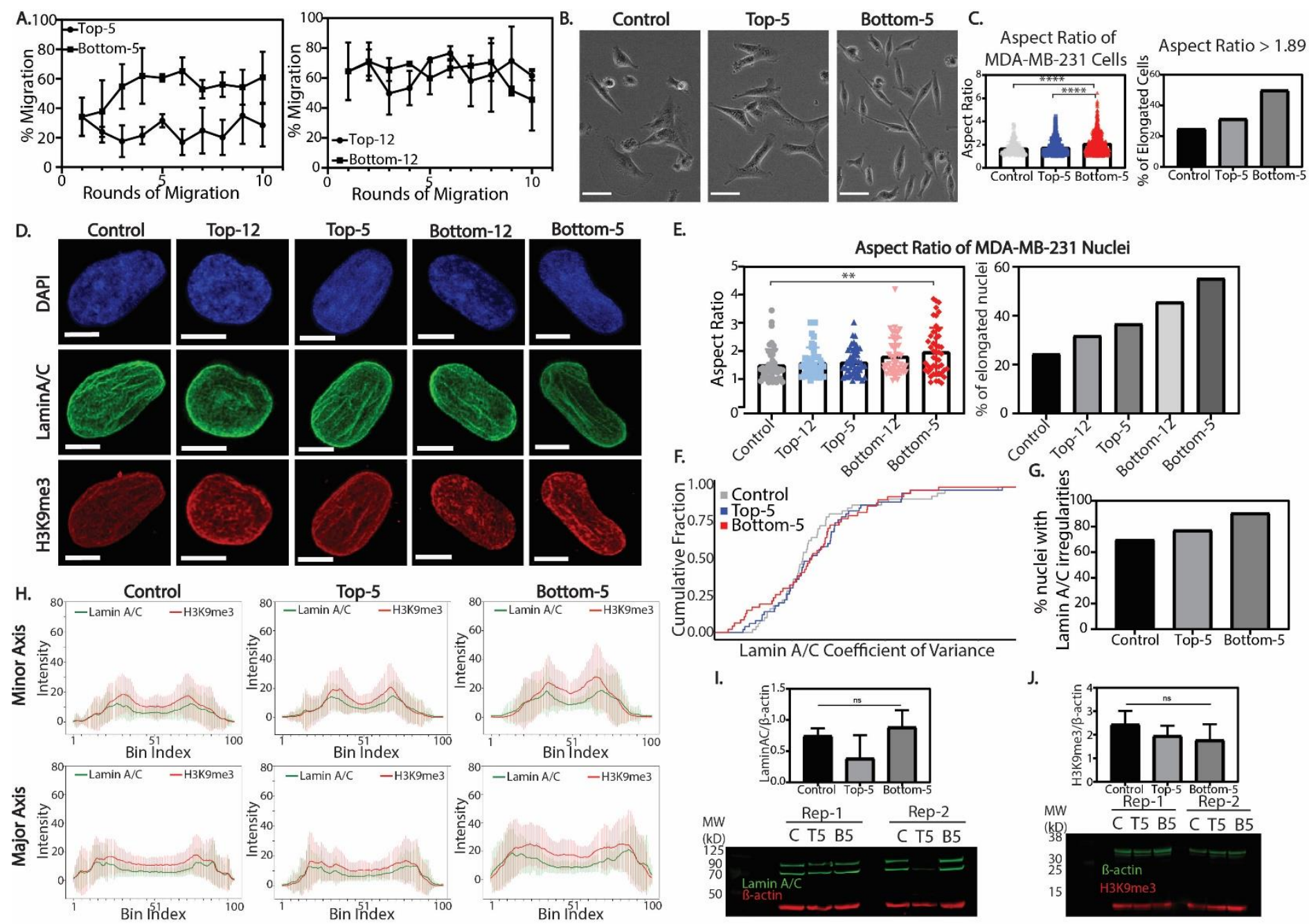

Supplementary Figure 3. Sequential rounds of constricted migration result in two distinct populations of MDA-MB-231 cells. (A) Transwell migration efficiency of MDA-MB-231 cells through 5 and $12 \mu \mathrm{m}$ pore sizes for 10 transwell migration rounds. Error bars $=$ mean $\pm \mathrm{SD}$ of $5 \mu \mathrm{m}$ (3 biological replicates) and $12 \mu \mathrm{m}$ ( 2 biological replicates $)$ transwell assays. (B) Phase contrast images of MDA-MB-231 cell subpopulations. Scale bars $=50 \mu \mathrm{m}$. (C) Left: Aspect ratio of MDA-MB-231 cells for Control $(n=142)$, Top-5 $(n=393)$ and Bottom-5 $(n=621)(* * * * p<0.0001$; two-tailed t-test). Right: Fraction of MDA-MB-231 cell subpopulations with an aspect ratio $>$ than $3^{\text {rd }}$ quartile of Control. (D) Maximum projected images of MDA-MB-231 nuclei immunostained with DAPI (blue), Lamin A/C (green) and H3K9me3 (red). Scale bars $=5 \mu \mathrm{m}$. (E) Left graph: Aspect ratio of MDA-MB-231 nuclei in Control $(n=49)$, Top-12 ( $n=47)$, Top-5 ( $n=49)$, Bottom-12 ( $=46)$ and Bottom-5 $(\mathrm{n}=47)(* * \mathrm{p}=0.0038$; two-tailed t-test). Right graph: Fraction of MDA-MB-231 nuclei that have an aspect ratio $>3^{\text {rd }}$ quartile of control. (F) Cumulative distribution plot of Lamin A/C coefficient of variance in Control, Top-5 and Bottom-5 MDA-MB-231 cells. Number of nuclei quantified remains the same as in E. KS-test shows no significant difference between conditions. (G) Fraction of MDA-MB-231 nuclei displaying irregularities in Lamin A/C distribution by visual inspection. (H) Line scan intensity for $\mathrm{H} 3 \mathrm{~K} 9 \mathrm{me} 3$ (red) and Lamin A/C (green) across major and minor axis of central slice images of MDA-MB-231 cells. Number of nuclei quantified remains the same as in E. Error bars $=$ mean \pm SD. (I-J) Western blot analysis and quantification of MDA-MB-231 Control, Top-5 and Bottom-5 cells 
probing for Lamin $\mathrm{A} / \mathrm{C}$ and $\mathrm{H} 3 \mathrm{~K} 9 \mathrm{me} 3$. Error bars = mean $\pm \mathrm{SD}$. No significant differences found in pairwise comparisons by two-tailed t-test.

Overall, our microscopic analyses imply that, in A375 cells, constricted migration is associated with alterations in the distribution of Lamin $\mathrm{A} / \mathrm{C}$ and heterochromatin that are visible at even 18 hours after migration, but is not dependent on changes in total Lamin $\mathrm{A} / \mathrm{C}$ or heterochromatin levels. Given the variability in Lamin A/C expression across different cell lines and cancer types, we repeated these sequential migration and imaging experiments in MDA-MB-231 cells (Figure S3). These cells exhibit a higher initial ability to migrate through $5 \mu \mathrm{m}$ constrictions when compared to A375 cells. MDA-MB-231 cells that migrate through $5 \mu \mathrm{m}$ pores for 10 rounds (Bottom-5) show an increase in migration efficiency, like A375 cells, though the change is not as dramatic (Figure S3A). When challenged to migrate through large 12 micron pores, MDA-MB231 Top-12 and Bottom-12 cells show no significant separation in their migratory efficiency, in contrast to A375 cells, which had a subpopulation that could not migrate through even large pores. This indicates that there is less initial heterogeneity among the MDA-MB-231 cells in their ability to migrate. Indeed, whether or not they have undergone constricted migration, MDA-MB-231 cells exhibit more mesenchymal phenotypes with elongated cell bodies and low cell-cell adhesions (Figure S3B). However, like A375 cells, the MDA-MB-231 cells that undergo constricted migration for 10 rounds (Bottom-5) and increase their migratory efficiency also show more cell elongation (Figure S3C).

We then investigated whether Lamin $A / C$ and heterochromatin organization in the nucleus were affected by constricted migration in MDA-MB-231 cells (Figure S3D). The nuclei of MDA-MB231 cells are generally elongated compared to A375 cells. However, about $60 \%$ of the Bottom-5 MDA-MB-231 nuclei are as elongated as the top 25\% of Control nuclei (Figure S3E). As in A375 cells, the increased migratory efficiency of MDA-MB-231 cells is not related to a change in overall Lamin A/C or H3K9me3 levels (Figure S3I and S3J). Differences in Lamin A/C distribution in MDA-MB-231 cells are more subtle than in A375 cells: there are no significant differences among Control, Top-5 and Bottom-5 cells in Lamin A/C intensity variance (Figure S3F), but a somewhat higher percentage $(90 \%)$ of Bottom-5 cells display visibly wrinkled nuclei compared to Control and Top-5 (75-80\%). Our results support previous observations in which elongated cell and nuclear shape correlated with higher migration propensity in MDA-MB-231 cells (Baskaran et al., 2020). Like A375 cells, MDA-MB-231 Bottom-5 cells have a higher H3K9me3 intensity at the nuclear periphery across the major and minor axis when compared to Control and Top-5 cells (Figure $\mathrm{S} 3 \mathrm{H}$ ).

In both these cancer cell types, constricted sequential migration can result in a more highly migratory subpopulation that exhibits some nucleus morphology changes and differs in the distribution, but not the levels of Lamin A/C or H3K9me3. Given the role of lamins and heterochromatin in organizing the 3D genome structure, we next asked whether differences are found in the 3D organization of chromosomes in sequentially constricted cells.

\section{Genomic regions change their compartmentalization after rounds of constricted migration}

To measure changes in chromosomal contacts in A375 cells, we performed genome-wide chromosome conformation capture (Hi-C) on Control, Top-5, Bottom-5, Top-12 and Bottom-12 cells (see Materials and Methods and Table S1 for processing and statistics). Strikingly, using 
$250 \mathrm{~kb}$ binned matrices, we observe regions of the genome that have a different pattern of interactions in Bottom-5 cells compared to all other conditions (Figure 3A, example indicated by black arrow). Since these changes primarily affected the plaid pattern that indicates spatial compartmentalization, we next performed Principal Component Analysis (PCA) to classify regions according to their $\mathrm{A} / \mathrm{B}$ compartment identity. We identified regions of the genome that have a consistent compartment identity among all unconstricted conditions (Control, Top-12, Top5, Bottom-12) but have a different compartment identity (A to B or B to A) in Bottom-5 cells (Figure 3B, highlighted region, for example). We determined that $1 \%$ of $250 \mathrm{~kb}$ regions across the genome switched from the B (typically more heterochromatic) to A (typically more euchromatic) compartment and about $2 \%$ of the $250 \mathrm{~Kb}$ bins switched from A to B compartment in Bottom-5 cells compared to Control (Figure 3C). We observed a comparatively very small number of compartment identity switches in all the other conditions (Figure 3C) implying that 3D genome structure differences could be specific to cells that have undergone constricted migration. We also extended migration through $5 \mu \mathrm{m}$ pores up to 20 rounds (Bottom20-5) and observe similar compartment patterns and compartment identity switches, reinforcing the idea that these specific rearrangements of the genome are related to constricted migration (Figure 3C and S4).

To investigate whether any other cell subpopulations showed shifts in compartmentalization at regions that switched compartments in Bottom-5, we investigated the distribution of PC1 values of these regions in all the A375 conditions (Figure 3D). Regions of the genome that are in the B compartment in Control cells but in the A compartment in Bottom-5 cells show a negative distribution of PC1 values in non-migrating cells (Top-12 and Top-5), consistent with a B compartment identity, similar to the Control. As expected, the PC1 distribution has a positive mean in cells that have undergone constricted migration (Bottom-5 and Bottom20-5) (Figure 3D, top panel). However, while Bottom-12 cells exhibit a negative PC1 mean (reflecting a B compartment identity similar to Control), it is less negative when compared to Control and Top cells (Figure 3D, top panel). A similar pattern is observed in regions of the genome that switch compartment identity from A to B type. While the mean of PC1 distribution is positive for Control and Top cells and negative for Bottom-5 and Bottom20-5 cells, Bottom-12 cells exhibit a less positive mean of PC1 distribution (Figure 3D, bottom panel). This observation that unconstricted migrating cells have a slight tendency toward the structure differences seen in constricted migration could mean that these changes are somewhat induced by migration in general even with minor nucleus deformations, and/or that a sub-population of cells within the unconstricted migrating set would be able to undergo constrictions, and this subset with a "Bottom-5-like" structure influences the average interaction signal.

Not only are compartment changes a visually apparent difference in constricted migrating cells, but also genome-wide hierarchical clustering analysis of the compartment eigenvectors segregates conditions according to whether they have undergone constricted migration or not, further linking changes in chromatin compartmentalization to migratory ability (Figure 3E). Since compartmentalization relates to the spatial segregation of heterochromatin and euchromatin, these changes may relate to our microscopic observations of increased $\mathrm{H} 3 \mathrm{~K} 9 \mathrm{me} 3$ peripheral localization after confined migration (Figure 2). To investigate this link further, we quantified whether genomic regions that change compartment identity in Bottom cells (when compared to their respective Top: Bottom-5 vs Top-5 and Bottom-12 vs Top-12) correspond to certain lamin associated domain (LAD) types. We used a previously established LAD atlas across a cohort of nine different cell 
types that classifies genomic regions as: cLADs (constitutive LADs; regions associated with the nuclear lamina in all cell types), ciLADs (constitutive inter LADs; regions located in the interior of the nucleus across all cell lines), fLADs and fiLADs (facultative LADs and facultative inter LADs; regions that are sometimes associated with the nuclear lamina across the cell types) (Kind et al., 2015, Carolyn de Graaf, 2019). We observed both B to A and A to B switches in constricted migration (Bottom-5) were enriched in fLADs (Figure 3F). The high incidence of compartment changes in fLAD regions might relate to their ability of these fLADs, representing their ability to transition between lamina-association and dissociation. Additionally, Bottom-12 and Bottom-5 presented with an enrichment of cLADs in the regions that switch from A to B compartment, suggesting a possible further spatial consolidation of heterochromatin regions corresponding to the observed coalescence of $\mathrm{H} 3 \mathrm{~K} 9 \mathrm{me} 3$ at the nuclear periphery. 
A. chr1: $181,785,969-235,044,680$

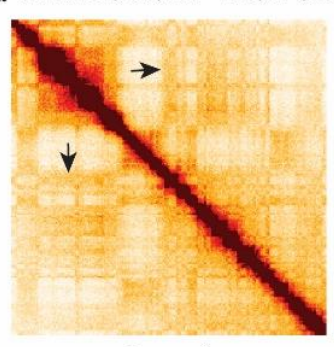

Control

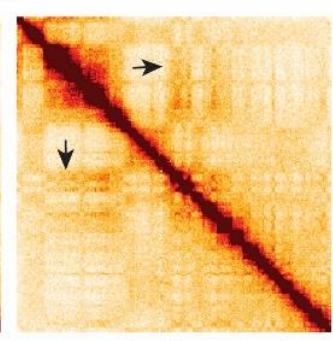

Top-12

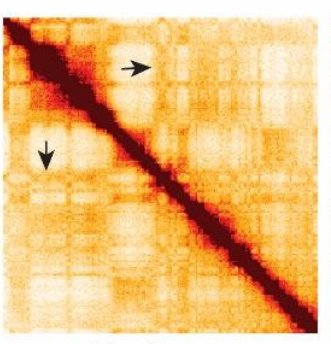

Top-5

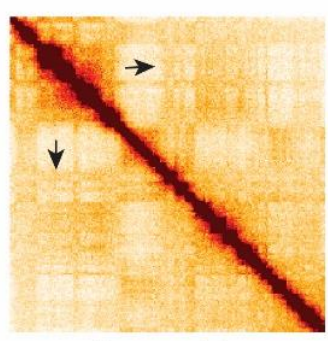

Bottom-12

C.

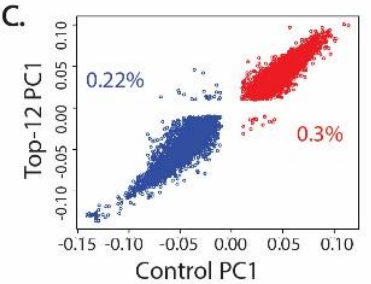

Control PC1

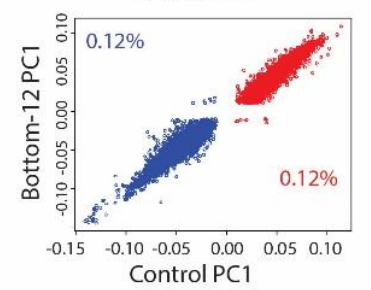

E.

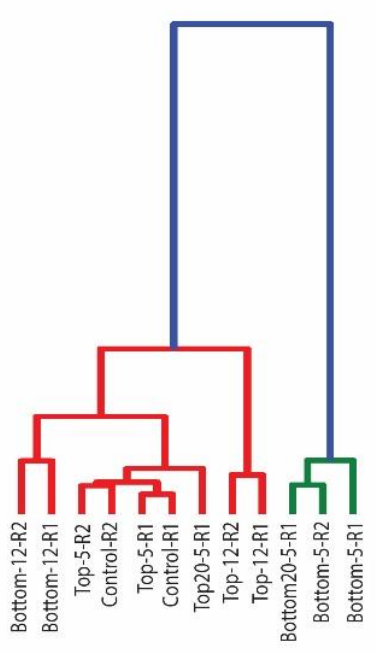

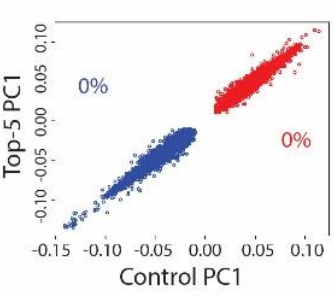

Control PC1

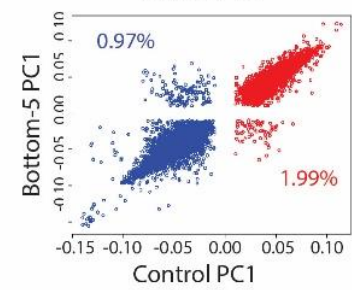

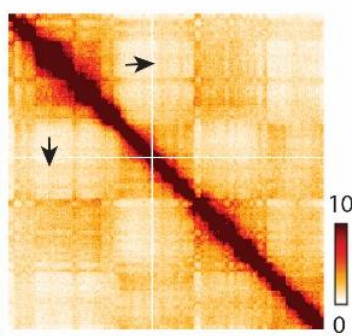

Bottom-5

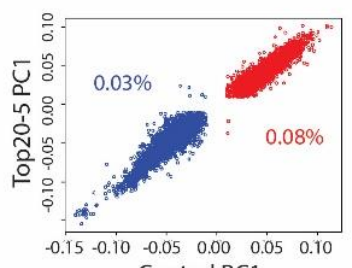

Control PC1

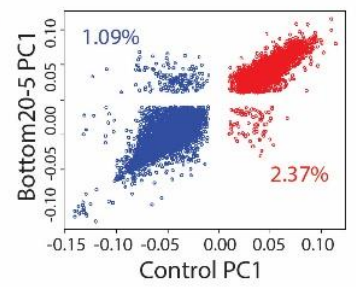

D.
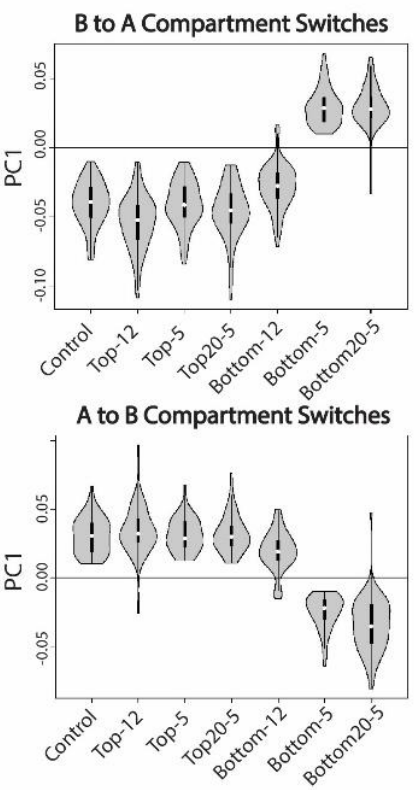

F.
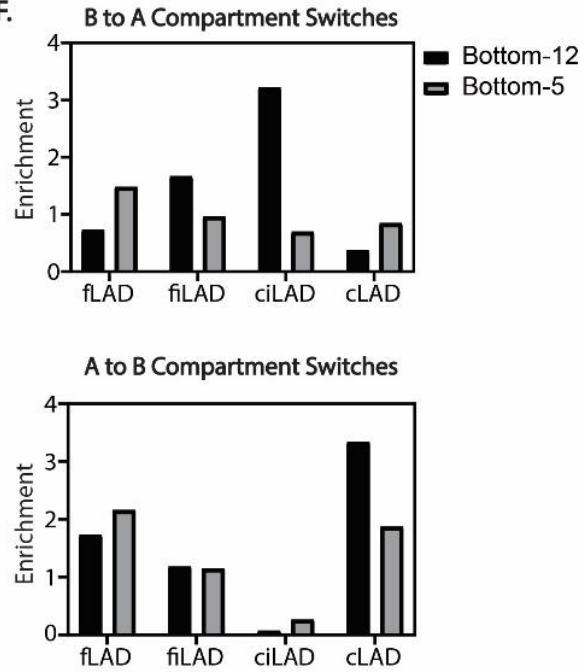

A to B Compartment Switches

Figure 3. Compartment identity switches observed after constricted migration. (A) $250 \mathrm{~Kb}$ binned Hi-C interaction heatmaps of chr1 (chr1:181,785,969 - 235,044,680) across all A375 subpopulations. Arrow indicates visible differences in heatmaps of Bottom-5 cells when compared to the rest. (B) PC1 track of compartment identity in the same region of chr1 across all A375 subpopulations. Compartment tracks are binned at 250Kb. Boxed region highlights one of several compartment switches in this region: the same switch highlighted by arrows in (A). (C) Correlation between A375 Control PC1 with A375 cells that did not undergo transwell migration (top three panels) and A375 cells that did undergo transwell migration (bottom three panels). Percentage of bins that met the criteria for "compartment switch" from B to A (PC1 $<-0.01$ to $>0.01)$ or A to B (PC1 $<-0.01$ to $>0.01)$ indicated on each panel. (D) Distribution of PC1 values across all A375 subpopulations for the regions that switched their compartment identity from B to A compartment (top panel) and A to B compartment (bottom panel) in Bottom-5 cells. (E) Clustering of all A375 subtypes by their compartment PC1. (F) Enrichment of different LAD types in regions that switch their compartments from B to A and 
A to B in Bottom-5 (compartment comparison: Bottom-5 vs Top-5) (grey) and Bottom-12 (compartment comparison: Bottom-12 vs Top-12) (black) cells.

A. chr12: $472,976-32,871,755$
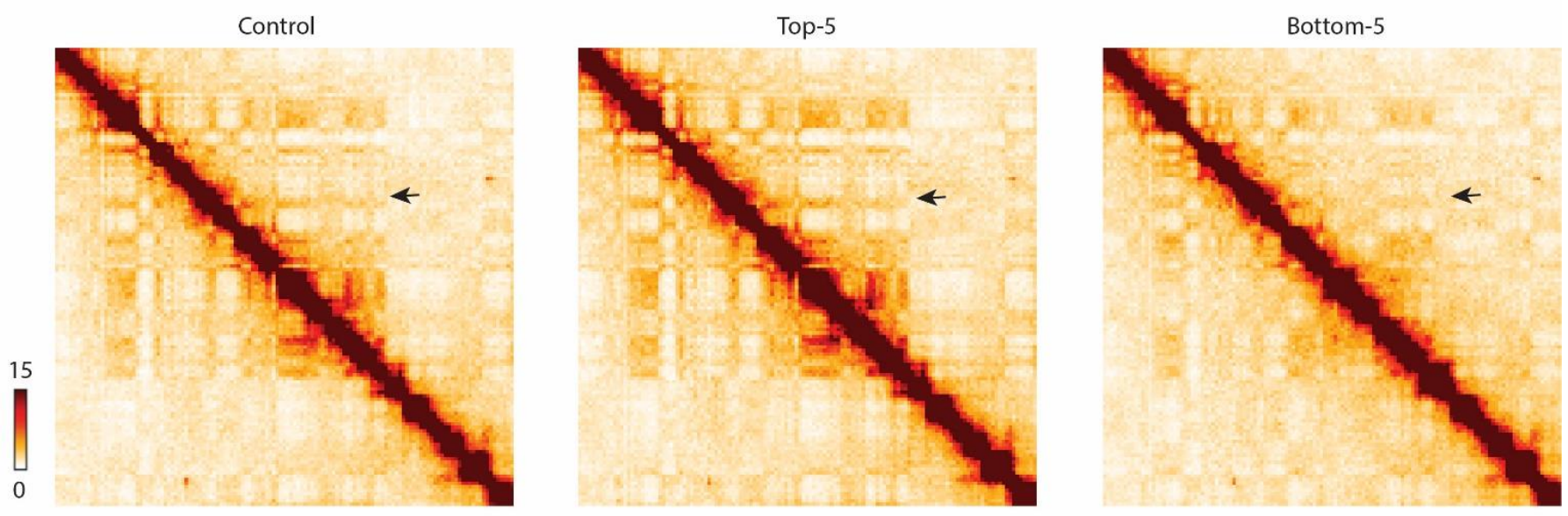

chr1: $181,785,969-235,044,680$

B.

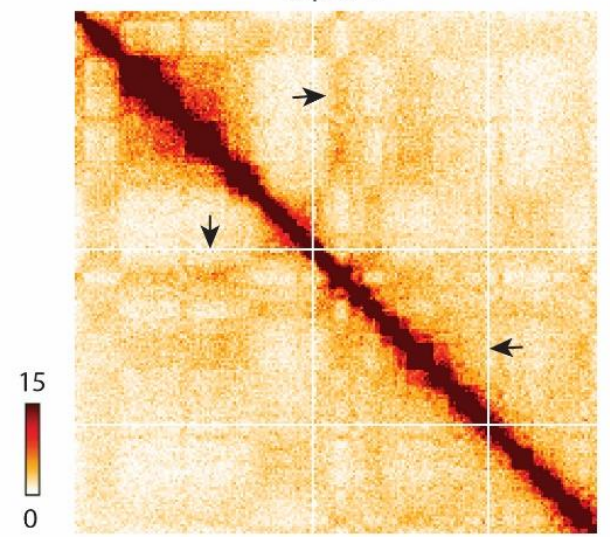

Bottom-5

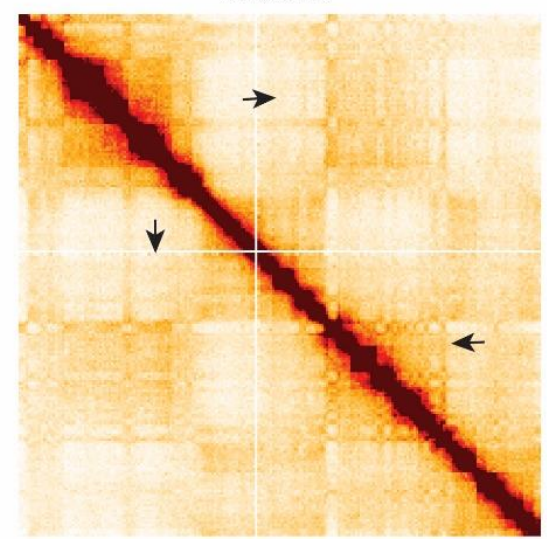

Bottom20-5

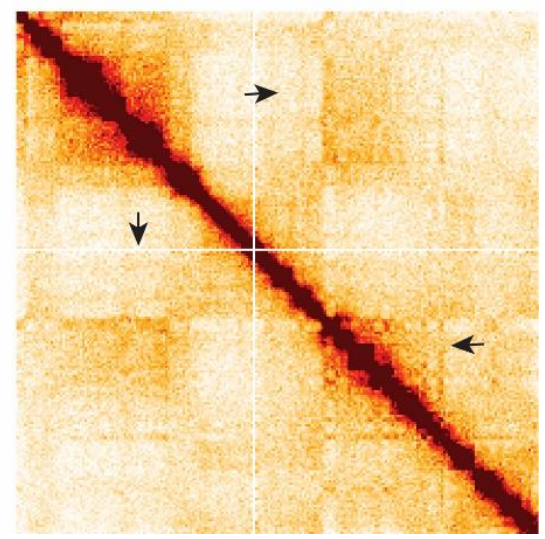

Supplementary Figure 4. Compartment identity switches are also observed after 20 rounds of 5- $\mu \mathrm{m}$ constricted migration. (A) Hi-C interaction heatmap of a chr12 region binned at $250 \mathrm{~Kb}$ in $\mathrm{A} 375$-Control, Top-5 and Bottom-5. (B) Hi-C interaction heatmaps of chr1 (same chromosomal location as Figure 3A) in A375 cells that have undergone 20 rounds of $5-\mu \mathrm{m}$ transwell migration. Black arrows indicate regions that exhibit changes in compartment profiles upon migration through $5-\mu \mathrm{m}$ constrictions.

Interestingly, we observed an over-representation of ciLADs in regions switching their identity from B to A compartment between Top-12 and Bottom-12 (Figure 3F, top panel). Given that ciLADs are regions that do not associate with the nuclear lamina in all the examined cell types, it was unusual to find these regions in the B-compartment in the non-migratory cells. We have identified 96 bins that are classified as ciLADs residing in a B compartment in Top-12 cells but are found in the A compartment in all other conditions. Gene ontology enrichment analysis identified functions correlating to cell motility and the regulation of actin cytoskeleton for the genes found in these regions. Additionally, we observed an over-representation of cLADs in 
regions that switched their compartment identity from A in the Top-12 to B in Bottom-12, encompassing 253 bins found in the A compartment in Top-12 and in the B compartment in all the other conditions. The genes in these regions were associated with melanogenesis and neuronal pathways. Taken together, these observations suggest that Top-12 cells (the least migratory in the constricted migration spectrum) harbor a 3D genome structure that separates them from the highly migratory cells (Bottom-5 and Bottom20-5) and likely reflects maintenance of melanocyte identity.

\section{Gene expression changes after constricted migration reflect metastatic potential}

To investigate potential differences in gene expression in cells that have undergone constricted migration, we performed RNA-Seq on all A375 subpopulations. We identified 977 and 1473 genes that were differentially expressed in Bottom-5 and Bottom20-5 relative to Control, respectively (Table S2). Hierarchical clustering of all conditions, starting with the subset of genes differentially expressed in Bottom-5 or Bottom20-5, revealed that cells that undergo constricted migration cluster separately from all other conditions (Figure 4A and Figure S5A). Overall, we observe three major gene clusters: cluster 1 included 482 genes that are upregulated in Bottom-5 and Bottom205 and downregulated in other subsets. Pathway enrichment analysis identified upregulated pathways related to metastasis, such as TGF-beta, TNF-alpha, EGFR and Integrin $\beta-4$ signaling pathways (Figure 4B). On the other hand, cluster 2 included 368 genes that were downregulated in Bottom-5 and Bottom20-5 but upregulated in all other cells. Interestingly, enriched downregulated pathways are involved in developmental pathways such as neural development. Since melanoma cells originate from neural crest, these observations suggest that this cluster relates to downregulation of melanocyte specific gene expression in constricted migrating cells (Figure 4B). Finally, cluster 3 included 533 genes that were downregulated in Bottom20-5 and upregulated in Top-5 (Figure 4A). Some of these genes are involved in cell adhesion, which correlates with the differences we observe in cell-cell contacts between these subsets (Figure 1C).

We next searched for other potential links between observed phenotypic differences (Figure 1 and Figure S5B) and changes in gene expression. We first compared cells which have migrated through non-constricted spaces to cells that do not migrate at all (Bottom-12 vs Top-12, Figure S5B). The majority of genes that were upregulated in Bottom-12 cells were related to TGF-beta, EGFR, integrin and p-53 signaling, all pathways related to cancer cell migration and metastasis. To assess whether we observe constriction-specific changes in gene expression, we next compared cells which have migrated through $5 \mu \mathrm{m}$ constrictions to cells which migrated without constriction (Bottom-5 vs Bottom-12, Figure S5B). Interestingly, genes that were more highly expressed in constricted vs. unconstricted migration are related to focal adhesion pathways and regulation of actin cytoskeleton. These changes correlate with the increase in protrusions and changes in cell shape observed for Bottom-5 cells in Figure 1 and S1 (Figure S5B). Similarly, when we compared cells that underwent $5 \mu \mathrm{m}$ constricted migration (Bottom-5) with the ones that were not able to migrate, even through large pores (Top-12), we found upregulated genes that are related to cancer invasiveness pathways such as EGF and VEGF. Additionally, many genes upregulated in Bottom5 vs. Top-12 were involved in focal adhesion pathways which correlates with the more punctate, focal, staining of F-actin by phalloidin in Figure S1F (Figure S5B). 
These gene expression changes also correlate with A/B compartment changes observed upon constricted migration (Fig. 4C). Genes found in regions that switch their compartment identity from A to B in Bottom-5 or Bottom 20-5 cells display an overall decrease in expression when compared to all other conditions (Figure 4C, top panel). Similarly, genes found in regions that switch their identity from B to A compartment in Bottom-5 and Bottom20-5 cells display an overall increase in expression (Figure 4C, bottom panel). These observations suggest that some of the compartment changes after confined migration directly relate to changes in gene regulation. We cannot definitively say whether certain key migration genes were, for example, already active and in the A compartment in a subset of A375 control cells, and these were selected by sequential migration, or whether some such genes became active after a compartment switch was induced by confined migration. However, we can conclude that at least part of the underlying biological function of the compartment switching we observe in confined migrating cells involves changes in gene expression.

Gene expression changes do not account for all compartment changes, however. Notably, we found that among the genomic bins that switch from A to B and B to A compartment, a larger than expected fraction contain no genes (4-fold and 2-fold enrichment over random expectation, respectively) (Figure 4D). This observation indicates that a substantial portion of structural changes after migration must be explained by something other than gene regulation changes. We hypothesize that these regions might change as a result of or to accommodate the physical strain on the chromatin fiber during constricted migration.

To investigate whether the observed gene expression changes relate to local genome structure changes, we zoomed in to regions of the genome encompassing some of the highest upregulated or downregulated genes after constricted migration (Figure 4E). We initially explored genes that were upregulated $(\log 2 \mathrm{FC}>1)$ in cells that had undergone constricted migration (Bottom-5 and Bottom20-5). When zooming in to the FBXL7 gene ( $~ 8$-fold upregulated in Bottom-5 and Bottom20-5), we observed the emergence of a domain-like structure in Bottom-5 cells and an increase in chromatin accessibility (Figure 4E, top panel). Similarly, when exploring genes that were downregulated after constricted migration (Bottom-5 and Bottom20-5), we found genes whose local 3D structure was altered in Bottom-5 or Bottom20-5 cells with the disappearance of the loop present in Top-5 and a decrease in chromatin accessibility (SOD3 and CCDC149 3-15 fold downregulated; Figure4E, bottom panel). However, we also encountered cases in which the genes were differentially expressed such as PLEKHA6 $(\log 2 \mathrm{FC}>2$ in Bottom-5 and Bottom205) and PKDCC $(\log 2 \mathrm{FC}=-2.5$ in Bottom-5 and Bottom-20) but their local genomic structures remained similar with modest changes in chromatin accessibility (Figure S5C). 
A.
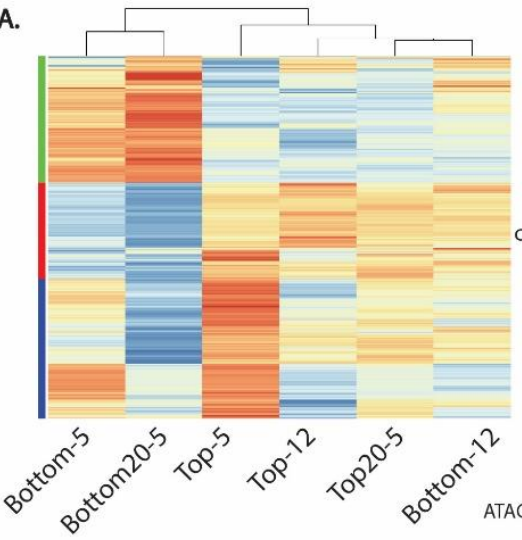

B.

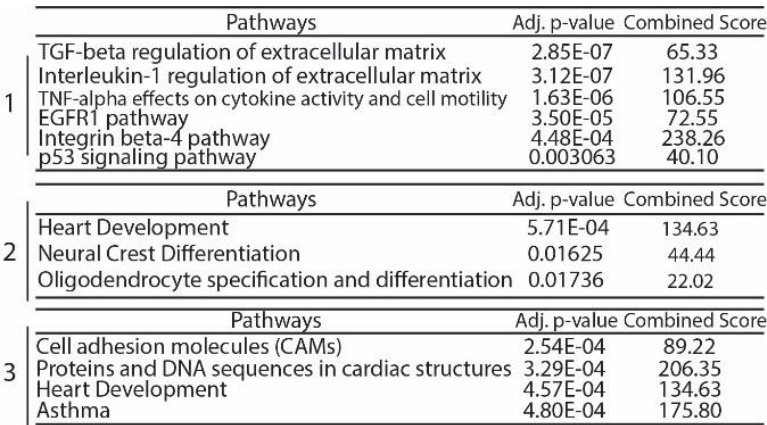

E. Upregulated in Bottom-5

c.

A to B Compartment Switches

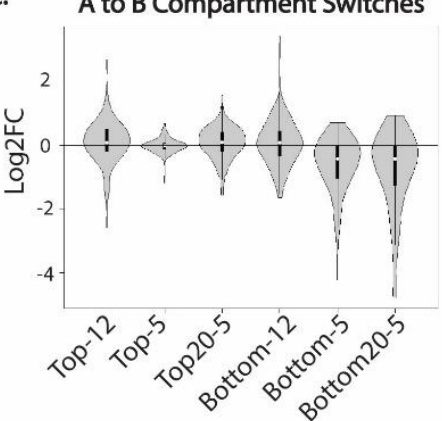

B to A Compartment Switches
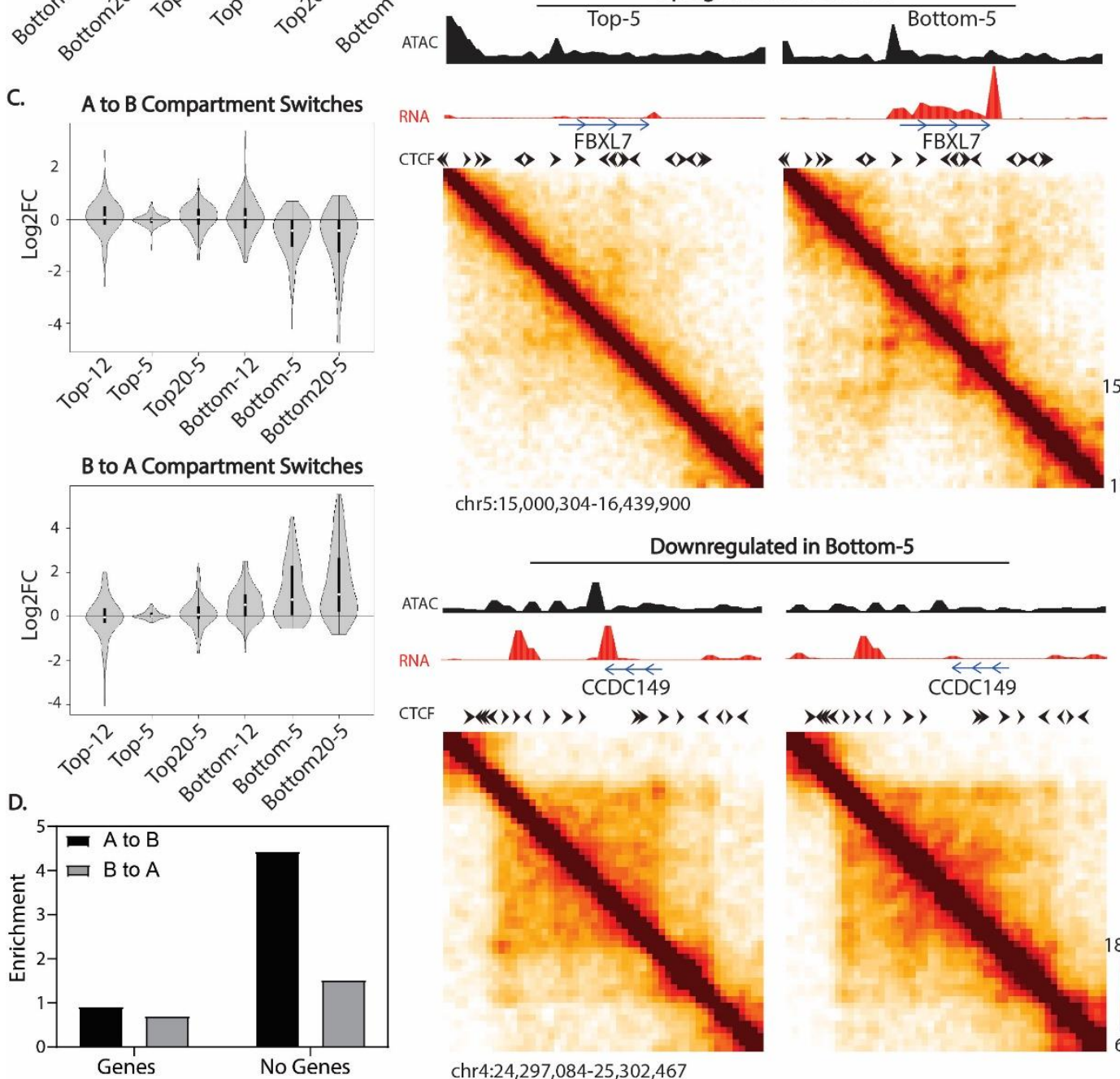

chr5:15,000,304-16,439,900

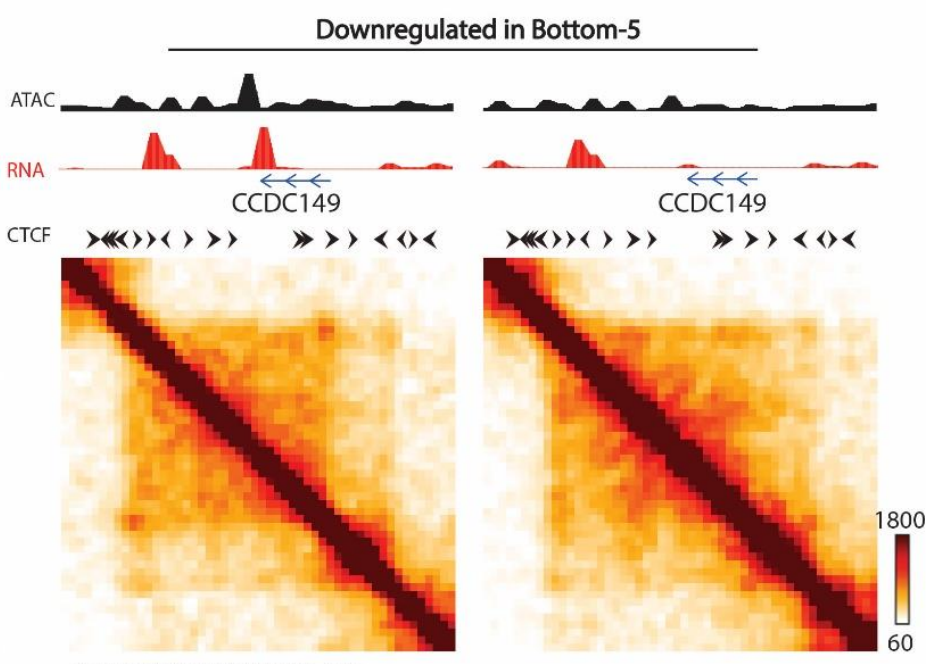

chr4:24,297,084-25,302,467

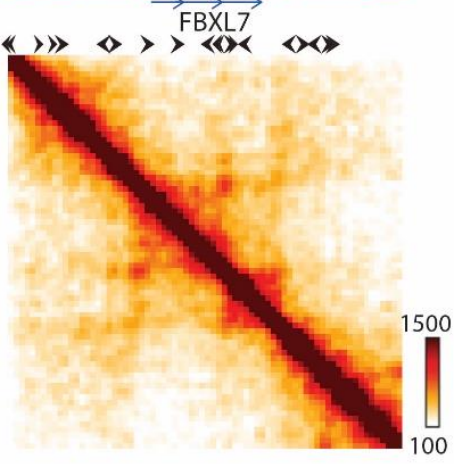

100

Figure 4. Changes in gene expression correlate with metastatic ability and chromosome structure changes. (A) Hierarchical clustering of RNA-Seq datasets based on differentially expressed genes of Bottom-20 cells relative to Control (Log2FC > 1). (B) Pathway enrichment analysis of identified gene clusters from (A) using BioPlanet 2019 package from Enrichr. (C) Log2FC of expression in the indicated condition vs. Control for genes located in regions that switch compartments from A to B (top panel) and B to A (bottom panel) in Bottom-5 cells. (D) Enrichment of regions that switched from A to B compartment based on the presence or absence of genes within the bin. (E) 20Kb binned Hi-C matrices of upregulated (FBXL7) and downregulated (CCDC149) genes in Bottom-5 cells. Tracks over the matrices represent ATAC-Seq (black) and RNA-Seq (red). The tracks have been smoothed with 40Kb bins. Black arrows indicate known CTCF motif directionality sites. 
A.

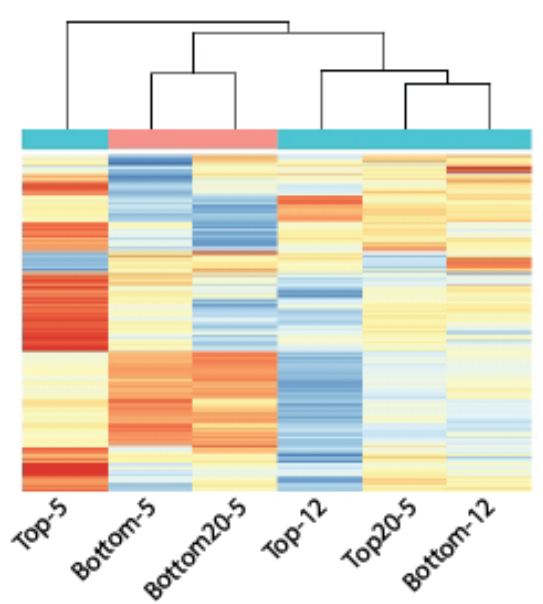

B.

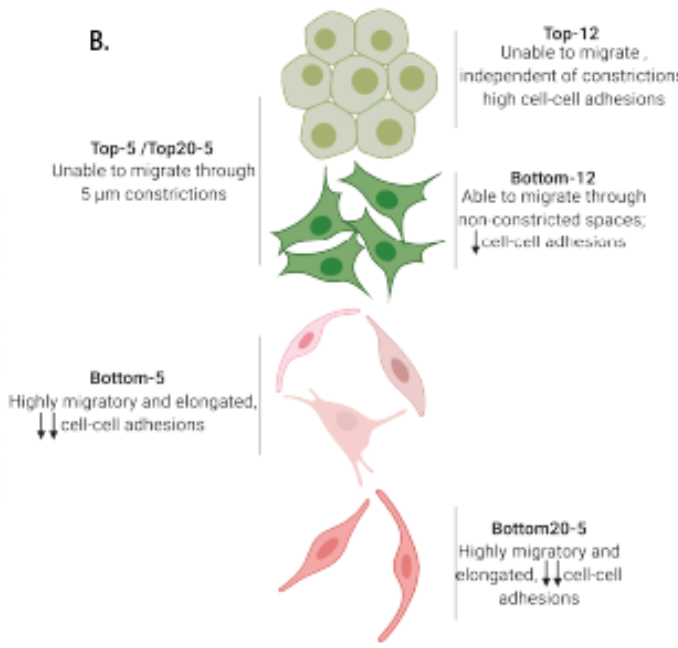

Bottom-12 vs Top-12 (Upregulated in Bottom-12)

\begin{tabular}{|c|c|c|}
\hline Patways & pvalue & Combinetscore \\
\hline Inteleulin-I regulation of extracellb]lar mattix & $2286-04$ & 111.73 \\
\hline TGF-beta regulation of extracelldarmatrix & $48 \mathrm{BZE}-04$ & 3785 \\
\hline Integrinsin angiogeresis & 8.AIE-04 & 114.82 \\
\hline TNF-apha effects on cytobine attivity, cell motility & 0.004676 & 4769 \\
\hline
\end{tabular}

Bottom-5 vs Bottom-12 (Upregulated in Bottom-5)

\begin{tabular}{|c|c|c|}
\hline Pathways & \multicolumn{2}{|c|}{ Adj.pralue Combinedscont } \\
\hline Focalkdhesion & $1.466-04$ & 31,69 \\
\hline EGF/EGFR Signaling Pathway & $1.91 E-04$ & \\
\hline $\begin{array}{l}\text { Regulation of Actin Cytoskeleton } \\
\text { TA - beta Receptor Signaling }\end{array}$ & $1.74 \mathrm{E}-04$ & 31,81 \\
\hline
\end{tabular}

Bottom-5 vs Top-12 (Upregulated in Bottom-5)

\begin{tabular}{|c|c|c|}
\hline Patways & \multicolumn{2}{|c|}{ Adj. pvalue CombinedScore } \\
\hline Focd Adhesion & $806 E-15$ & 3165 \\
\hline EGFEG S Signaling Pathway & $3.4 \pi-15$ & 19.35 \\
\hline Hippe Merlin Signaling Dysregultation & 0.007376 & 1865 \\
\hline VEGFA VEGFR2 Signaling Pathway & 0.016143 & 1284 \\
\hline
\end{tabular}

Downregulated in Bottom-5

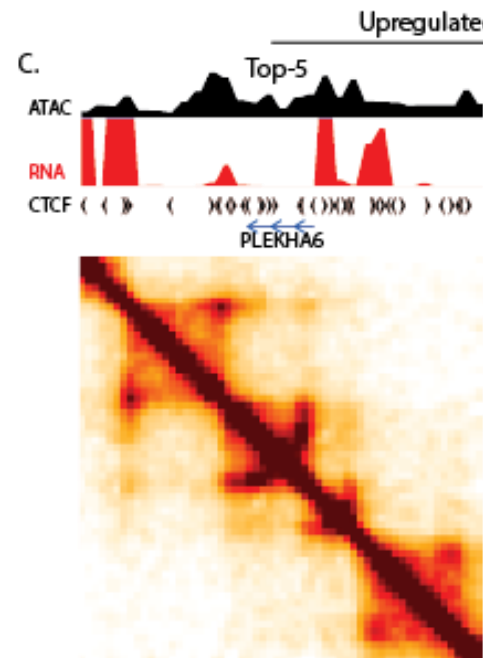

chr1:203,687,978-204,829,057
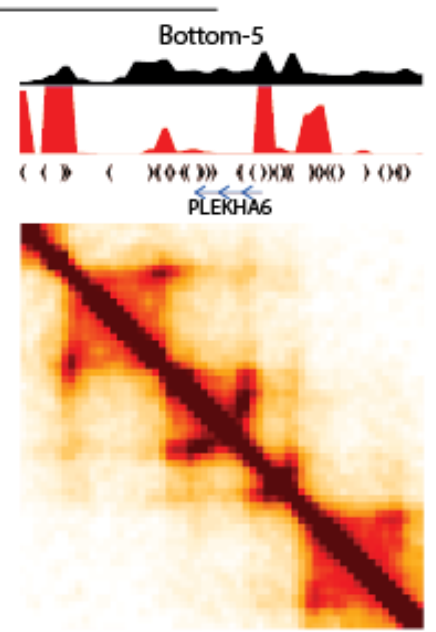

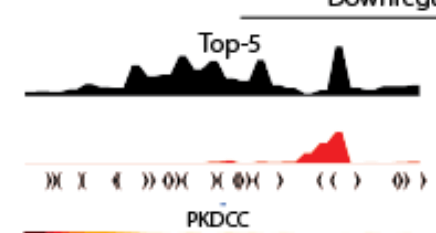

PKDCC

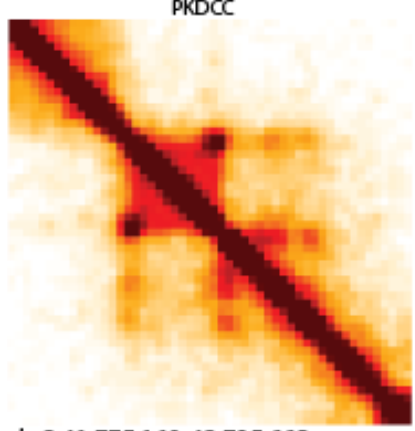

chr2:41,775,160-42,785,668
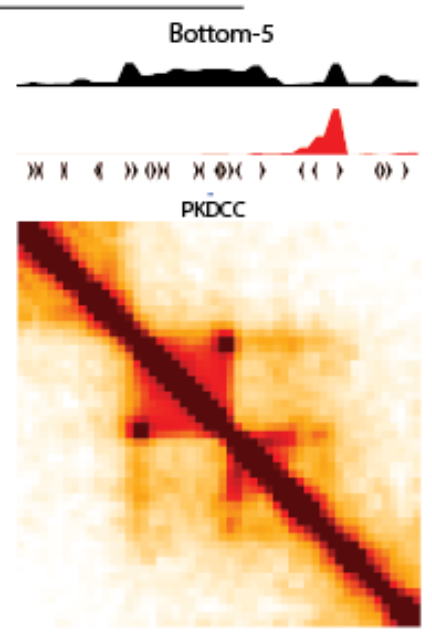

D.
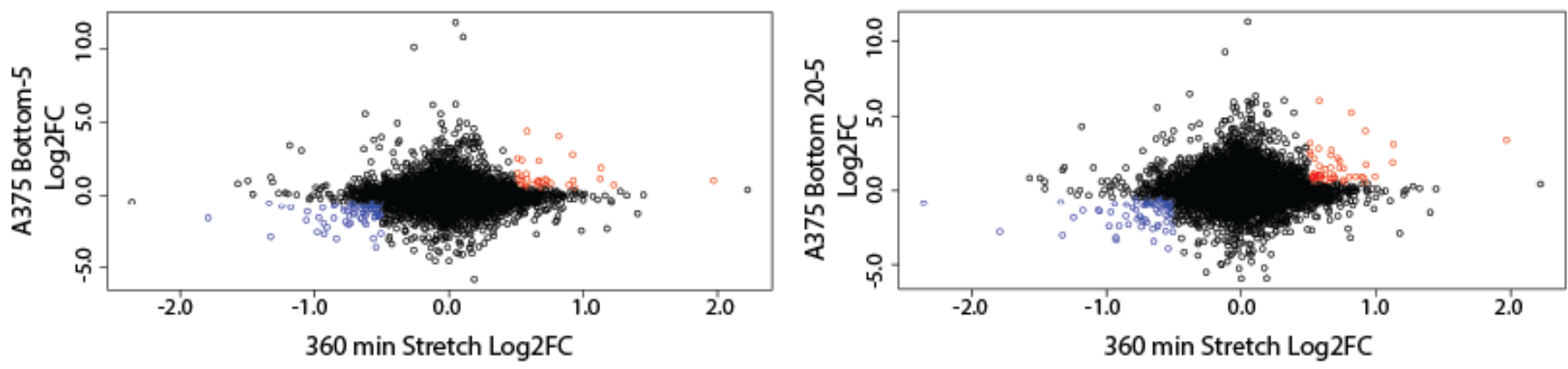

Supplementary Figure 5. Gene expression profile separately clusters cells that have undergone constricted migration (Bottom-5 and Bottom-20) from all other A375 subpopulations. (A) Hierarchical clustering of all A375 subset of cells based on genes that are differentially expressed in Bottom-5 cells relative to Control (Log2FC >1). (B) Gene ontology analysis of differentially expressed genes comparing indicated sub-populations of A375 cells. Cell illustration indicates morphology differences we observe within each sub-population of A375 cells. (C) Hi-C contact matrices binned at $20 \mathrm{~Kb}$ and smoothed at $40 \mathrm{~Kb}$ bin size of upregulated genes (PLEKHA6, left two panels) and downregulated genes (PKDCC, right two panels) in Bottom-5 cells. Black track represents ATAC-Seq signal while the red track represents 
RNA-Seq signal. Black arrows indicate known CTCF motif directionality. (D) Correlation plots of differentially expressed genes between mechanically stretched cells (Nava et al., 2020) and A375 cells that have undergone constricted migration (10 rounds of 5 micron constriction, left; 20 rounds of 5 micron constriction, right).

We observe that the loss or formation of loops or domains associated with changes in transcription occurs in regions that had few or no other strong architectural loops, such as the kind mediated by CTCF. Genes that change expression without notable 3D looping changes, in contrast, were located in regions with many other loops and TAD boundaries. These observations support the idea that transcription driven domains can arise separately from CTCF-based domains (Rowley et al., 2017, Zhang et al., 2020). Further, the transcription-associated CCDC149 loop occurs between an existing TAD boundary and a promoter, and could be explained by a collision between opposing direction loop extrusion and RNA polymerase activity, as suggested in other systems (Brandao et al., 2019).

Previous work has observed gene expression changes induced by mechanical stress, such as stretching (Nava et al., 2020, Le et al., 2016). We observe little correlation between differentially expressed genes in cells that have undergone constricted migration and cells that have been mechanically stretched (Figure S5D). This points to differences between a cell being passively deformed and one that is actively coordinating its own migration through a tight constriction.

\section{Inter-compartment interactions increase after constricted migration}

While the switching of compartment identity after confined migration is a striking phenomenon, and clearly apparent by visual inspection of the contact maps, quantitatively, only $\sim 3 \%$ of the genomic bins $(250 \mathrm{~Kb}$ bins) were affected by a complete compartment switch according to our thresholds. To evaluate how constricted migration may impact the rest of the chromosome contacts, we evaluated contacts not involved in compartment identity switches by reordering the $250 \mathrm{~Kb}$ binned matrices from the strongest B to strongest A bins based on PC1 values (Figure 5A) (Imakaev et al., 2012). We observe an evident separation between the B and A compartment in all subpopulations of A375 arising from $5 \mu \mathrm{m}$ (Figure 5A top panel and Figure S6A) and $12 \mu \mathrm{m}$ (Figure 5A bottom panel and Figure S6A) Transwell migration experiments. However, the relative strength of inter and intra-compartment contacts changes between Top and Bottom cells (Figure 5A, middle panels). Bottom-5 cells exhibit a loss in the strongest B-B interactions and an overall increase in interactions between the strongest B and strongest A compartments. This phenomenon has been previously reported in neutrophils after passage through small pores, suggesting it may be a general feature of confined migration genomic structural changes (Jacobson et al., 2018). This change in interaction frequency correlates with changes in gene expression. Regions that exhibit a strong B-B interaction loss display an overall increase in expression of genes found in these regions. Additionally, the expression of genes found in regions that display a gain in B-B interactions show an overall decrease in expression correlating with strengthening of the B-B interactions (Figure S6B). Interestingly, though there is increased mixing of the strongest A and B compartments after confined migration, there is actually increased segregation of regions that are weakly compartmentalized (eigenvector values near 0 ) in cells passed through constrictions. It appears that the B compartment bins that were previously ambiguous or near compartment boundaries in Top cells are more strongly associated with the rest of the B compartment after 
confined migration. We also observe a loss of the strongest B-B contacts in Bottom-12 as compared to Top-12, though this effect is not as strong as in the constricted migration case. In contrast to Bottom-5 cells, Bottom-12 cells exhibit an increase of interactions between A-A contacts relative to Top-12.
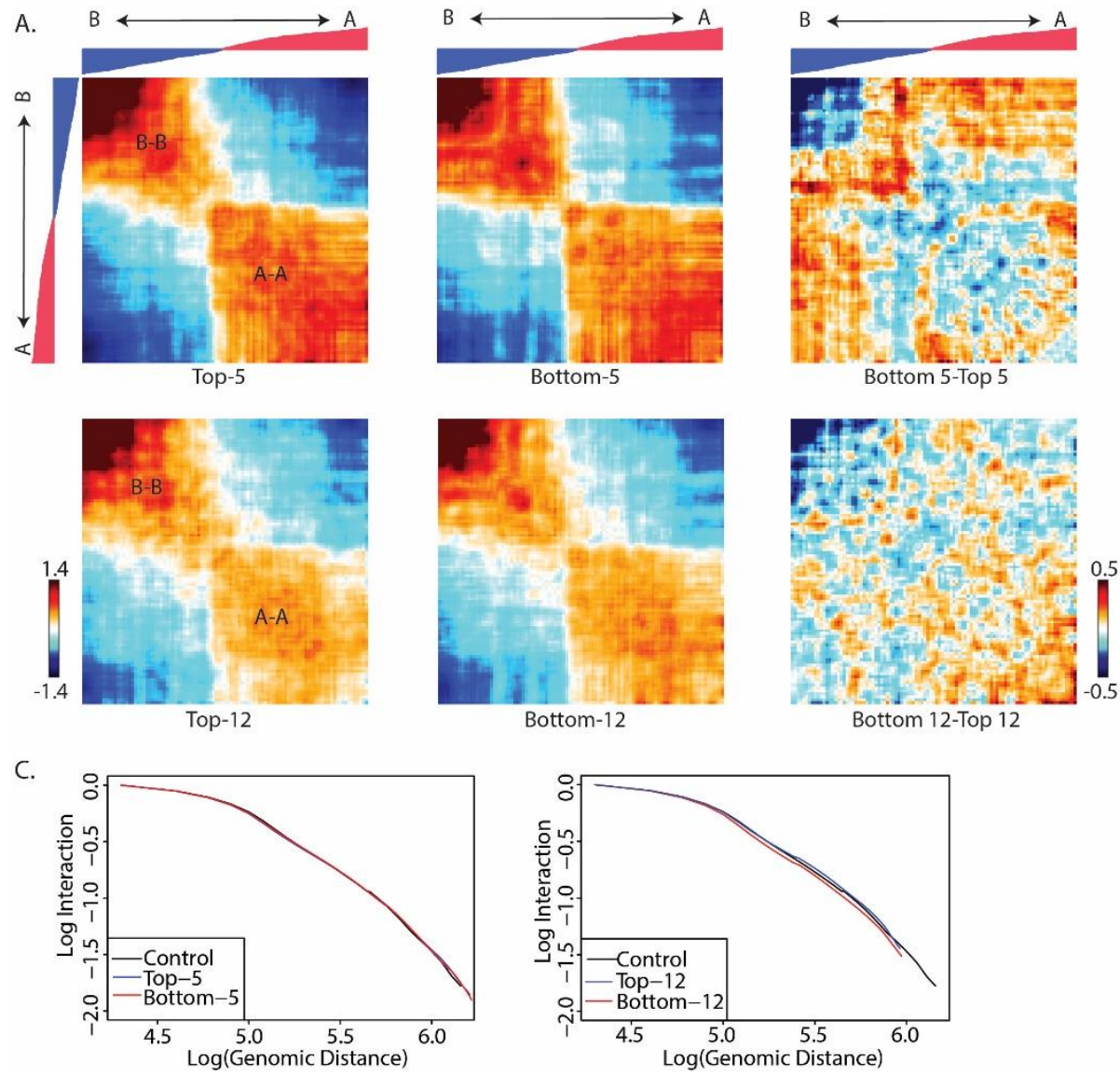

Figure 5. Changes in compartment strength associated with constricted migration. (A) Compartmentalization saddle plots of chr10 display interaction Z-score (interactions normalized by generic distance decay) or Z score difference (right column) between all bin pairs, reordered by PC1 values derived from A375 Control HiC data. Interactions between the strongest $\mathrm{B}$ regions are in the upper left corner while A-A interactions are in the lower right corner. The reordered Control PC1 values are displayed over the saddle plots. (B) Along chromosome 1 (chr1:170,000,001225,000,000), from top to bottom: Distal to local (DLR; $100 \mathrm{~kb}$ bins) ratio for Top-5 cells; DLR of Bottom-5 cells; Delta DLR (Bottom-5 - Top5). Positive DLR values indicate a gain of distal interactions $(>3 \mathrm{Mb}$ ) while negative values indicate a loss of distal and gain of local interactions ( $<3 \mathrm{Mb})$; PC1 values ( $250 \mathrm{~kb}$ bins) of Top-5 (black) and Bottom-5 (red) samples; Delta DLR (Bottom12-Top12); PC1 values of Top-12 (black) and Bottom-12 (red). Positive PC1 values represent A-compartment identity and negative $\mathrm{PC} 1$ values B-compartment identity. (C) Whole genome scaling plots at $20 \mathrm{~Kb}$ bin size comparing A375 cells that have been exposed to 5- $\mu \mathrm{m}$ transwell migration (top plot) and $12-\mu \mathrm{m}$ transwell migration (bottom).

To understand how these differences in compartment interaction frequencies relate to interactions with linearly local or distal chromosome regions, we calculated the distal-to-local ratio (DLR) of $\mathrm{Hi}-\mathrm{C}$ interaction frequencies (Figure 5B). Here, distal is defined as interactions with regions more than $3 \mathrm{Mb}$ away along the chromosome. This measure has previously been associated with changes in chromosome compaction (Heinz et al., 2018) and is related to a measure used to quantify loss of local chromosome structure with chromosome fiber digestion (Belaghzal et al., 2019). We find 
that in general, where regions along the chromosome become stronger A compartments, distal interactions decrease relative to local interactions (negative DLR value). Where regions increase their B compartmentalization or lose A identity, distal interactions increase (positive DLR). This could suggest that increased B compartmentalization often occurs when a region is brought closer to other heterochromatin regions far away on the chromosome, perhaps by co-localization at the nuclear lamina, while loss of B/increased A compartmentalization involves breaking distal contacts and increasing local contacts. (highlighted region, Figure 5B).

A.

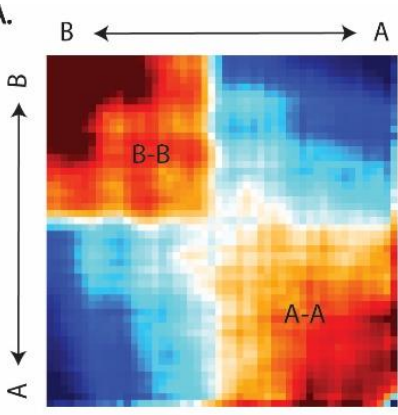

Top-5

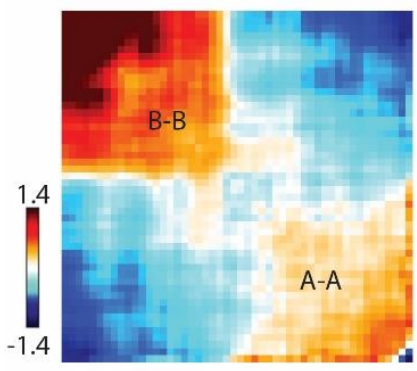

Top-12

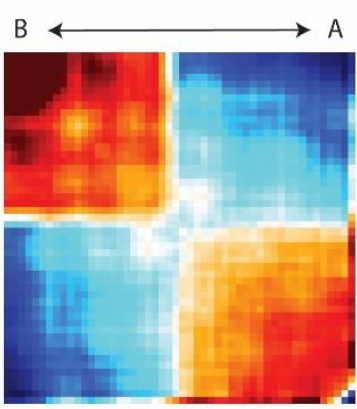

Bottom-5

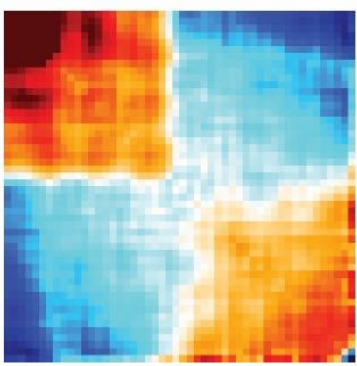

Bottom-12

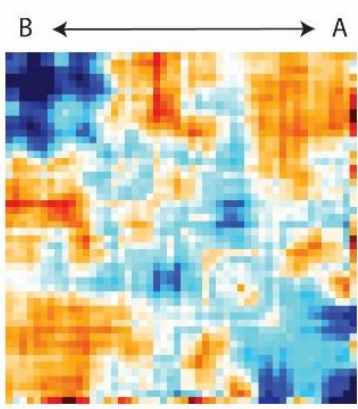

Bottom 5-Top 5

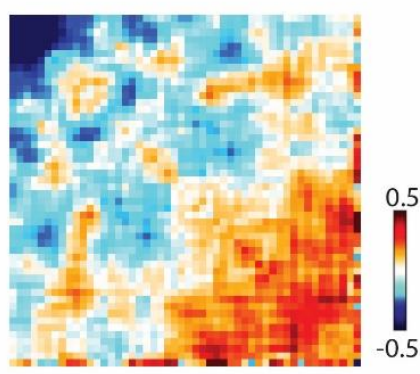

Bottom 12-Top 12

B.

(i)

c.

Top-5
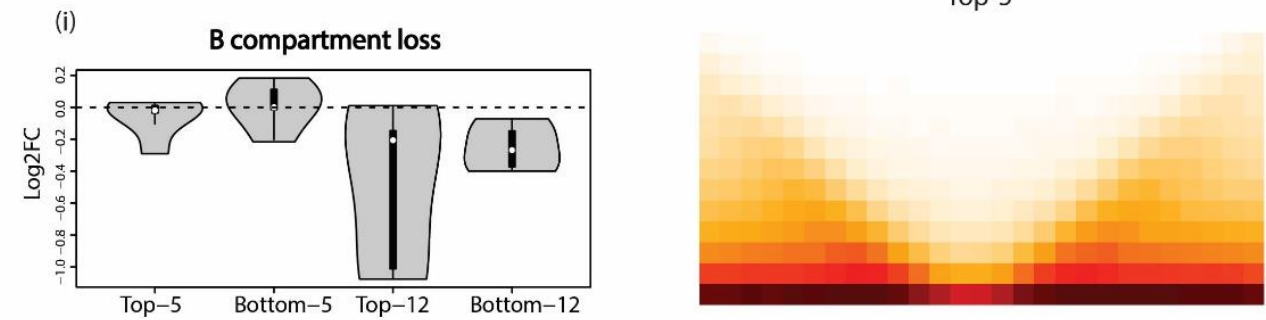

(ii)

B compartment gain
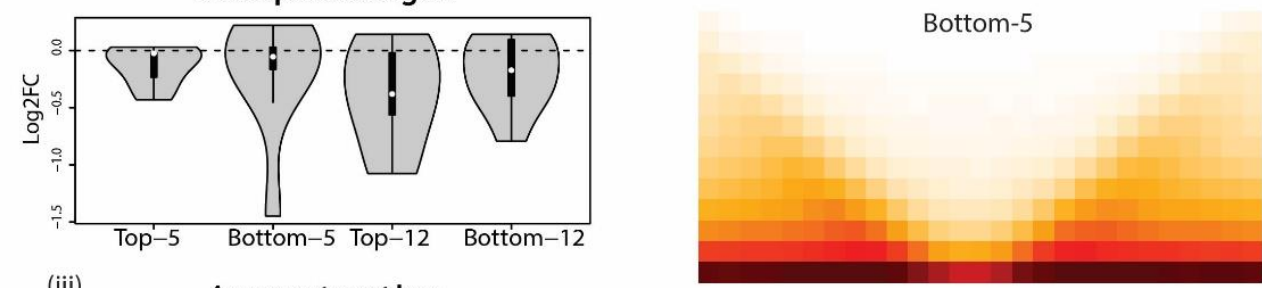

(iii) A compartment loss

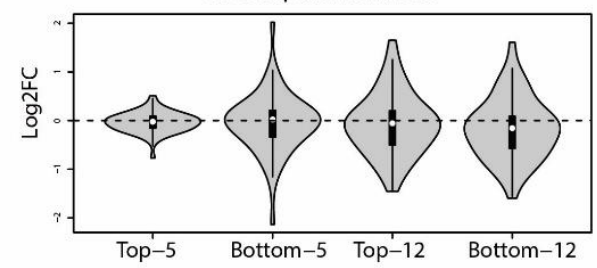

$\log 2$ (Bottom-5/Top-5)

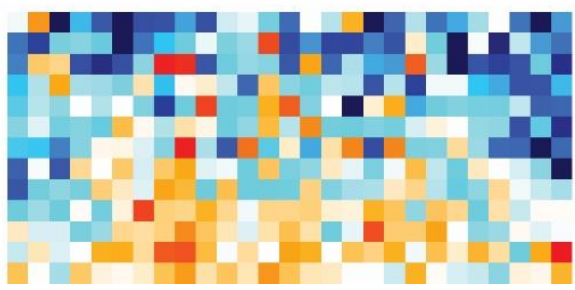


Supplementary Figure 6. Changes in compartment interaction strength correlates with overall gene expression pattern. (A) Saddle plots binned and smoothed using $500 \mathrm{~Kb}$ bin size for chr18 reordered from strongest $\mathrm{B}$ to strongest $\mathrm{A}$ compartment. (B) Gene expression changes corresponding to strong B-B interaction loss (i), moderate B-B interaction gain (ii) and A-A interaction loss (iii). (C) Aggregate contact maps (40 kb bins) at TAD boundaries called by the Insulation Score method of cworld-dekker with strength greater than 1 of Top-5 (Top panel) and Bottom-5 (middle panel).

Although the DLR shows that individual regions do have different local and distal interaction patterns, the average decay of interactions with distance does not change among any of the A375 subpopulations (Figure 5C). This local interaction scaling reflects local chromatin compaction and average local loop size and density, and thus we show that constricted migration does not overall change these local chromosome features. Moreover, we investigated whether constricted migration is associated with changes in TAD boundaries, and we observe no clear differences between any of the conditions (Figure S6C). These observations demonstrate that the major differences with constricted migration occur in larger scale chromosome structures and are in line with previous reports that TAD-scale interactions are independent from compartment-scale interactions such that one can change without dramatically affecting the other (Nuebler et al., 2018).

\section{Global genomic rearrangements after constricted migration}

Constricted migration has previously been shown to result in DNA damage and genome instability (Irianto et al., 2017a). Since Hi-C can detect structural aberrations such as translocations, we examined interchromosomal interactions in $2.5 \mathrm{Mb}$ binned matrices to search for potential genomic aberrations after confined migration (Figure 6).

At first glance, it is evident that translocations inherent to A375 are present in all sub-populations of cells (Figure 6A and S7). However, a new translocation between chr5 and $\operatorname{chr} 13(\mathrm{t}(5 ; 13))$ is evident only in cells that had undergone constricted migration (Bottom-5 and Bottom20-5) (Figure $6 \mathrm{~B}$ and S7). To narrow the specific breakpoint region of this translocation, we focused on Hi-C contact frequency between chr5 and chr13 (Figure S7). While in Top cells (Top-12, Top-5 and Top20-5) contact frequencies between chr5 and 13 remain uniform across the whole chromosome, in Bottom-5 cells we observe a high frequency of interaction between chromosome 5 and chromosome 13 followed by a sudden drop of interactions, indicating the translocation breakpoint (Figure S7). Interestingly, the translocation breakpoint falls in a gene poor region of both chromosomes.

We next used Hi-C contacts to estimate what fraction of the chromosomes in the population contain this translocation (Figure 6C, See Materials and Methods for detailed analysis approach). We found that this translocation was only present in $6.13 \%$ of chromosomes in Bottom-5 and $2.89 \%$ in Bottom-20. Since A375 cells have an average of 3 copies of each chromosome per cell, this can be extrapolated to this translocation occurring on one chromosome copy in $\sim 18 \%$ of the Bottom-5 cells and 9\% of the Bottom 20-5 cells (Figure 6C). Interestingly, this translocation was not detected in the cells that did not undergo constricted migration (Top-12, Top-5, Top20-5 and Bottom-12) as the fraction of reads coming from the translocation site matched the random background level of interchromosomal interactions in the Hi-C contact map (Figure 6C, negative control). The absence of this translocation in non-migratory cells (Top-12, Top-5 and Top20-5) and in Bottom-12 cells suggests that the translocation event may have arisen due to the physical stress on the nucleus during constricted migration. However, it is also possible that this 
translocation was present at undetectable levels in the heterogeneous control A375 population, and we are selecting the cells with this translocation during sequential migration.

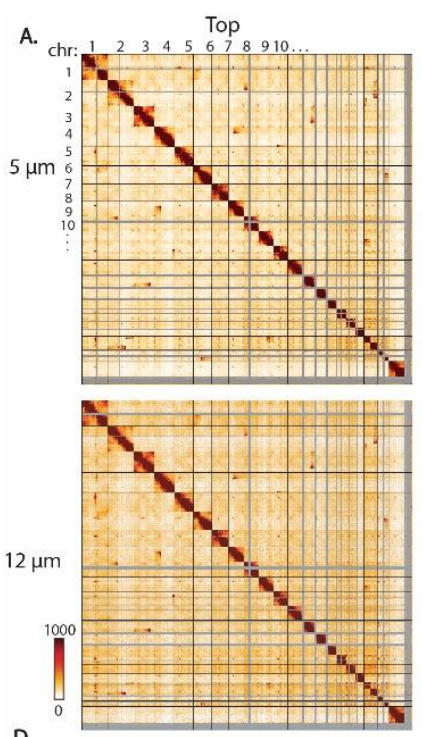

D.

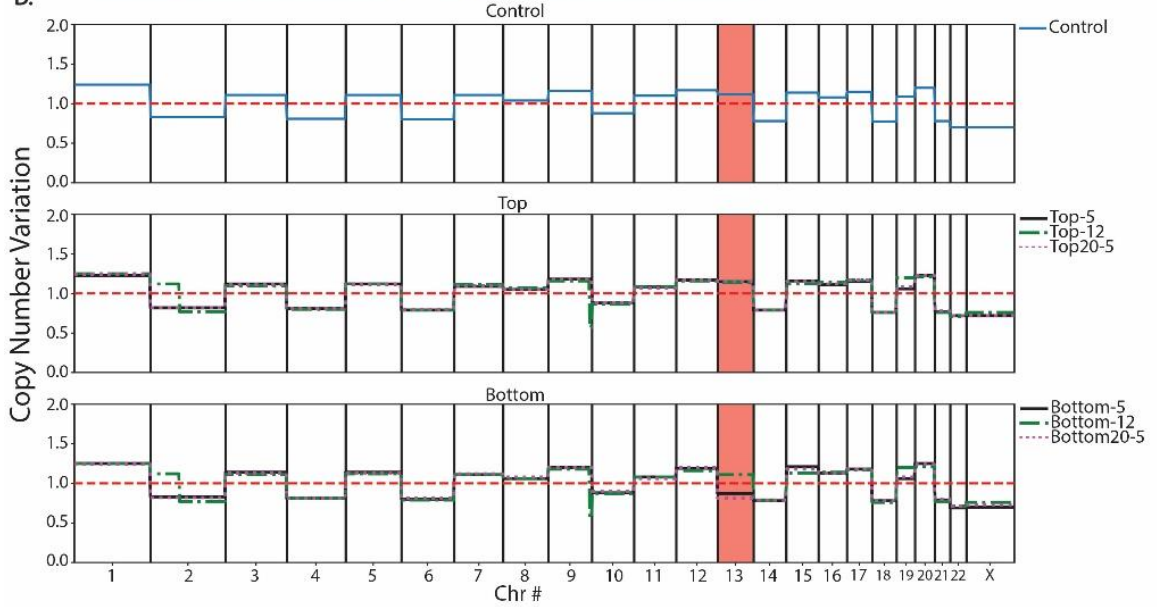

B.
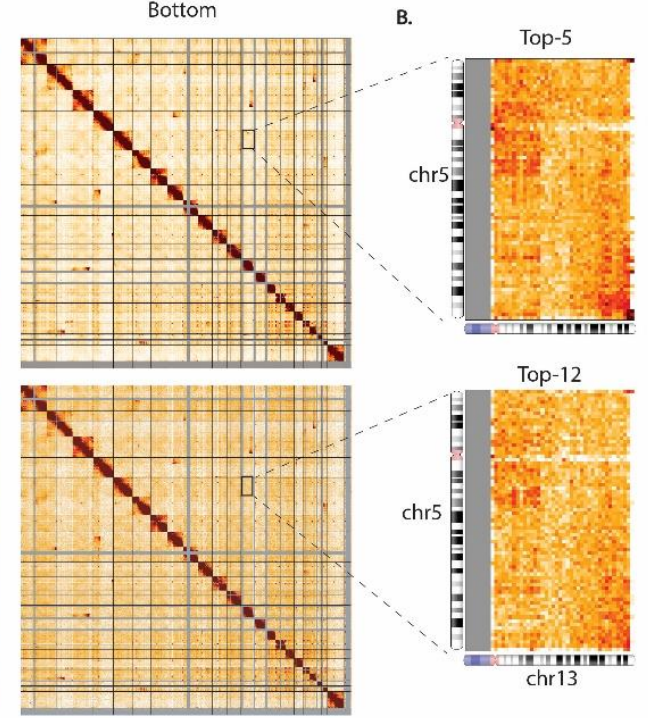

$\lim 13$

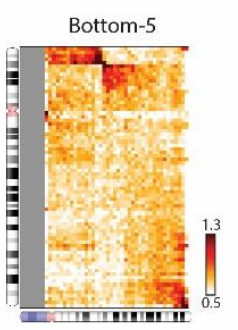

Bottom-12
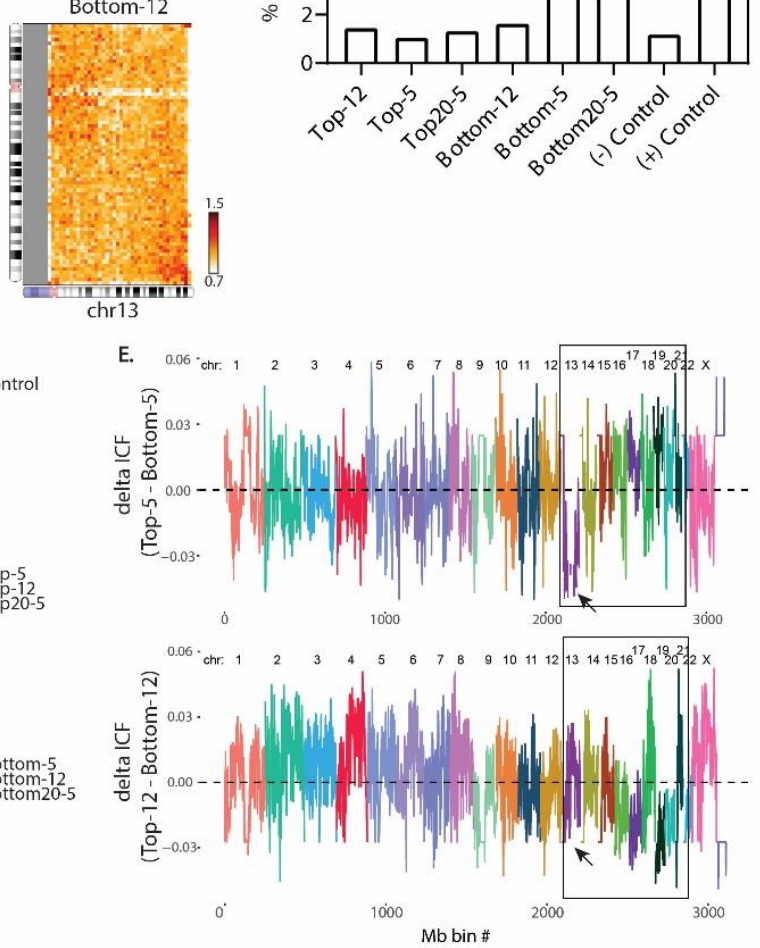

Figure 6. Global genomic rearrangements after constricted migration. (A) Whole genome 2.5Mb Hi-C interaction frequency maps for cells that have undergone 5 and $12-\mu \mathrm{m}$ transwell migration. (B) Zoom-in of inter-chromosomal interactions between chr5 and chr13 for cells that have undergone 5 and $12-\mu \mathrm{m}$ transwell migration. (C). Estimation of the $\%$ of chromosomes bearing the $\mathrm{t}(5 ; 13)$ based on the frequency of the proposed translocation interaction divided by the average neighboring bin cis interactions. (D) Copy number variation among all A375 subtypes inferred from total raw Hi-C counts. Red dashed line represents the mean copy number level while the other lines represent the copy number of A375 cell subpopulations. The region highlighted in red shows that chr13 exhibits copy number loss after 10 rounds of constricted migration. (E) Plots represent the difference in inter-chromosomal fraction (delta ICF) in cells that have undergone migration through $5-\mu \mathrm{m}$ constrictions (top plot) and cells that have undergone migration through $12-\mu \mathrm{m}$ constrictions (bottom plot) using $1 \mathrm{Mb}$ binned Hi-C contacts. The boxed region highlights regions of difference between constricted and unconstricted migration. 
A.
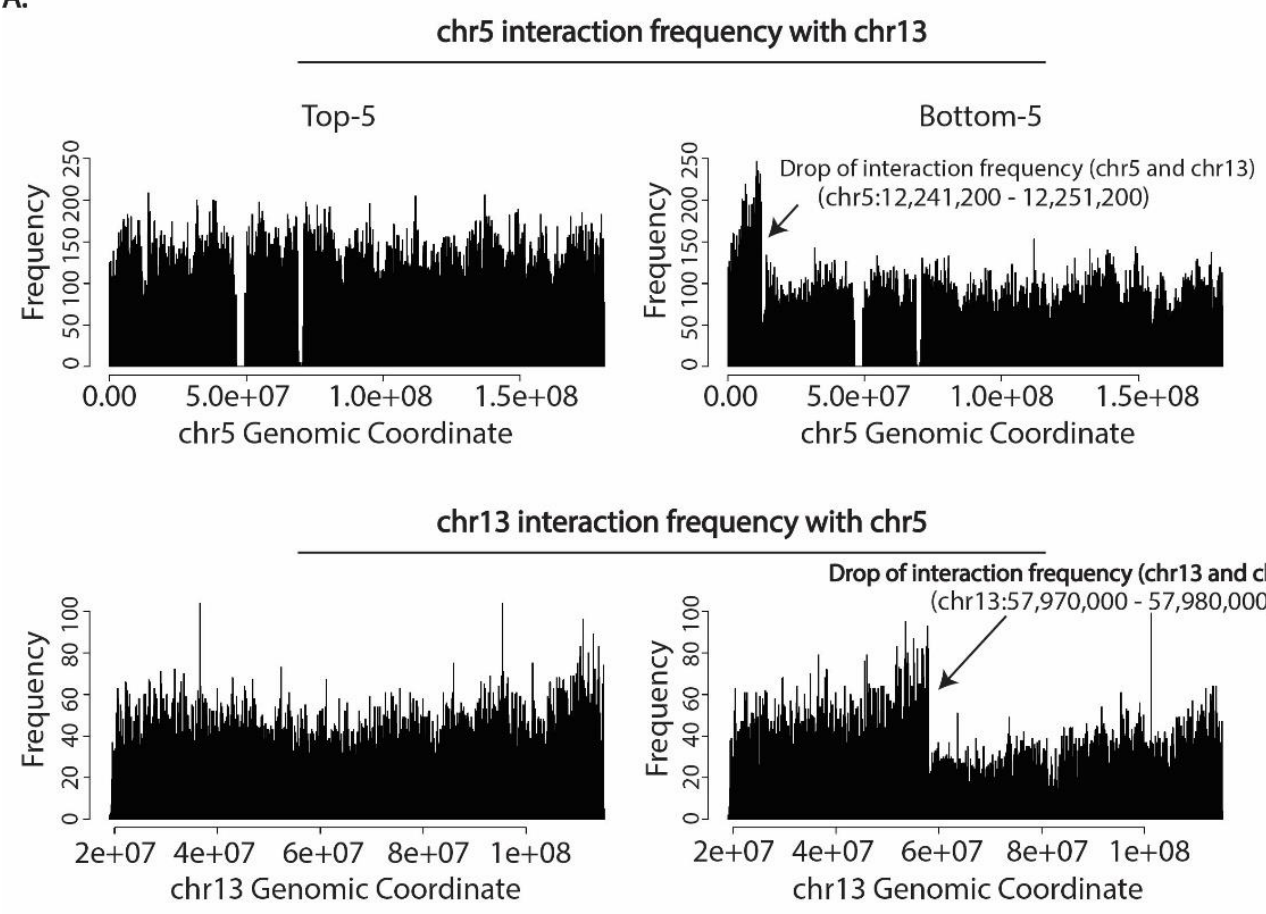

B.
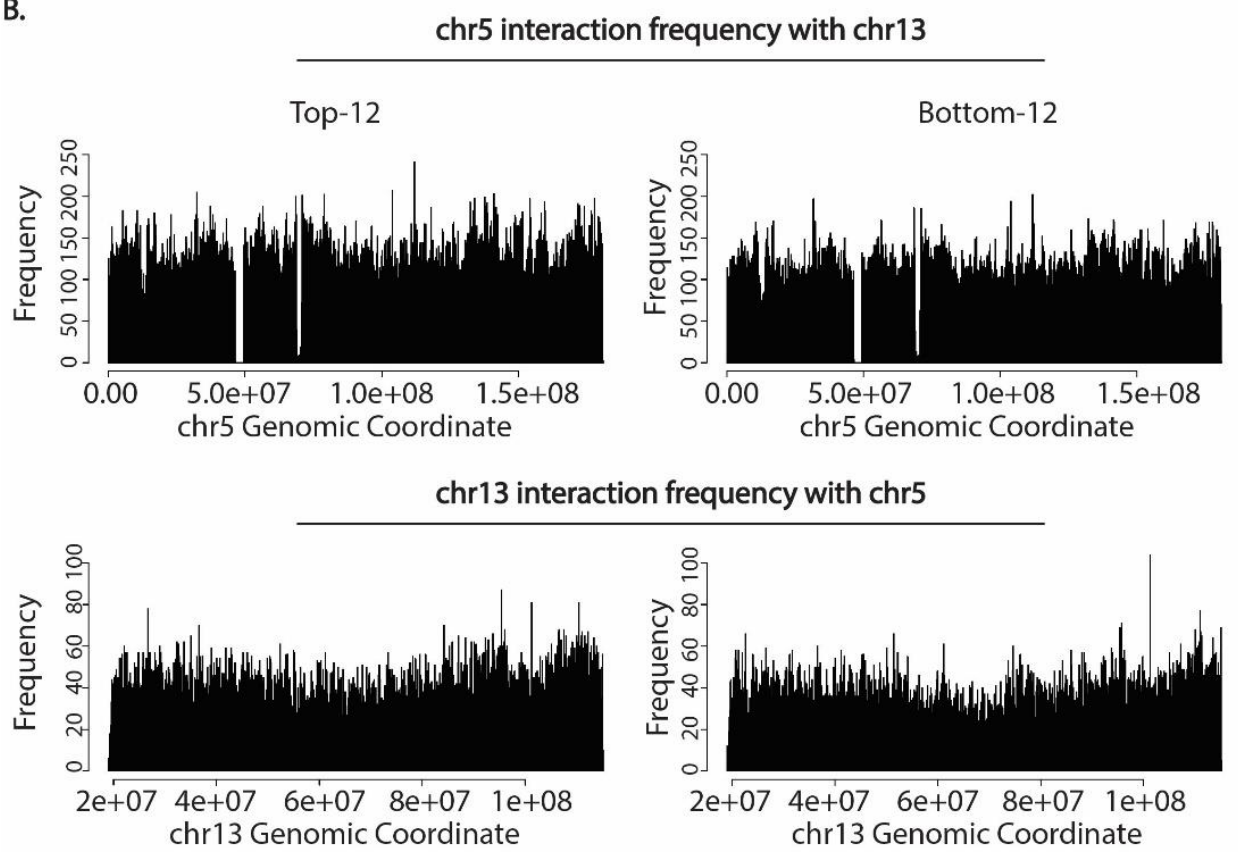

Supplementary Figure 7. Translocation between chr5 and chr13 is specific to migration through $5 \mu \mathrm{m}$ constrictions. (A) Top panel: Contact frequency of chr5 genomic coordinates with chr13 in Top-5 cells (left) and Bottom-5 cells (right). Bottom panel: Contact frequency of chr13 genomic coordinates with chr5 in Top-5 cells (left) and Bottom-5 cells (right). Black arrows indicate a decrease in contact frequency between chr5 and chr13 (Top panel) and chr13 and chr5 (Bottom panel) indicating the end of the translocated region. (B) Top panel: Contact frequency of chr5 genomic coordinates with chr13 in Top-12 cells (left) and Bottom-12 cells (right). Bottom panel: Contact frequency of chr13 genomic coordinates with chr5 in Top-12 cells (left) and Bottom-12 cells (right). A drop in contact interaction frequency is not observed due to undetectable $\mathrm{t}(5,13)$. 
In addition to translocations, changes in chromosome copy number have been previously reported after constricted migration (Irianto et al., 2017a). We therefore followed a published approach (Servant et al., 2018) to use raw read counts from our Hi-C data to investigate possible copy number variations (CNV) due to constricted migration in A375 subpopulation of cells (Figure 6D). The control population of A375 cells already exhibits non-uniform copy number across chromosomes and chromosome regions (Figure 6D, top panel). When comparing the subpopulations of A375, most of the chromosomes maintained their copy numbers independent of constricted migration. However, cells that have undergone constricted migration (Bottom-5 and Bottom20-5) exhibit notable copy number loss in chr13 (Figure 6D, bottom panel).

Beyond revealing translocations, interchromosomal contact data can reveal changes in patterns of whole chromosome territory interactions between conditions. So, we next sought to explore how the interchromosomal fraction (ICF) of interactions (Heinz et al., 2018) across the genome varies among the cells that have undergone constricted migration (Figure 6E). Interestingly, we observe a decrease in delta ICF of chr13 (Figure 6E, top panel, indicated by black box) in Bottom-5 cells. This is not likely to be explained purely by copy number loss at chr13, as this would decrease both inter and intra-chromosomal contacts rather than changing the ratio between the two. Additionally, smaller chromosomes (chr14-chr22) display an overall increase in delta ICF in Bottom-5 cells (Figure 6E, top panel, indicated by black box) but a decrease of ICF in Bottom-12 cells (Figure $6 \mathrm{E}$, bottom panel, indicated by black box). This measurement could indicate that smaller chromosomes differ in their relative compactness and intermixing depending on constricted migration.

\section{Cells that have undergone constricted migration exhibit altered nuclear morphology in 3D collagen matrices}

To investigate whether the cells that had undergone multiple rounds of constricted migration show metastatic behavior in more biologically-relevant environments, we embedded A375 Control, Top-5 and Bottom-5 cells expressing Dendra2-H4-GFP (histone-4 ) in 3D collagen gel matrices as described previously (Denais et al., 2016). Bottom-5 cells embedded in collagen with a density of $2.42 \mathrm{mg} / \mathrm{mL}$, displayed long cytoplasmic protrusions and nuclear deformations compared to Control and Top-5 which exhibited rounder cell and nuclear morphologies (Figure 7A and S8A). Bottom-5 cells showed protrusions after only 5 hours after embedding in collagen and these protrusions increased after 24 and 48 hours of incubation in the 3D collagen matrix (Figure 7B). In contrast, only a small fraction of cells that did not undergo constricted migration in the transwell (Top-5 and Control) exhibited cell protrusions even after $48 \mathrm{~h}$ incubation in 3D collagen matrices (Figure 7B). With increasing incubation time in the 3D collagen matrices, the nuclei of the Bottom5 cells that are extending protrusions also appear to be more elongated than Control and Top-5 cells, suggesting that Bottom-5 cells are migrating through the collagen fibers and deforming their nuclei (Figure 7C). Indeed, Bottom-5 cells display highly motile behavior in 3D collagen matrices compared to Top-5 cells (Figure 7D, Movies S5 and S6). When migrating through collagen, Bottom-5 cells travel longer distances at a higher speed (Figure 7E, Movie S6). The minimal nucleus diameter of Bottom-5 cells migrating through the collagen fiber meshwork ranges from 3$11 \mu \mathrm{m}$ (Figure S8B). These nucleus constriction sizes suggest that the collagen meshwork produces constrictions comparable in size with transwell pore sizes through which cells must squeeze their nuclei. 
Analyzing the nuclear morphology differences at higher resolution, we observe that Bottom-5 cells display larger deformations of the nucleus in collagen than Control and Top-5 cells (Figures 7F, S8C, Movie S7 and S8). About 30\% of Bottom-5 cells exhibit elongated nuclear morphology (defined by aspect ratio > 2.5) in collagen while only 1-3\% of Control and Top-5 cells exhibited elongated nuclei (Figure 7G).

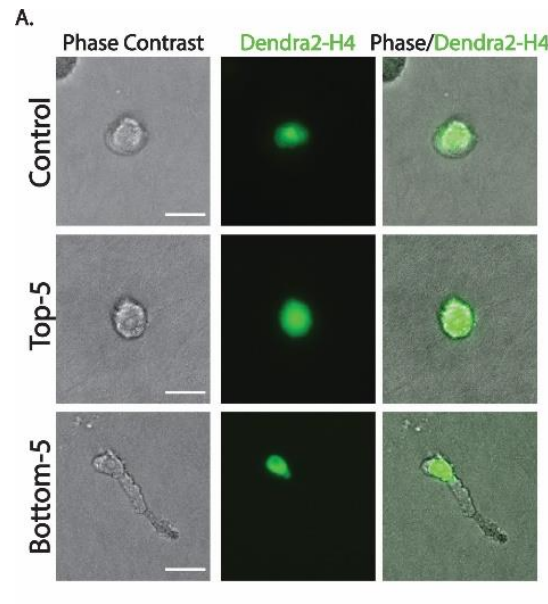

F.
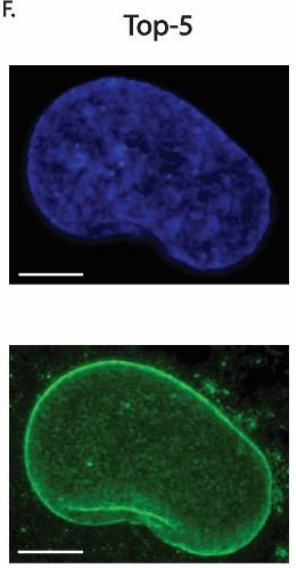

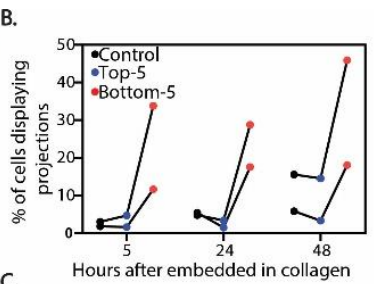

C.

Nuclear Shape of cells displaying projections

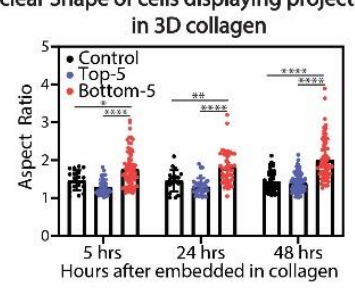

Bottom-5
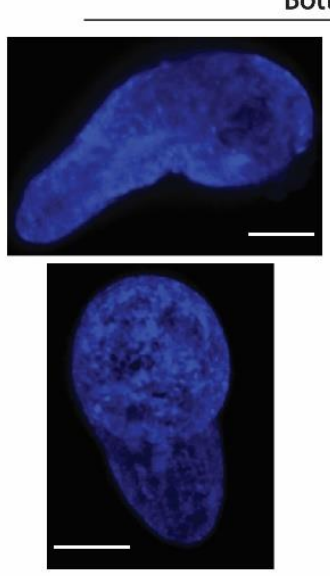

DAPI Lamin A/C
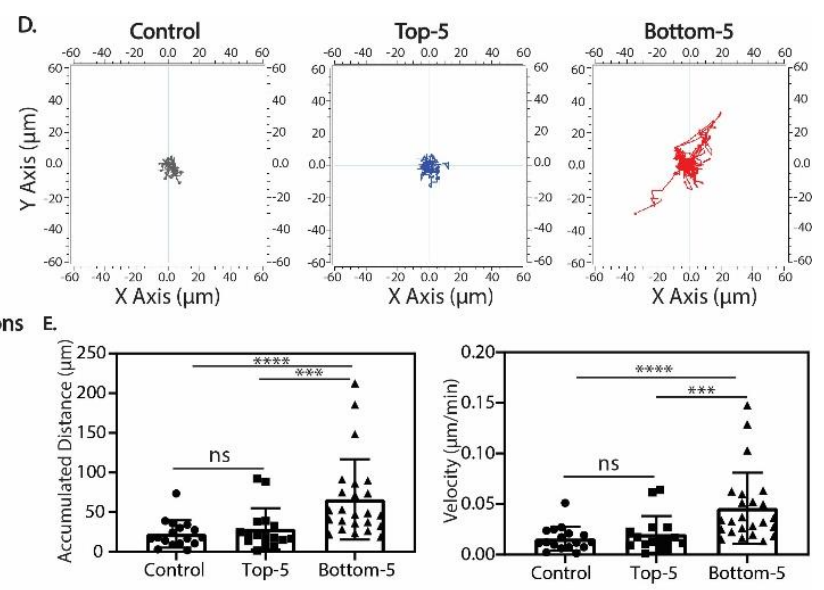

G.
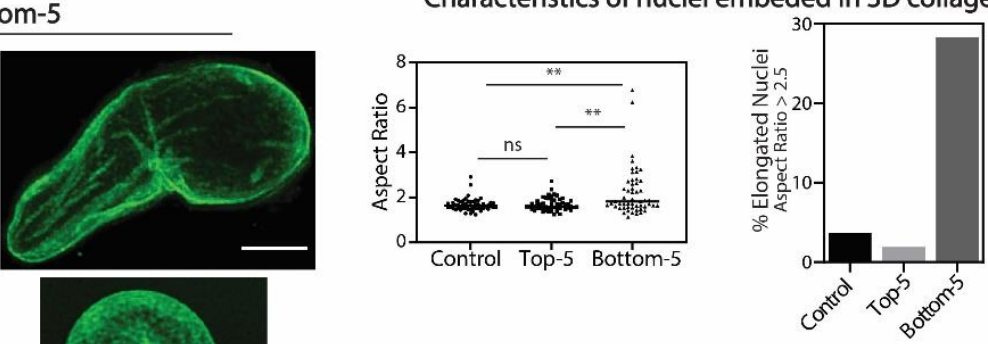

Distribution of Lamin A/C of nuclei embedded in 3D collagen
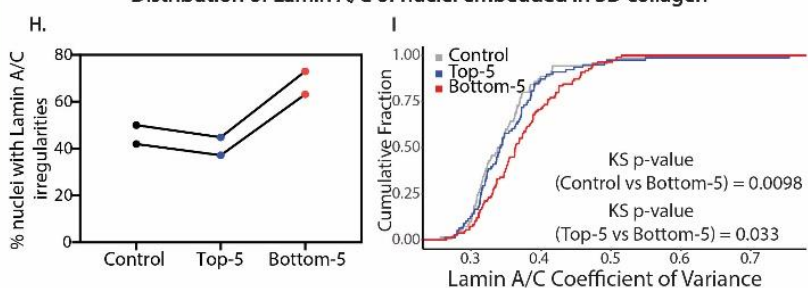

Figure 7. Sequentially constricted cells show elongated nuclei in 3D collagen matrix model. (A) Phase contrast images of A375 cells 48 hours after embedded in 3D collagen matrices show differences in their cell morphology. Dendra2-H4-GFP labels the nucleus (green). (B) Fraction of Control, Top-5 and Bottom-5 cells displaying projections at indicated timepoints after embedding in 3D collagen matrices. Each biological replicate is connected by a line. (C) Aspect ratio quantification of A375 nuclei at timepoints after collagen embedding for Control, Top-5 and Bottom-5 cells. ( $\mathrm{N}>20$ for each condition; $* \mathrm{p}=0.0168, * * \mathrm{p}=0.0016, * * * * \mathrm{p}<0.0001$; two tailed t-test). (D) Live cell image tracking of Control, Top-5 and Bottom5 cells migrating in 3D collagen matrices. (E) Quantification of accumulated distance and velocity of Control ( $n=17)$, Top$5(\mathrm{n}=17)$ and Bottom-5 ( $\mathrm{n}=24)$ migrating in 3D collagen matrices. (F) Nuclei of Top-5 (left) and Bottom-5 cells ( 2 different cells, right) stained with DAPI (blue) and Lamin A/C (green). Scale bars (white) $=5 \mu \mathrm{m}$. For 3D reconstruction visualization, see Movie S5 and S6. (G) Left panel: Measurements of nucleus elongation by aspect ratio in Control $(\mathrm{n}=54)$, Top-5 ( $\mathrm{n}=$ 52) and Bottom-5 ( $\mathrm{n}=53)$. Top-5 vs Control $(\mathrm{p}=0.8232)$; Bottom-5 vs Top-5 (**p = 0.0054); Bottom-5 vs Control (**p = 0.0031) as calculated by two-tailed t-test. Right panel: Percent of cells with elongated nuclei in A375 Control, Top-5 and Bottom-5 in 3D collagen (Aspect Ratio > 2.5). (H) Percent of nuclei that display irregularities in Lamin A/C distribution in Control, Top-5 and Bottom-5 cells embedded in 3D collagen by visual inspection. Each biological replicate connected by a 
line. (I) Cumulative distribution plot of Lamin A/C coefficient of variance for Control, Top-5 and Bottom-5 cells embedded in 3D collagen matrices. Number of nuclei quantified remains the same as in $\mathrm{G}$.

Changes in nuclear morphology also correlated with changes in distribution of Lamin $\mathrm{A} / \mathrm{C}$ in Bottom-5 nuclei embedded in 3D collagen. While nuclear wrinkling and therefore abnormal Lamin A/C patterns were evident in all A375 subpopulations, a higher fraction of Bottom-5 nuclei exhibit these irregularities (Figure 7H). Bottom-5 cells exhibit a higher Lamin A/C coefficient of variance in the nucleus when compared to Control and Top-5 cells (Figure 7I). Overall, quantification of nuclear shape differences in collagen distinguished cells that had undergone constricted migration in transwell chambers from cells that did not, indicating that the ability to deform their nucleus and migrate in a 3D environment is a key distinguishing factor among the A375 cell subpopulations.

A

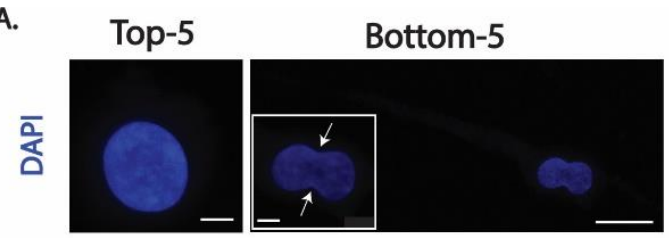

B.
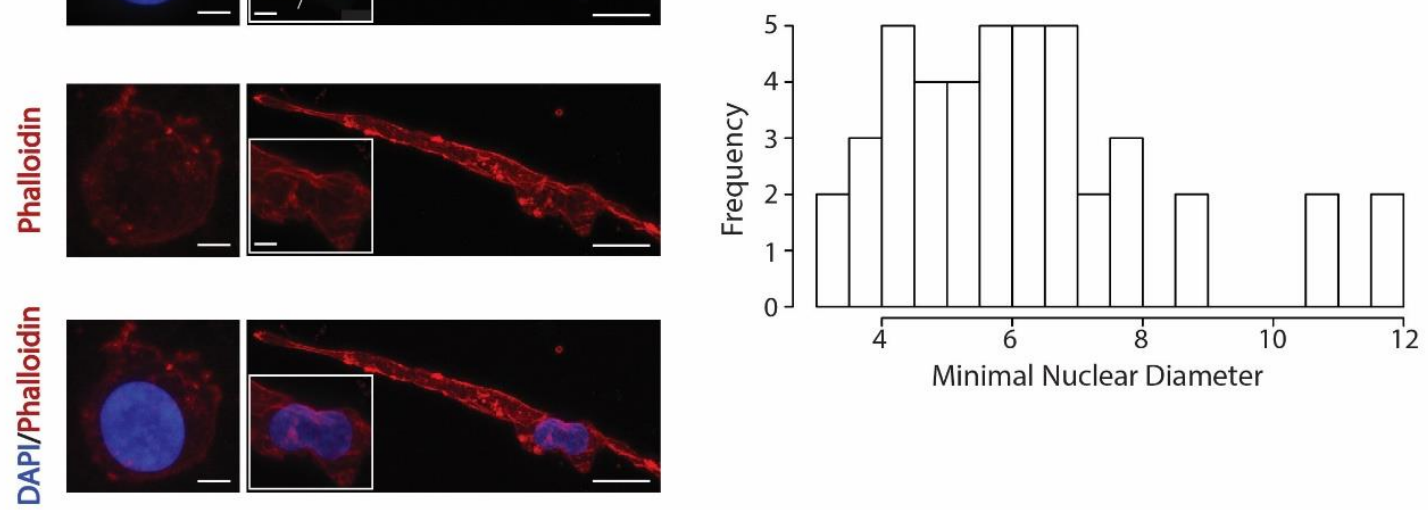

c.

Top-5
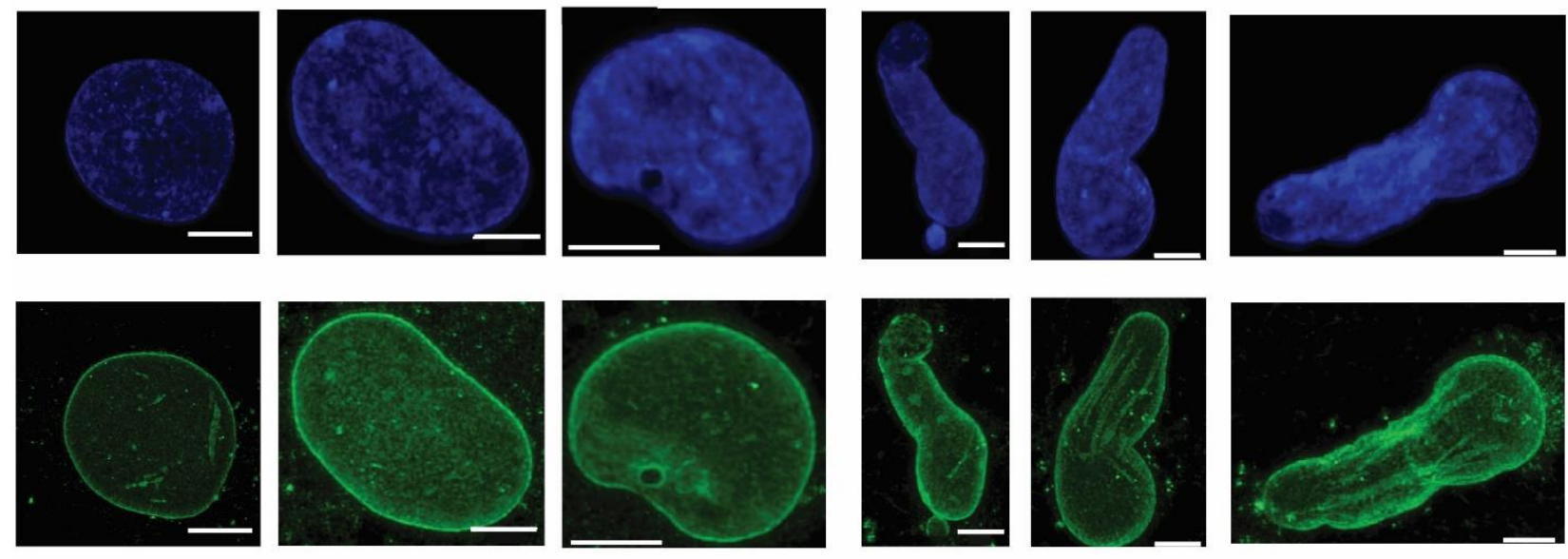

DAPI Lamin A/C

DAPI Lamin A/C

Supplementary Figure 8. A375 cells that have undergone sequential transwell migration deform their nuclei during migration through 3D collagen matrices (A) Maximum projection confocal images of Top-5 and Bottom-5 cells stained with DAPI (blue) and Phalloidin (red). (Insets) Zoom in of nucleus of Bottom5 cell. Scale bars (white) indicate $5 \mu \mathrm{m}$ for Top-5 and Bottom-5 insets; $20 \mu \mathrm{m}$ for Bottom- 5 zoomed out 
images. White arrows in insets indicate the minimal nuclear diameter. (B) Distribution of minimal nuclear diameter of all elongated Bottom-5 nuclei embedded in 3D collagen. (C) Maximum projection confocal images of Top-5 (left panel) and Bottom-5 (right panel) nuclei visualizing DAPI (blue) and Lamin A/C (green). Scale bars (white) indicate a length of $5 \mu \mathrm{m}$.

\section{Agent based modeling reveals that heterogeneity and constricted migration induced changes could both contribute to sequential migration effects}

As described above, the presence of the subpopulation of A375 cells that cannot migrate at all (Top-12) demonstrates an inherent heterogeneity in migratory ability within the population, as previously reported in this cell line (Kozlowski et al., 1984). However, it is not clear whether the increase in migratory efficiency and associated 3D genome and nucleus morphology alterations in Bottom- 5 cells are induced by repeated constricted migration or represent a pre-existing population selected by the constriction (Figure S9A).

To evaluate whether either or both of these options could explain our observed migration results, we used agent-based modeling $(\mathrm{ABM})$ to simulate a variety of initial population compositions and changes with migration (Figure S9B; see Materials and Methods for more detail). This model reports what fraction of cells would go through a transwell filter at each round of migration based on probabilistic choices of migration and division (Figure S9C). If the initial population contains a mixture of moderate and super-migrators, the migration efficiency of Top cells does not decline over the rounds of migration, which does not replicate the results of A375 cells, but does in some ways mimic the behavior of MDA-MB-231 cells (Figures S9B and S9D, first panel). The A375 experimental data can be recapitulated if the initial starting population is composed of three heterogeneous subpopulations (non-migrators, moderate migrators and super migrators) with highly migratory cells representing $0.5 \%$ of the population (Figure S9D, second panel). If this scenario is true, then our Bottom-5 specific 3D genome and nucleus structures were pre-existing in a small fraction of the initial population and primed these cells for confined migration. However, we are also able to recapitulate our experimental data with a scenario in which there are only non-migrators and moderate migrators in the initial population but then cells that squeeze through constrictions experience an induced change that alters their phenotype (boosting function shown in Figure S9D, third panel). In contrast, this same mixed population of non-migrators and moderate migrators without induced changes cannot recapitulate the increase in migration efficiency we observe (Figures S9D, fourth panel). Overall, our modeling results show that A375 cells must have an initial non-migratory subpopulation, but that the increase in migratory efficiency with constriction could either be a selection or induction process or a combination of both. 


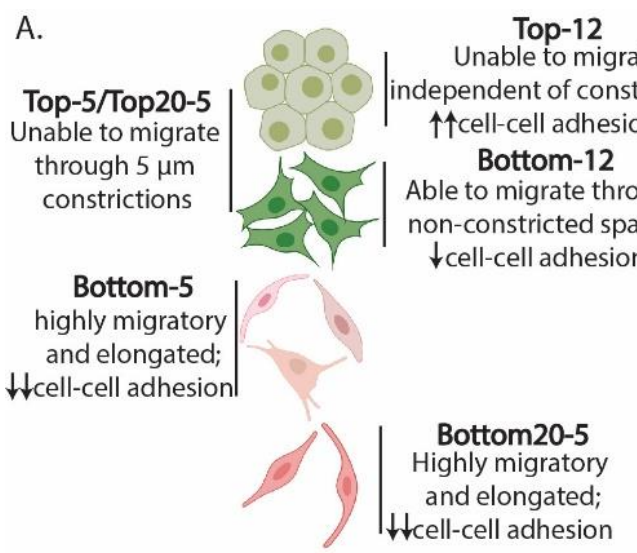

D.

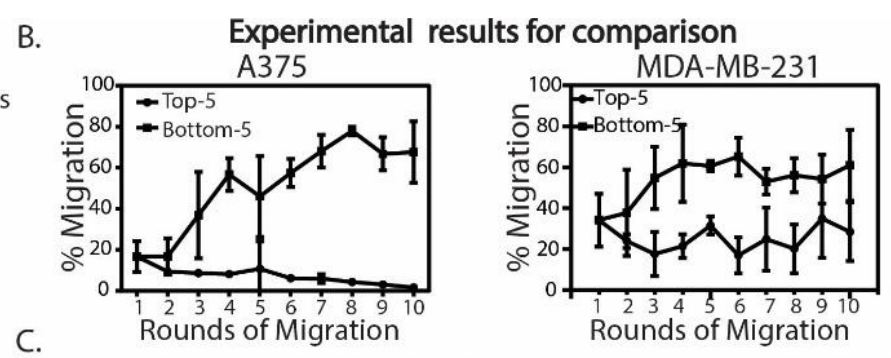

Choices during each of 25 timesteps in a given round of migration

\begin{tabular}{|c|c|c|c|}
\hline Die & Divide & Move horizontally & Migrate through pore \\
\hline & & & \\
\hline
\end{tabular}

\begin{tabular}{|c|c|c|c|c|}
\hline Scenario & $\begin{array}{l}\text { Initial Cell } \\
\text { Population }\end{array}$ & $\begin{array}{l}\text { Initial } \\
\text { Parameters }\end{array}$ & Change after migration & Result \\
\hline $\begin{array}{l}\text { Two population } \\
\text { heterogeneity } \\
\text { with initial } \\
\text { Super Migrators }\end{array}$ & & $\begin{array}{l}99.5 \% \\
P_{\text {mig }}=0.01 \\
0.5 \% \\
P_{\text {mig }}=0.05\end{array}$ & None & 事 \\
\hline $\begin{array}{l}\text { Three population } \\
\text { heterogeneity } \\
\text { with initial } \\
\text { Super Migrators }\end{array}$ & & $\begin{array}{l}54.5 \% \\
P_{\text {mig }}=0.0001 \\
45 \% \\
P_{\text {mig }}=0.01 \\
0.5 \% \\
P_{\text {mig }}=0.05\end{array}$ & None & 每) \\
\hline $\begin{array}{l}\text { Two population } \\
\text { heterogeneity } \\
\text { with moderate } \\
\text { migrators and } \\
\text { induced change }\end{array}$ & & $\begin{array}{l}50 \% \\
P_{\text {mig }}=0.001 \\
50 \% \\
P_{\text {mig }}=0.01\end{array}$ & $\begin{array}{l}P_{\text {mig }} \text { boosted by function } \\
\text { after successful migration }\end{array}$ & (100) \\
\hline $\begin{array}{l}\text { Two population } \\
\text { heterogeneity } \\
\text { with moderate } \\
\text { migrators }\end{array}$ & & $\begin{array}{l}50 \% \\
P_{\text {mig }}=0.001 \\
50 \% \\
P_{\text {mig }}=0.01\end{array}$ & None & 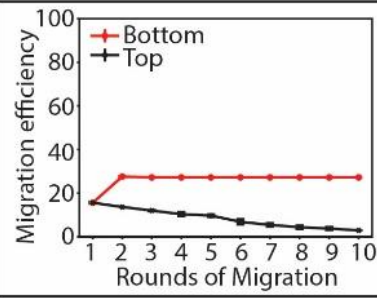 \\
\hline $\begin{array}{l}\text { Random variation } \\
\text { within a single } \\
\text { distribution }\end{array}$ & & 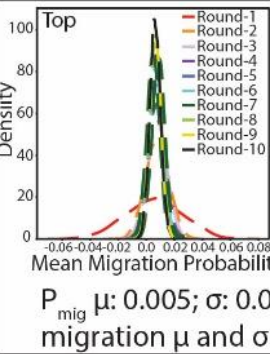 & 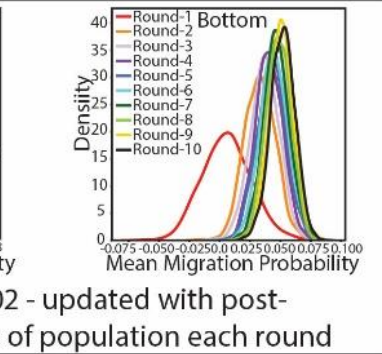 & Rounds of Migration \\
\hline
\end{tabular}


Supplementary Figure 9. Agent based modeling of cell populations undergoing constricted migration. (A) A375 cell subpopulations observed after sequential constricted migration. (B) For comparison with model results, results of sequential transwell migration through $5 \mu \mathrm{m}$ constrictions are recapitulated from Figure 1 for A375 (left) and from Figure S3 for MDA-MB-231 (right) cells. (C) Choices a cell can make at each timestep during each simulated migration round. (D) Parameters used in each agent-based model (left columns) and results of each model (rightmost column).

\section{Discussion}

Constricted migration is an important phenomenon in cancer metastasis and presents a major challenge to nuclear mechanics. Major avenues of previous research have separately investigated the role of the nucleus in confined migration, the impact of migration on linear DNA integrity, and the role of 3D genome structure in cancer. Our present results bridge these fields, revealing differences in spatial chromosome compartmentalization specific to cells that have passed through numerous constrictions smaller than their nucleus. These 3D genome structures are associated with notable differences in cell and nucleus phenotypes both when the cells are migrating on a 2D surface and when they are squeezing through a $3 \mathrm{D}$ collagen matrix. Cells proficient at confined migration more often deform their nuclei, elongate their cell body, and have fewer cell-cell attachments.

As described in our agent based modeling results, a question raised by our results is whether the differences in 3D genome structure we see in cells that have undergone confined migration (Bottom-5 and Bottom20-5) result from a selection process on an initially heterogeneous population or a "training process" where confined migration itself causes chromosome structure changes. Our ABM results indicate that either selection, training, or a combination could explain the differences observed in sequentially constricted cells. It is biologically plausible that cells which are initially primed for confined migration in a heterogeneous tumor begin to squeeze through tight junctions, and that then their chromosome structure is further rearranged as a result of the nucleus deformations. Within melanoma lesions, a select group of cells can gain the ability to metastasize, and that further diversification and phenotype change can occur as a result of metastasis (Damsky et al., 2010). Overall, our data suggest that both selection and training could be taking place.

As discussed, our isolation of A375 cells that cannot migrate at all, even given 10 chances to go through a wide pore (Top-12 cells), shows that the initial A375 population is heterogeneous, as expected from previous reports (Kozlowski et al., 1984). The genome structures and gene expression patterns specific to this subset informs us about the properties of cells that cannot migrate. On the other hand, the fact that Bottom-12 cells, which have passed through a large pore, present with genome structure differences compared to Bottom-5 cells shows that we are not simply distinguishing between cells with a pre-existing ability to migrate. There are cellular, nuclear, and genome organization properties specific to confined migration. Further, some structures and phenotypes of Bottom-5 cells, such as the chromosome 5-13 translocation and extremely elongated cell shapes, are not detectable in the original control population and could be a result of induced phenotype changes or random events that are further reinforced by a selection process. As passage through a constriction physically moves the chromosomal regions 
leading to the possibility of physical mixing of domains in the nucleus. This provides loci previously more distant with an opportunity to associate. Recent work has demonstrated that attractions between heterochromatic regions are an essential part of the phase separation that organizes chromatin in the nucleus (Falk et al., 2019). During constriction, these domains could cause new associations to occur. This could be an explanation for the strengthening of interactions we observe between previously weak B compartments and stronger B compartment regions. Meanwhile, certain interactions may be pulled apart as suggested by chromatin stretching previously described (Irianto et al., 2017b) and loss of B-B interaction strength with confined migration observed in neutrophils (Jacobson et al., 2018). We note while genome-wide changes like compartment weakening might result directly from nucleus deformation and physical movement of chromatin domains, highly specific local compartment switches would be unlikely to have been pushed or pulled in the same way in every individual cell. Such specific changes could arise either by selection of pre-existing differences in the population, selection of a beneficial change that is induced by deformation in some cells during migration, or induction of a programmed cell response to constricted migration. It is known that mechanical signaling can induce cellular reprogramming and that cellular reprogramming, such as an epithelial to mesenchymal cell transition (Shivashankar, 2019), can involve genome structure changes.

Our results suggest that the confined migration-specific 3D genome structure relates to several biological processes. First, we observe an overall correlation between spatial compartmentalization changes and gene expression alterations, and the altered genes relate to migratory ability. For example, in Bottom-5 cells, we observe downregulation of a group of genes important for cell-cell/matrix adhesion (CADM3, CADM1, ITGA9). Why would 3D genome changes be needed to accompany gene expression changes? Altered local gene regulation alone can be sufficient to explain temporary changes in cellular behaviors in response to a stress or stimulus, and these changes do not require 3D genome rearrangement (Jin et al., 2013). But our data suggests that migration behaviors of the different A375 sub-populations are stably divergent. From our observations, we propose that the stability of this phenotype is encoded in the 3D genome structure change we measure, since rearrangement of whole genomic to different spatial and chromatin environments is less reversible than transiently regulating individual genes. Such stable differences in 3D genome structure after confined migration could underlie the distinct phenotype and increased in vitro invasiveness of cancer cells derived from metastatic sites compared to those from primary tumors or normal tissue (Oppenheimer, 2006).

Many genomic regions with altered compartmentalization in sequentially constricted cells do not show a connection to gene regulation. In fact, we observe a striking enrichment of regions with no genes at all among the set of regions that switch from the A to the B compartment in confined migration. This suggests that the genome structure differences we observe could have a role beyond gene regulation and could play a role in modulating the physical properties of the cancer cell nucleus. Indeed, we observe that the nuclei of Bottom-5 cells deform more than Top-5 cells when embedded in a collagen matrix or even when spontaneously migrating on a 2D surface. Previous research has shown that nucleus stiffness can be altered by increasing or decreasing the overall expression of Lamin A/C or by changing overall levels of heterochromatin (Lammerding et al., 2006, Davidson et al., 2014, Stephens et al., 2017, Stephens et al., 2018). But, the apparent change in nucleus pliability observed in the current study cannot be explained by changes in overall Lamin A/C content or heterochromatin levels: Lamin A/C and H3K9me3 levels were 
unchanged as measured by both immunostaining and western blot. Instead, we observed a redistribution of Lamin $\mathrm{A} / \mathrm{C}$ and $\mathrm{H} 3 \mathrm{~K} 9 \mathrm{me} 3$ localization in the nucleus, with individual heterochromatin foci originally in the interior of the nucleus merging at the periphery and Lamin $\mathrm{A} / \mathrm{C}$ becoming less evenly distributed. These observations in A375 cells, also recapitulated in MDA-MB-231 cells, suggest that changing levels of Lamin A/C and heterochromatin are not always required to increase constricted migration potential and that re-localization of these proteins and chromosome regions could also be important to the ability of the nucleus to undergo physical deformations. The visibly altered heterochromatin localization in sequentially constricted cells may relate to differences in chromosome compartmentalization we observe with $\mathrm{Hi}-\mathrm{C}$. We observe that regions with stronger B compartment identity gain more distal interactions, consistent with the observation that disparate heterochromatin foci come together at the nuclear periphery in sequentially constricted cells. Future work will be required to determine whether the 3D genome changes we observe translate into quantitative differences in nucleus physical properties.

Our data also provide insight about basic 3D genome organization principles. As described above, our data allow conceptual links between changes in contacts observed in Hi-C data and the appearance and localization of chromatin types observed by imaging. Further, our observation that compartments, compartment strength, and whole chromosome interactions change while TADs are unaltered reinforces the idea that these are separate and largely independent layers of genome organization (Mirny et al., 2019, Schwarzer et al., 2017). These changes also suggest that the compartment and whole chromosome level of genome structure may be more important to nuclear mechanics than the TAD and loop level of organization. Meanwhile, our observation that local punctate interactions change around sites where gene expression changes echo previous evidence that collisions between loop extrusion and transcription can influence local contact patterns (Brandao et al., 2019).

Are the 3D genome changes we observe in our constricted migration cell population diagnostic of metastatic potential? Previous reports have sometimes detected gene expression signatures in primary tumors that may be predictive of metastasis (Ramaswamy et al., 2003). Nuclear morphology abnormalities ("nuclear atypia") are also already used clinically as a marker of cancer aggressiveness (Kadota et al., 2012). Recent reports have taken advantage of microfluidic engineering to predict metastatic potential of breast cancer cells based on their morphological features (Yankaskas et al., 2019). But, beyond being a marker, the biological significance of such abnormalities and what chromosome structure changes accompany them have not been defined. Here, we provide evidence that chromosome structure changes could link metastatic gene expression signatures with the abnormal nuclear appearance of aggressive cancer. Our results reveal chromosome spatial compartmentalization differences in genomic regions related to metastatic potential in a highly invasive subset of A375 cells. Future work will be needed to investigate whether such changes are also observed in patient metastatic melanoma samples. Our data provides a foundation for future investigation of whether similar structural changes accompany constricted migration in other cancer types and therefore constitute 3D genome structure signatures of metastatic cancer potential. 


\section{Acknowledgements}

We thank Mariano Labrador, Jacob Sanders, and Yang Xu for insightful discussion. We thank Jan Lammerding for advice about the project. We thank Bas van Steensel for providing the LAD type annotations. BJ1-hTERT cells were provided by Adayabalam Balajee at Oak Ridge Institute of Science and Education. Confocal images were obtained at the University of Tennessee Advanced Microscopy Imaging Core. This research was supported in part by a Ralph E. Powe Junior Faculty Enhancement Award from Oak Ridge Associated Universities to R.P.M. and by NIH NIGMS grant R35GM133557 to R.P.M. R.G. is supported in part by a Yates Dissertation Fellowship from UTK. D.T. was supported in part by a UTK Summer Undergraduate Research Internship award.

\section{Author Contributions}

R.G. and R.P.M. conceived the project, designed the experiments, and wrote the paper with input from all authors. R.G. performed genomic, cell culture, and imaging experiments and bioinformatics data analysis. T.F. performed the MDA-MB-231 sequential migration experiments and assisted with A375 experiments and Hi-C. P.D. designed and implemented the agent based modeling and assisted with computational analysis. T.I.R. performed 3D collagen immunostaining and quantification. R.SM. assisted with experimental design and interpretation. C.P. carried out some immunofluorescence experiments and analysis. D.T provided experimental assistance and performed single cell migration video analysis.

\section{Conflict of Interests}

The authors declare that they have no conflict of interest. 


\section{Supplementary Tables}

\begin{tabular}{|l|c|c|c|c|c|c|}
\hline \multicolumn{1}{|c|}{ Sample } & $\begin{array}{c}\text { Total Raw } \\
\text { Reads }\end{array}$ & $\begin{array}{c}\text { Both Sides } \\
\text { Mapped }\end{array}$ & Valid Pairs & $\begin{array}{c}\text { Unique } \\
\text { Valid Pairs }\end{array}$ & $\begin{array}{c}\text { \% Cis } \\
\text { Interactions }\end{array}$ & $\begin{array}{c}\text { \% } \\
\text { Dangling } \\
\text { Ends }\end{array}$ \\
\hline Control-R1 & $201,352,157$ & $124,670,760$ & $123,653,686$ & $107,358,325$ & 61.2 & 0.35 \\
\hline Control-R2 & $200,881,087$ & $102,710,892$ & $101,397,252$ & $80,394,938$ & 47.7 & 0.31 \\
\hline Top5-R1 & $320,786,521$ & $163,004,931$ & $161,788,811$ & $132,650,834$ & 55.6 & 0.23 \\
\hline Bottom5-R1 & $386,733,576$ & $193,207,211$ & $191,853,175$ & $152,440,505$ & 60.3 & 0.21 \\
\hline Top5-R2 & $164,616,353$ & $84,226,628$ & $83,087,615$ & $68,000,595$ & 48.7 & 0.28 \\
\hline Bottom5-R2 & $107,320,517$ & $54,380,776$ & $53,662,580$ & $43,911,557$ & 49.2 & 0.45 \\
\hline Top20-5-R1 & $142,531,635$ & $66,090,879$ & $62,567,577$ & $49,317,732$ & 47.7 & 0.60 \\
\hline $\begin{array}{l}\text { Bottom20-5- } \\
\text { R1 }\end{array}$ & $159,577,275$ & $73,992,021$ & $70,695,806$ & $57,329,882$ & 49.7 & 0.44 \\
\hline Top12-R1 & $117,695,787$ & $90,932,905$ & $90,442,670$ & $81,815,020$ & 43.0 & 0.39 \\
\hline $\begin{array}{l}\text { Bottom12- } \\
\text { R1 }\end{array}$ & $110,637,334$ & $85,346,366$ & $84,975,979$ & $76,728,534$ & 37.0 & 0.30 \\
\hline Top12-R2 & $145,063,083$ & $110,772,496$ & $110,380,318$ & $98,396,558$ & 40.4 & 0.26 \\
\hline $\begin{array}{l}\text { Bottom12- } \\
\text { R2 }\end{array}$ & $126,055,079$ & $96,662,104$ & $96,161,324$ & $86,277,860$ & 43.5 & 0.34 \\
\hline
\end{tabular}

Table S1. Summary Statistics for Hi-C Sequencing Experiments

\begin{tabular}{|c|c|c|c|}
\hline Sample & Total Reads after rRNA removal & Mapped Reads & Percent Mapped Reads \\
\hline Control-R1 & $25,802,932$ & $23,454,526$ & 90.9 \\
\hline Control-R2 & $44,936,964$ & $39,168,478$ & 87.16 \\
\hline Top5-R1 & $57,420,692$ & $49,189,316$ & 85.66 \\
\hline Top5-R2 & $40,240,820$ & $34,943,927$ & 86.84 \\
\hline Bottom5-R1 & $44,784,816$ & $37,982,597$ & 84.81 \\
\hline Bottom5-R2 & $42,149,066$ & $36,445,763$ & 86.47 \\
\hline Top20-5-R1 & $39,235,465$ & $36,102,375$ & 92.01 \\
\hline Top20-5-R2 & $97,958,087$ & $89,841,371$ & 91.71 \\
\hline Bottom20-5-R1 & $107,282,198$ & $98,413,826$ & 91.73 \\
\hline Bottom20-5-R2 & $54,332,623$ & $49,381,035$ & 90.89 \\
\hline Top12-R1 & $47,231,386$ & $42,228,487$ & 89.41 \\
\hline Top12-R2 & $44,863,196$ & $41,601,169$ & 92.73 \\
\hline Bottom12-R1 & $43,203,103$ & $38,744,667$ & 89.68 \\
\hline Bottom12-R2 & $8,436,059$ & $7,655,956$ & 90.75 \\
\hline
\end{tabular}

Table S2. Summary Statistics for RNA Sequencing Experiments

\begin{tabular}{|c|c|c|c|c|}
\hline Sample & Total Reads & Reads after trimming & Mapped Reads & Percent Mapped Reads \\
\hline Control-R1 & $169,579,026$ & $169,348,735$ & $137,428,769$ & 81.15 \\
\hline Top5-R1 & $169,763,417$ & $113,906,483$ & $94,322,265$ & 82.81 \\
\hline Bottom5-R1 & $213,830,754$ & $115,332,896$ & $108,423,723$ & 94.01 \\
\hline
\end{tabular}

Table S3. Summary Statistics for ATAC Sequencing Experiments

\section{Supplementary Movie Captions}

Supplementary Movie 1. Phase contrast live cell imaging in a 2D culture dish of a Top-5 cell. This cell is exhibiting amoeboid like migration.

Supplementary Movie 2. Phase contrast live cell imaging in a 2D culture dish of Bottom-5 cells. An integration of amoeboid and lobopodian/lamellipodia type of migration is observed. 
Supplementary Movie 3. 3D rendering of Top-5 nucleus using Leica Sp8 software displaying Lamin A/C (green) and H3K9me3 (red). Scale bars (white) indicate a length of $2 \mu \mathrm{m}$.

Supplementary Movie 4. 3D rendering of Bottom-5 nucleus using Leica Sp8 software displaying Lamin A/C (green) and H3K9me3 (red). Scale bars (white) indicate a length of $2 \mu \mathrm{m}$.

Supplementary Movie 5. Live time-lapse imaging of Top-5 cells migrating through 3D collagen matrices. Nuclei labelled with Dendra2-Histone H4.

Supplementary Movie 6. Live time-lapse imaging of Bottom-5 cells migrating through 3D collagen matrices. Nuclei labelled with Dendra2-Histone H4.

Supplementary Movie 7. 3D rendering of nucleus of collagen embedded Top-5 cell stained with DAPI (blue) displays a uniform distribution of Lamin A/C (green). Scale bars (white) indicate a length of $2 \mu \mathrm{m}$.

Supplementary Movie 8. 3D rendering of nucleus of collagen embedded Bottom-5 cell stained with DAPI (blue) displays an elongated shape and an altered distribution of Lamin A/C (green) with appearance of fiber like structures on the side of the constriction. Scale bars (white) indicate a length of $5 \mu \mathrm{m}$.

\section{MATERIALS and METHODS}

KEY RESOURCES TABLE

\begin{tabular}{l|l|l}
\multicolumn{1}{c|}{ REAGENT or RESOURCE } & \multicolumn{1}{c}{ SOURCE } & \multicolumn{1}{c}{ IDENTIFIER } \\
\hline Antibodies (IF) & & Sc-376248 \\
\hline Lamin A/C & Santa Cruz & ab133741 \\
\hline Lamin B1 & Abcam & ab176916 \\
\hline H3K9me3 & Abcam & R37117 \\
\hline Alexa Fluor 594 & Invitrogen & R37120 \\
\hline Alexa Fluor 488 & Invitrogen & \\
\hline Antibodies (Western Blot) & & PA1-16889 \\
\hline Beta Actin - Rabbit Polyclonal & Thermo Fisher & MA1-140 \\
\hline Beta Actin - Mouse Monoclonal & Thermo Fisher & 92568071 \\
\hline Goat anti-rabbit secondary & Licor & $95-32210$ \\
\hline Goat anti-mouse secondary & Licor & \\
\hline Chemicals & & $10-013-C V$ \\
\hline DMEM & Corning & $35-010-C V$ \\
\hline FBS & Corning & $14140-122$ \\
\hline Pen-Strep & Gibco & $25030-081$ \\
\hline L-Glutamine & Gibco & $12-119 \mathrm{~F}$ \\
\hline Medium 199 & Lonza & $30-240-\mathrm{CR}$ \\
\hline Hygromycin B & Corning & $25053 \mathrm{CI}$ \\
\hline Trypsin & Corning & I89900 \\
\hline RIPA buffer & Thermo Scientific & 354236 \\
\hline Collagen & Corning & $50-101-5485$
\end{tabular}




\begin{tabular}{|c|c|c|}
\hline phosphatase inhibitors & GenDepot & $50-101-5488$ \\
\hline micrococcal nuclease & Thermo Scientific & FEREN0181 \\
\hline BCA Protein Assay Kit & Thermo & 234225 \\
\hline 4-12\% Bis-Tris Plus gels & Invitrogen & NW04120BOX \\
\hline PVDF membranes & Invitrogen & B1000 \\
\hline \multicolumn{3}{|l|}{ Critical Commercial Assays } \\
\hline RNA easy Kit & Qiagen & 74134 \\
\hline rRNA Depletion Kit & New England Biolabs & E63105 \\
\hline Ultra II RNA library prep kit & New England Biolabs & E7770G \\
\hline Multiplex Oligos for Illumina & New England Biolabs & E7335G \\
\hline \multicolumn{3}{|l|}{ Deposited Data } \\
\hline $\begin{array}{l}\text { Hi-C, RNA-Seq and ATAC-Seq } \\
\text { from A } 375 \text { cell line }\end{array}$ & This study & GEO:GSE143678 \\
\hline \multicolumn{3}{|l|}{ Experimental Models: Cell Lines } \\
\hline A375 & ATCC & CRL-1619 \\
\hline BJ1-hTERT & Clontech & CCD00309196 \\
\hline \multicolumn{3}{|l|}{$\begin{array}{l}\text { Transwell Migration } \\
\text { Experiments }\end{array}$} \\
\hline Fibronectin & Corning & 354008 \\
\hline Transwell Filters $(12 \mu \mathrm{m})$ & VWR & $10769-224$ \\
\hline Transwell Filters $(5 \mu \mathrm{m})$ & VWR & $10769-236$ \\
\hline \multicolumn{3}{|l|}{ Software and Algorithms } \\
\hline Bowtie2 & $\begin{array}{l}\text { (Langmead and } \\
\text { Salzberg, 2012) }\end{array}$ & $\begin{array}{l}\text { http://bowtie- } \\
\text { bio.sourceforge.net/bowtie2/ind } \\
\text { ex.shtml }\end{array}$ \\
\hline C-World & Job Dekker Lab & $\begin{array}{l}\text { https://github.com/dekkerlab/cw } \\
\text { orld-dekker }\end{array}$ \\
\hline STAR & (Dobin et al., 2013) & $\begin{array}{l}\text { https://github.com/alexdobin/ST } \\
\text { AR }\end{array}$ \\
\hline MACS2 & (Zhang et al., 2008) & https://github.com/taoliu/MACS \\
\hline HTSeq & (Anders et al., 2015) & https://htseq.readthedocs.io/ \\
\hline DESeq2 & (Love et al., 2014) & $\begin{array}{l}\text { https://bioconductor.org/packag } \\
\text { es/release/bioc/html/DESEQ2.h } \\
\underline{\text { tml }}\end{array}$ \\
\hline Bedtools & $\begin{array}{l}\text { (Quinlan and Hall, } \\
\text { 2010) }\end{array}$ & $\begin{array}{l}\text { http://bedtools.readthedocs.io/e } \\
\text { n/latest/ }\end{array}$ \\
\hline Samtools & (Li et al., 2009) & http://samtools.sourceforge.net/ \\
\hline BBTools & & $\begin{array}{l}\text { https://github.com/kbaseapps/B } \\
\text { BTools }\end{array}$ \\
\hline CNV estimation & (Servant et al., 2018) & $\begin{array}{l}\text { https://github.com/nservant/can } \\
\text { cer-hic-norm }\end{array}$ \\
\hline Agent Based Modeling & $\begin{array}{l}\text { Modified from } \\
\underline{\text { https://github.com/zcol }} \\
\underline{\text { burn/cell-sheet-abm }}\end{array}$ & https://github.com/rpmccordlab \\
\hline
\end{tabular}




\section{CONTACT FOR REAGENT AND RESOURCE SHARING}

Further information and requests for resources and reagents should be directed to and will be fulfilled by the Lead Contact, Rachel Patton McCord (rmccord@utk.edu).

\section{EXPERIMENTAL MODEL AND SUBJECT DETAILS}

\section{Cell Lines and Cell Culture}

A375 and MDA-MB-231 cells were obtained from ATCC (CRL-1619 and HTB-26, respectively). Cells were verified to be negative for mycoplasma and were grown using complete DMEM medium (Corning - 10-013-CV; 10\% FBS, 1\% Pen-Strep, 1\% L-Glutamine) at $37^{\circ} \mathrm{C}$ supplied with $5 \% \mathrm{CO}_{2}$.

\section{METHOD DETAILS}

\section{Sequential Transwell Migration}

For the sequential transwell migration, we used transwells with $12 \mu \mathrm{m}$ (VWR-10769-224) and 5 $\mu \mathrm{m}$ pore sizes (VWR-10769-236). Briefly, the bottom of the transwells were coated with $40 \mu \mathrm{L}$ of $10 \mu \mathrm{g} / \mathrm{mL}$ fibronectin for $\sim 45$ minutes. 24 well plates were prepared for transwell migration assay adding $500 \mu \mathrm{L}$ of 1x DMEM (Corning) with full supplements per well. A375 cells were detached from culture dishes at $80-90 \%$ confluency and aliquoted to 100,000 cells per $100 \mu \mathrm{L}$ of 1xDMEM. Each transwell was placed into its corresponding well of the 24 well plate and $100 \mu \mathrm{L}$ of the cell suspension was added to the top of each filter. Cells were incubated at $37^{\circ} \mathrm{C}, 5 \% \mathrm{CO}_{2}$ and allowed to migrate for 24 hours. After the 24-hour incubation, migration efficiency was quantified as follows. First, freely floating cells were removed from the top of the filter (unmigrated; "Top" cells) and from the well beneath the filter (migrated "Bottom" cells) and placed in two separate tubes. Then, $400 \mu \mathrm{L}$ of trypsin was added into the bottom chamber of the 24 well plate and $200 \mu \mathrm{L}$ of trypsin was added into the top chamber to detach any remaining attached cells. Recovered cells after trypsinization were added to the unmigrated or migrated tubes, accordingly. Cells were spun down (1000 rpm, 5min) and counted (using trypan blue) to calculate \% migration such as: \#bottom/(\#top+\#bottom). Additionally, a small aliquot of cells was saved for immunofluorescence (IF). The rest of the cells were seeded into wells of a 24-well plate to expand. When cells reached $80-90 \%$ confluency, another transwell migration was performed (R2). A375 Top and Bottom cells were detached and counted. Two transwell filters were prepared as previously described (one for Top and one for Bottom). Then 100,000 cells suspended in $100 \mu \mathrm{L}$ of $1 \mathrm{xDMEM}$ without supplements were seeded into the transwell filters. After 24-hour incubation at $37^{\circ} \mathrm{C}$ and $5 \% \mathrm{CO}_{2}$, cells were trypsinized as previously described to quantify migration efficiency. Only the cells that were always on top (Top of Top) and the cells that were always on the bottom (Bottom of Bottom) were saved and grown for further sequential rounds of migration. This process was repeated for 10 and 20 rounds of migration which lead to 
the generation of A375-Top5, Bottom-5, Top20-5, Bottom20-5, Top-12 and Bottom-12, A37512-M10, A375-5-NM20 and A375-5-M20.

\section{D Single Cell migration}

Live cell imaging

To track single cell movement in 2D, A375-Control, Top-5 and Bottom-5 cells were seeded on wells of a 6-well plate at a 30,000 cells/well density. After cells were attached, live cell imaging was performed using the EVOS FL Auto microscope at $40 \mathrm{X}$ magnification. Images were acquired every 10 minutes for a 24-hour time period.

\section{Cell morphology analysis}

Parameters that describe cell morphology such as solidity and aspect ratio were quantified using the Shape Descriptors plugin in ImageJ.

\section{Immunocytochemistry}

\section{IF staining}

Approximately 50,000 - 100,000 cells for each sub-population of A375 were seeded into either poly-D-lysine treated coverslips or 35-mm coverslip bottom dishes. Cells were allowed to attach overnight and then crosslinked with $4 \%$ formaldehyde for 10 min followed by three, 5-minute washes with PBS. After washing, cells were permeabilized with permeabilization buffer (10\% goat serum, $0.5 \%$ Triton in PBS) for 1 hour at room temperature. After the incubation, primary antibodies (Lamin A - sc-376248, Lamin B1 - ab133741, H3K9me3 - ab176916), diluted in antibody dilution buffer (5\% Goat serum, $0.25 \%$ Triton in PBS) were added and incubated overnight at $4^{\circ} \mathrm{C}$. After primary antibody incubation, cells were washed 3 times with PBS for 5 minutes for each wash. Cells were then incubated with secondary antibodies (Alexa Fluor 594 and Alexa Fluor 488) per manufacturer's directions (2 drops of secondary antibody/1mL of PBS - R37117 and R37120) for 30 minutes at room temperature. After secondary antibody incubation, cells were washed 3 times with PBS and sealed using mounting media with DAPI. Slides were treated in the mounting media for 24 hours before imaging.

Cells were imaged using a Leica Sp8 Confocal microscope was equipped with a 63x oil immersion objective.

\section{Nuclear morphology analysis}

To analyze the diameter (minor axis), aspect ratio and standard deviation of maximum projected nuclei, Image J Shape Descriptor plugin was used. For morphological analysis of 3D reconstructed nuclei, Image J Nucleus J plugin was used with default parameters. Lamin A/C coefficient of variance was quantified as the ratio of Lamin A/C standard deviation to Lamin $\mathrm{A} / \mathrm{C}$ mean intensity.

\section{Radial distribution of Lamin A/C and H3K9me3}

Lamin A/C and $\mathrm{H} 3 \mathrm{~K} 9$ me3 radial distribution was quantified using Measure Object Intensity Distribution module in Cell Profiler. The maximum projected nuclei were separated into four 
equidistant bins. Mean fractional intensities for each bin (4 total bins; starting from innermost (bin1) to outermost (bin4) radial position) was plotted.

\section{Line scan analysis}

To quantify the distribution of Lamin A/C and H3K9me3 in the nucleus we also employed line scan analysis of nuclear central slices in Control, Top-5 and Bottom-5 cells. Line scans of same length were drawn across major and minor axis of nuclei using Leica SP8 Image Analysis software and intensity distribution was recorded for each nucleus. We then created bins of equal size ranging from 0-1 and normalized the distance for all nuclei. The line scan data from all the nuclei was aggregated by taking the mean of intensity values for each bin window.

\section{Western Blot}

A375 cells were trypsinized as previously described, and approximately 5 million cells were collected by centrifugation (1000 rcf, $5 \mathrm{~min}$, room temperature). The cell pellets were resuspended in $300 \mathrm{ml}$ of RIPA buffer (Thermo Scientific, I89900), supplemented with protease inhibitors/EDTA (GenDepot 50-101-5485), and phosphatase inhibitors (GenDepot 50-1015488). Cells were then incubated on ice for 10 minutes. DNA was degraded by adding $6 \mu$ of micrococcal nuclease $(0.5 \mathrm{U} / \mathrm{ml}$ stock, Thermo Scientific, FEREN0181) and $12 \mu \mathrm{l}$ of calcium chloride (100 mM stock) to each lysate, followed by incubation at $37^{\circ} \mathrm{C}$ for $15 \mathrm{~min}$. Nuclease activity was inhibited by subsequent incubations at $68{ }^{\circ} \mathrm{C}$ for $15 \mathrm{~min}$, and ice for $10 \mathrm{~min}$. Protein samples were stored at $-80^{\circ} \mathrm{C}$ until use. Protein concentration was measured using the BCA Protein Assay Kit. Thermo (234225), according to the manufacturer's instructions.

Denatured protein samples were resolved using a mini gel tank (Invitrogen, A25977) for 35 min at 200V, using 4-12\% Bis-Tris Plus gels (Invitrogen, NW04120BOX) for all targets. Protein was transferred to low fluorescence PVDF membranes using the mini Bolt Blotting System (Invitrogen, B1000), along with system-specific reagents. Blotting was performed using the Odyssey TBS blocking system (Licor, 927-400000), according to the manufacturer's protocol. Briefly, membranes were activated with methanol after transfer ( $1 \mathrm{~min}, \mathrm{RT})$, washed twice with milliQ water ( $5 \mathrm{~min}$ ), twice with TBS (2 min), and blocked with Odyssey TBS blocking solution for 1 hour at RT. Primary antibodies were diluted in blocking buffer (containing $0.2 \%$ Tween), and incubated over night at $4^{\circ} \mathrm{C}$ as follows: H3K9me3 (1:1000, ab176916), LaminA/C (1:1000, sc-376248) and LaminB1 (1:1000, ab133741). Beta actin was used as a loading control, using the appropriate antibody (1:10,000; rabbit polyclonal PA1-16889, Thermo Fisher or 1:10,000; mouse monoclonal MA1-140, Thermo Fisher) alongside with the targets of interest. Detection was carried out using the following secondary antibodies: goat anti-rabbit (1:10,000; IRDye 680RD [92568071]; Licor) and goat anti-mouse (1:10,000, IRDye 800CW [95-32210]; Licor). Secondary antibodies were diluted in Odyssey TBS blocking buffer containing $0.2 \%$ Tween and $0.01 \%$ SDS. Membranes were incubated in secondary antibody for 1 hour at RT, followed by three washes (TBST, 5 min each).

Images of near infrared fluorescent signal were acquired using an Odyssey scanner (Licor) in both the red and green channels. Signal was quantified using the Image Studio software (Licor). 


\section{Hi-C}

\section{Library Preparation}

Hi-C libraries were prepared for each cell sub-population (A375-Control, Top-5, Bottom-5, Top20-5, Bottom20-5, Top-12 and Bottom-12) as previously described (Golloshi et al., 2018) including two biological duplicates for each condition. Briefly, 10 million cells were grown in T75 cell culture flasks to $80-90 \%$ confluency and crosslinked with $1 \%$ formaldehyde for $10 \mathrm{~min}$. Crosslinked cells were then suspended in lysis buffer to permeabilize the cell membrane and were dounce homogenized. Chromatin was then digested in-nucleus overnight using DpnII restriction enzyme. Digested ends were filled in with biotin-dATP, and the blunt ends of interacting fragments were ligated together. DNA was then purified by phenol-chloroform extraction. For library preparation, the NEBNext Ultra II DNA Library prep kit (NEB) was used for libraries with size ranges from 200-400bp. End Prep, Adaptor Ligation, and PCR amplification reactions were carried out on bead bound DNA libraries.

Sequencing was performed at the Oklahoma Medical Research Foundation Clinical Genomics facility using the Illumina HiSeq 3000 platform with 75 bp paired end reads or a NovaSeq 6000 with 50 bp paired end reads. Sequencing reads were mapped to the human genome (hg19), filtered, and iteratively corrected as previously described (Imakaev et al., 2012) (https://github.com/dekkerlab/cMapping). All Hi-C contact matrices were scaled to a sum of 1 million interactions to allow comparisons between conditions in downstream analysis. For library quality and mapping statistics see Table S1.

\section{Compartment Analysis}

Compartment analysis was performed by running principal component analysis using matrix 2compartment.pl script in the cworld-dekker pipeline available on GitHub (https://github.com/dekkerlab/cworld-dekker). The PC1 value was then used to determine compartment identity for 100 and $250 \mathrm{~Kb}$ binned matrices. We considered PC1 values greater than 0.01 to be A compartment and less than -0.01 to be B compartment for this analysis and determination of compartment switches.

\section{Saddle Plots}

Saddle plots were constructed to investigate changes in interaction frequency between or within compartments in highly migratory and non-migratory melanoma cells. Briefly, PCA analysis was performed on $100 \mathrm{~Kb}$ binned matrices to assign compartment identity for each bin. For the analysis, interaction zScores, normalizing for interaction decay for genomic distance, were calculated according to the matrix 2compartment.pl script in cworld-dekker. Zscore matrices were reordered based on compartment strength (from strongest B to strongest A using eigenvector values). Finally, matrices were smoothed at $500 \mathrm{~Kb}$ bin size.

\section{Interchromosomal Fraction (ICF)}

Ratio of interchromosomal interactions relative to the total number of interactions for a given chromosome as previously described (Heinz et al., 2018). 


$$
\begin{gathered}
I C F=\frac{\text { Interchromosomal Interactions }}{\text { Inter }+ \text { Intra chromosomal Interactions }} \\
\text { deltaICF }=\text { ICFBottom }- \text { ICFTop }
\end{gathered}
$$

\section{Distal to Local Ratio (DLR)}

$\mathrm{Log} 2$ ratio of $\mathrm{HiC}$ interactions with distance greater than $3 \mathrm{Mb}$ relative to local interactions less than $3 \mathrm{Mb}$ away. To find the change in DLR after constricted migration, delta DLR was calculated as DLR Bottom $_{-}$DLR $_{\text {Top }}$ as previously described (Heinz et al., 2018).

$$
\begin{gathered}
D L R=\log 2 \frac{\text { Distal Interactions }(>3 M b)}{\text { Local Interactions }(<3 M b)} \\
\text { deltaDLR }=\text { DLRTop }- \text { DLRBottom }
\end{gathered}
$$

\section{Copy Number Variation Estimation}

CNV estimation was performed using the approach available from https://github.com/nservant/cancer-hic-norm (Servant et al., 2018)

\section{Translocation Detection and Frequency Calculation}

For the novel translocation visibly evident in $2.5 \mathrm{Mb}$ binned contact maps for Bottom-5 constricted migrated cells, we further pinpointed the specific break site on each chromosome (chr5 and chr13) using raw valid pair counts within the region. First, we filtered all valid pair interactions between chr 5 and chr13 to include only regions of chr13 between 38.3 and $57.5 \mathrm{Mb}$ (a range of coordinates upstream of the translocation site, which all interact more than expected with chr5). Then, we plotted a histogram of interaction frequencies between each locus along chr5 and this set of chr13 coordinates. We noted a sharp interaction drop within the region chr5:12.24-12.25 Mb, which represents the translocation breakpoint. We then reversed this process to determine the breakpoint along chr13.

To calculate the percent of chromosomes containing this chr5-13 translocation in each subpopulation, we first found the $2.5 \mathrm{Mb}$ bin with the maximum raw $\mathrm{Hi}-\mathrm{C}$ counts near the translocation site in Bottom-5 cells. We then calculated an average value for raw Hi-C counts between neighboring bins (one bin off diagonal) in cis on chr7. We then calculated the percent of chromosomes bearing the translocation in any given cell type as the ratio of raw interaction counts at the translocation bin over average interaction counts between neighbors in cis. Given the median triploid karyotype of A375 cells, we then multiplied this \% of chromosomes by 3 to estimate a $\%$ of cells carrying the translocation.

\section{Distance Decay Scaling Plots}

Using 40 and $20 \mathrm{~Kb}$ binned iteratively corrected and scaled contact matrices, we extracted contact frequencies between bins at each genomic distance, excluding the diagonal bin (zero distance). A loess fit was then used to find a smooth curve describing interaction decay vs. distance (using the matrix2loess.pl script in cworld-dekker). The interaction frequencies were 
then normalized to set the maximum value (loess fit interaction value for the minimum distance) for each dataset to 1 and then plotted on a log scale vs. log genomic distance.

\section{RNA-Seq}

\section{Library Preparation}

For Control, Top-5 and Bottom-5 A375 cells, RNA was extracted, and the library was prepared in our laboratory. Briefly, RNA was extracted using Qiagen RNAeasy plus mini kit (Cat. No. 74134). Cells were lysed and homogenized, spun down in gDNA eliminator columns to remove any genomic DNA. All samples were washed with ethanol and the total RNA was eluted. The quality and quantity of the RNA were quantified using Agilent Bioanalyzer Nano RNA kit. All the libraries used were characterized by a RIN value between 9 and 10. rRNA was depleted using NebNext rRNA Depletion Kit (Cat. No. E6310S). Total RNA was hybridized to the probe followed by RNaseH and DNase I digestion. RNA was then purified using AmpureXP beads from Beckman Coulter (Ref. A63881) at a 2.2x concentration of beads. RNA libraries were prepared using NebNext Ultra II RNA library prep Kit (Cat. No. E7770G). After rRNA depletion, RNA was fragmented ( 200 nt) and primed following first and second strand cDNA synthesis. The double stranded cDNA was then purified using AmpureXP beads at a 1.8X concentration. After purification, cDNA libraries were end prepped, ligated adapter and PCR amplified for 7 cycles to enrichment for adaptor ligated DNA using NebNext Multiplex Oligos for illumine (Cat. No. E7335G). cDNA librariers were then purified using AmpureXP beads at a 0.9X concentration and their quality was checked using Agilent Bioanalyzer high sensitivity DNA kit. cDNA samples were then sent to Oklahoma Medical Research Facility (OMRF) for high throughput sequencing.

For the rest of A375 libraries, Top20-5, Bottom20-5, Top-12 and Bottom-12, RNA was extracted using the Qiagen RNAeasy plus mini kit as described above. Total RNA was then sent for library preparation and sequencing at GeneWiz. For library quality and mapping statistics see Table S2.

\section{RNA-Seq Data Analysis}

Quality of reads was checked using Fastqc and adapter sequences were trimmed using BBTools (https://github.com/kbaseapps/BBTools). Additionally, quality trimming of the reads was performed and any reads with a lower than 28 quality score were discarded. Reads were then aligned using STAR alignment (https://github.com/alexdobin/STAR) with an average alignment rate of $89 \%$. The aligned reads were then sorted by genomic position and feature counts was performed using htseq 0.11.1 (https://github.com/simon-anders/htseq). Differential expression of genes was determined by using DESeq through Galaxy.

\section{ATAC-Seq library preparation and analysis}

ATAC-Seq libraries for Top-5 and Bottom-5 cells was prepared as previously described (Buenrostro et al., 2015). Libraries were generated using Ad1_noMX and Ad2.1-2.3 barcoded primers from (Buenrostro et al., 2015) and were amplified for a total of 12-13 cycles. The quality and quantity of the libraries were measured using Agilent Bioanalyzer High Sensitivity DNA kit. Sequencing was performed at Oklahoma Medical Research Facility using HiSeq3000 with 75 bp paired end reads. For library quality and mapping statistics see Table S3. 


\section{ATAC-Seq Data Analysis.}

Adapters and reads with a quality score less than 20 were trimmed from the final libraries using Skewer/0.2.2 (https://github.com/relipmoc/skewer). Trimmed reads were aligned to the hg19 genome using bowtie 2 with default parameters (https://github.com/BenLangmead/bowtie2). Aligned reads were sorted, indexed and ChrM reads were removed using samtools. Duplicated reads were removed using Picard (https://github.com/broadinstitute/picard/blob/master/src/main/java/picard/sam/markduplicates/ MarkDuplicates.java). Finally, peaks were called using MACS2 (https://github.com/taoliu/MACS) with the following parameters: --nomodel --extsize 300 -g hs -keep-dup all.

\section{D Collagen Matrix}

Experiments investigating the morphology and migration of A375 subpopulation of cells in 3D environment were performed using single cell suspension in 3D collagen matrices (A375Control, A375-Top5 A375-Bottom10 generated from passage of A375 through 5 and $12 \mu \mathrm{m}$ sized pore transwells) as previously described (Denais et al., 2016). Briefly, 75,000 cells/condition were added into collagen matrices (Rat Tail, Corning 354236) with a density of $2.32 \mathrm{mg} / \mathrm{ml}$. The $\mathrm{pH}$ of the collagen gels was normalized to a neutral $\mathrm{pH}$ and gels were incubated at $37^{\circ} \mathrm{C}$ for $30 \mathrm{~min}$ to gel. After the incubation, media with full supplements was supplied to the collagen gels. Cell were allowed to migrate through the collagen for 5 days before the cells were stained and imaged.

\section{Immunofluorescence for $3 D$ collagen matrices}

Cells embedded on collagen were stained as previously described (Denais et al., 2016). Briefly, collagen matrices were fixed in $4 \%$ formaldehyde for $30 \mathrm{~min}$ at $37 \mathrm{C}$. Collagen matrices were then washed with 1 XPBS for $10 \mathrm{~min}$ for three times. Each collagen matrix was then incubated with blocking buffer $(0.5 \%$ Triton, $10 \%$ Goat Serum in 1xPBS) overnight at 4C. After blocking, samples were then incubated with primary antibody (LaminA - sc376248) at a 1:500 dilution in 1xBlocking Buffer:1xPBS at 4C overnight. After incubation, aspirate primary antibody solution and wash three times with $1 x P B S$ for 10 min each. Samples were then incubated in secondary antibody ( 2 drops/mL of PBS) for $1 \mathrm{hr}$ and room temperature. After secondary antibody incubation, samples were then washed with 1xPBS three times for 10 min each. Samples were incubated with DAPI $(1 \mu \mathrm{g} / \mathrm{mL})$ for $30 \mathrm{~min}$ at RT. Collagen matrices were then washed three times with 1xPBS for 10 min each. Z-stacks of collagen matrices were taken with Leica SP8 confocal microscope at 40x water objective.

Image analysis for cells embedded in $3 D$ collagen matrices

Aspect ratio and Lamin A/C standard deviation of maximum projected nuclei was quantified using ImageJ plugin Shape Descriptors. Tracking of cells migrating in 3D collagen matrices was performed using ImageJ Manual Tracking plugin. The resulting data was then used in Chemotaxis and Migration tool (Ibidi) to generate accumulated distance and velocity measurements.

\section{Agent Based Modeling of Constricted Migration}


We model constricted cell migration using an on-lattice two-dimensional (2D) agent-based model (ABM) system. In this model, cells are represented by agents. The basic building block of this agent-based system is obtained from the collective cell migration ABM (collectiveABM), available on GitHub (https://github.com/zcolburn/cell-sheet-abm) and necessary changes are made to model cell transmigration. Most of the parameter values and the model working procedures of collective ABM are kept untouched unless otherwise mentioned. Since the collectiveABM models a wound healing assay, we exclude the wound scratch section of the code from our model. We use two squared 2D grid spaces of size 20x20 to the agent-based system in place of a single 2D grid space: one to represent the top of the transwell, where the cells are seeded at the beginning of each round of sequential migration, and another to represent the bottom of the transwell, where the cells transmigrate from the top compartment. The beginning of each round of sequential migration model starts with 2000 cells seeded on the top compartment. The population of the cells is either considered to be homogenous or heterogeneous depending on the transmigration probability (Pmig). A total of 25 timepoint iterations are implemented to mimic the $\sim 24$ hour duration of experimental migration rounds. At each timestep, each cell can choose to either transmigrate to the bottom, divide, die, or move horizontally. After each round of sequential migrations, the proportion of cells in the bottom and top compartment is measured, and the cells from the bottom or top are propagated to the next simulated round of migration. The directionality of the transmigration is only from top to bottom compartment and once the cells reach the bottom compartment, they stay there. The constricted migration of a cell is modeled by comparing its assigned Pmig with a uniform random number drawn from the range $[0,1)$. If the random number is less than Pmig, then that cell will transmigrate to the bottom compartment from the top. In addition to having models with fixed Pmig values, we also designed agent-based model systems having variable Pmig : 1) the Pmig value of bottom cells are boosted by a function after each round and 2) each cell has different Pmig, drawn from a normal distribution and after each round, the mean and standard deviation of top or bottom compartment cells depending on the sequential transwell migration experiment type will be used in next round's normal distribution. The efficiency of migration is calculated at the end of each round by dividing the number of cells in the bottom compartment by total cells in the top and bottom compartments combined. For all the different test cases, three independent runs are performed by using different random number seeds.

\section{DATA AND SOFTWARE AVAILABILITY}

All relevant data supporting the key findings of this study are available within the article and its Supplementary Information files or from the corresponding author on reasonable request. Hi-C, RNA-Seq, and ATAC-Seq sequence data and processed data for A375 cell line experiments are deposited under GEO: GSE143678. Software and code used for the analyses presented are available as public github packages, as described in the Methods section.

\section{REFERENCES}


ABBAS, A., HE, X., NIU, J., ZHOU, B., ZHU, G., MA, T., SONG, J., GAO, J., ZHANG, M. Q. \& ZENG, J. 2019. Integrating $\mathrm{Hi}-\mathrm{C}$ and FISH data for modeling of the 3D organization of chromosomes. Nat Commun, 10, 2049.

ANDERS, S., PYL, P. T. \& HUBER, W. 2015. HTSeq--a Python framework to work with high-throughput sequencing data. Bioinformatics, 31, 166-9.

BARUTCU, A. R., LAJOIE, B. R., MCCORD, R. P., TYE, C. E., HONG, D., MESSIER, T. L., BROWNE, G., VAN WIJNEN, A. J., LIAN, J. B., STEIN, J. L., DEKKER, J., IMBALZANO, A. N. \& STEIN, G. S. 2015. Chromatin interaction analysis reveals changes in small chromosome and telomere clustering between epithelial and breast cancer cells. Genome Biol, 16, 214.

BASKARAN, J. P., WELDY, A., GUARIN, J., MUNOZ, G., SHPILKER, P. H., KOTLIK, M., SUBBIAH, N., WISHART, A., PENG, Y., MILLER, M. A., COWEN, L. \& OUDIN, M. J. 2020. Cell shape, and not 2D migration, predicts extracellular matrix-driven $3 D$ cell invasion in breast cancer. APL Bioeng, 4, 026105.

BELAGHZAL, H., BORRMAN, T., STEPHENS, A. D., LAFONTAINE, D. L., VENEV, S. V., WENG, Z., MARKO, J. F. \& DEKKER, J. 2019. Compartment-dependent chromatin interaction dynamics revealed by liquid chromatin Hi-C. bioRxiv, 704957.

BICKMORE, W. A. \& VAN STEENSEL, B. 2013. Genome architecture: domain organization of interphase chromosomes. Cell, 152, 1270-84.

BRANDAO, H. B., PAUL, P., VAN DEN BERG, A. A., RUDNER, D. Z., WANG, X. \& MIRNY, L. A. 2019. RNA polymerases as moving barriers to condensin loop extrusion. Proc Natl Acad Sci U S A, 116, 20489-20499.

BROERS, J. L., RAYMOND, Y., ROT, M. K., KUIJPERS, H., WAGENAAR, S. S. \& RAMAEKERS, F. C. 1993. Nuclear A-type lamins are differentially expressed in human lung cancer subtypes. Am J Pathol, 143, 211-20.

BUENROSTRO, J. D., WU, B., CHANG, H. Y. \& GREENLEAF, W. J. 2015. ATAC-seq: A Method for Assaying Chromatin Accessibility Genome-Wide. Curr Protoc Mol Biol, 109, 2129 1-9.

CAROLYN DE GRAAF, J. K., LUDO PAGIE, DAAN PERIC HUPKES, BAS VAN STEENSEL. 2019. LAD Atlas [Online]. Available: https://osf.io/dk8pm/ [Accessed].

CHAMBERS, A. F., GROOM, A. C. \& MACDONALD, I. C. 2002. Dissemination and growth of cancer cells in metastatic sites. Nat Rev Cancer, 2, 563-72.

DAMSKY, W. E., ROSENBAUM, L. E. \& BOSENBERG, M. 2010. Decoding melanoma metastasis. Cancers, 3, 126-163.

DAVIDSON, P. M., DENAIS, C., BAKSHI, M. C. \& LAMMERDING, J. 2014. Nuclear deformability constitutes a rate-limiting step during cell migration in 3-D environments. Cell Mol Bioeng, 7, 293-306.

DAVIDSON, P. M. \& LAMMERDING, J. 2014. Broken nuclei--lamins, nuclear mechanics, and disease. Trends Cell Biol, 24, 247-56.

DEKKER, J., RIPPE, K., DEKKER, M. \& KLECKNER, N. 2002. Capturing chromosome conformation. Science, 295, 1306-11.

DENAIS, C. M., GILBERT, R. M., ISERMANN, P., MCGREGOR, A. L., TE LINDERT, M., WEIGELIN, B., DAVIDSON, P. M., FRIEDL, P., WOLF, K. \& LAMMERDING, J. 2016. Nuclear envelope rupture and repair during cancer cell migration. Science, 352, 353-8.

DOBIN, A., DAVIS, C. A., SCHLESINGER, F., DRENKOW, J., ZALESKI, C., JHA, S., BATUT, P., CHAISSON, M. \& GINGERAS, T. R. 2013. STAR: ultrafast universal RNA-seq aligner. Bioinformatics, 29, 15-21.

FALK, M., FEODOROVA, Y., NAUMOVA, N., IMAKAEV, M., LAJOIE, B. R., LEONHARDT, H., JOFFE, B., DEKKER, J., FUDENBERG, G., SOLOVEI, I. \& MIRNY, L. A. 2019. Heterochromatin drives compartmentalization of inverted and conventional nuclei. Nature, 570, 395-399.

FIDLER, I. J. 2003. The pathogenesis of cancer metastasis: the 'seed and soil' hypothesis revisited. Nat Rev Cancer, 3, 453-8. 
FRIEDL, P., WOLF, K. \& LAMMERDING, J. 2011. Nuclear mechanics during cell migration. Curr Opin Cell Biol, 23, 55-64.

FU, Y., CHIN, L. K., BOUROUINA, T., LIU, A. Q. \& VANDONGEN, A. M. 2012. Nuclear deformation during breast cancer cell transmigration. Lab Chip, 12, 3774-8.

GASPAR-MAIA, A., ALAJEM, A., MESHORER, E. \& RAMALHO-SANTOS, M. 2011. Open chromatin in pluripotency and reprogramming. Nat Rev Mol Cell Biol, 12, 36-47.

GERLITZ, G. \& BUSTIN, M. 2010. Efficient cell migration requires global chromatin condensation. J Cell Sci, 123, 2207-17.

GOLLOSHI, R., SANDERS, J. T. \& MCCORD, R. P. 2018. Iteratively improving Hi-C experiments one step at a time. Methods, 142, 47-58.

GUPTA, G. P. \& MASSAGUE, J. 2006. Cancer metastasis: building a framework. Cell, 127, 679-95.

HARADA, T., SWIFT, J., IRIANTO, J., SHIN, J. W., SPINLER, K. R., ATHIRASALA, A., DIEGMILLER, R., DINGAL, P. C., IVANOVSKA, I. L. \& DISCHER, D. E. 2014. Nuclear lamin stiffness is a barrier to 3D migration, but softness can limit survival. J Cell Biol, 204, 669-82.

HEINZ, S., TEXARI, L., HAYES, M. G. B., URBANOWSKI, M., CHANG, M. W., GIVARKES, N., RIALDI, A., WHITE, K. M., ALBRECHT, R. A., PACHE, L., MARAZZI, I., GARCIA-SASTRE, A., SHAW, M. L. \& BENNER, C. 2018. Transcription Elongation Can Affect Genome 3D Structure. Cell, 174, 15221536 e22.

HNISZ, D., WEINTRAUB, A. S., DAY, D. S., VALTON, A. L., BAK, R. O., LI, C. H., GOLDMANN, J., LAJOIE, B. R., FAN, Z. P., SIGOVA, A. A., REDDY, J., BORGES-RIVERA, D., LEE, T. I., JAENISCH, R., PORTEUS, M. H., DEKKER, J. \& YOUNG, R. A. 2016. Activation of proto-oncogenes by disruption of chromosome neighborhoods. Science, 351, 1454-8.

IMAKAEV, M., FUDENBERG, G., MCCORD, R. P., NAUMOVA, N., GOLOBORODKO, A., LAJOIE, B. R., DEKKER, J. \& MIRNY, L. A. 2012. Iterative correction of Hi-C data reveals hallmarks of chromosome organization. Nat Methods, 9, 999-1003.

IRIANTO, J., XIA, Y., PFEIFER, C. R., ATHIRASALA, A., JI, J., ALVEY, C., TEWARI, M., BENNETT, R. R., HARDING, S. M., LIU, A. J., GREENBERG, R. A. \& DISCHER, D. E. 2017a. DNA Damage Follows Repair Factor Depletion and Portends Genome Variation in Cancer Cells after Pore Migration. Curr Biol, 27, 210-223.

IRIANTO, J., XIA, Y., PFEIFER, C. R., GREENBERG, R. A. \& DISCHER, D. E. 2017b. As a Nucleus Enters a Small Pore, Chromatin Stretches and Maintains Integrity, Even with DNA Breaks. Biophys J, 112, 446-449.

JACOBSON, E. C., PERRY, J. K., LONG, D. S., OLINS, A. L., OLINS, D. E., WRIGHT, B. E., VICKERS, M. H. \& O'SULLIVAN, J. M. 2018. Migration through a small pore disrupts inactive chromatin organization in neutrophil-like cells. BMC Biol, 16, 142.

JIN, F., LI, Y., DIXON, J. R., SELVARAJ, S., YE, Z., LEE, A. Y., YEN, C. A., SCHMITT, A. D., ESPINOZA, C. A. \& REN, B. 2013. A high-resolution map of the three-dimensional chromatin interactome in human cells. Nature, 503, 290-4.

KADOTA, K., SUZUKI, K., COLOVOS, C., SIMA, C. S., RUSCH, V. W., TRAVIS, W. D. \& ADUSUMILLI, P. S. 2012. A nuclear grading system is a strong predictor of survival in epitheloid diffuse malignant pleural mesothelioma. Mod Pathol, 25, 260-71.

KIM, D. H. \& WIRTZ, D. 2013. Focal adhesion size uniquely predicts cell migration. FASEB J, 27, 1351-61.

KIND, J., PAGIE, L., DE VRIES, S. S., NAHIDIAZAR, L., DEY, S. S., BIENKO, M., ZHAN, Y., LAJOIE, B., DE GRAAF, C. A., AMENDOLA, M., FUDENBERG, G., IMAKAEV, M., MIRNY, L. A., JALINK, K., DEKKER, J., VAN OUDENAARDEN, A. \& VAN STEENSEL, B. 2015. Genome-wide maps of nuclear lamina interactions in single human cells. Cell, 163, 134-47.

KOZLOWSKI, J. M., HART, I. R., FIDLER, I. J. \& HANNA, N. 1984. A human melanoma line heterogeneous with respect to metastatic capacity in athymic nude mice. J Natl Cancer Inst, 72, 913-7. 
KRAUSE, M., YANG, F. W., TE LINDERT, M., ISERMANN, P., SCHEPENS, J., MAAS, R. J. A., VENKATARAMAN, C., LAMMERDING, J., MADZVAMUSE, A., HENDRIKS, W., TE RIET, J. \& WOLF, K. 2019. Cell migration through three-dimensional confining pores: speed accelerations by deformation and recoil of the nucleus. Philos Trans R Soc Lond B Biol Sci, 374, 20180225.

KRIJGER, P. H. \& DE LAAT, W. 2016. Regulation of disease-associated gene expression in the 3D genome. Nat Rev Mol Cell Biol, 17, 771-782.

LAMBERT, A. W., PATTABIRAMAN, D. R. \& WEINBERG, R. A. 2017. Emerging Biological Principles of Metastasis. Cell, 168, 670-691.

LAMMERDING, J., FONG, L. G., JI, J. Y., REUE, K., STEWART, C. L., YOUNG, S. G. \& LEE, R. T. 2006. Lamins $A$ and $C$ but not lamin B1 regulate nuclear mechanics. $J$ Biol Chem, 281, 25768-80.

LANGMEAD, B. \& SALZBERG, S. L. 2012. Fast gapped-read alignment with Bowtie 2. Nat Methods, 9, 3579.

LARSON, A. G., ELNATAN, D., KEENEN, M. M., TRNKA, M. J., JOHNSTON, J. B., BURLINGAME, A. L., AGARD, D. A., REDDING, S. \& NARLIKAR, G. J. 2017. Liquid droplet formation by HP1alpha suggests a role for phase separation in heterochromatin. Nature, 547, 236-240.

LE, H. Q., GHATAK, S., YEUNG, C. Y., TELLKAMP, F., GUNSCHMANN, C., DIETERICH, C., YEROSLAVIZ, A., HABERMANN, B., POMBO, A., NIESSEN, C. M. \& WICKSTROM, S. A. 2016. Mechanical regulation of transcription controls Polycomb-mediated gene silencing during lineage commitment. Nat Cell Biol, 18, 864-75.

LEE, J. S., HALE, C. M., PANORCHAN, P., KHATAU, S. B., GEORGE, J. P., TSENG, Y., STEWART, C. L., HODZIC, D. \& WIRTZ, D. 2007. Nuclear lamin A/C deficiency induces defects in cell mechanics, polarization, and migration. Biophys J, 93, 2542-52.

LI, H., HANDSAKER, B., WYSOKER, A., FENNELL, T., RUAN, J., HOMER, N., MARTH, G., ABECASIS, G., DURBIN, R. \& GENOME PROJECT DATA PROCESSING, S. 2009. The Sequence Alignment/Map format and SAMtools. Bioinformatics, 25, 2078-9.

LOVE, M. I., HUBER, W. \& ANDERS, S. 2014. Moderated estimation of fold change and dispersion for RNA-seq data with DESeq2. Genome Biol, 15, 550.

LYONS, S. M., ALIZADEH, E., MANNHEIMER, J., SCHUAMBERG, K., CASTLE, J., SCHRODER, B., TURK, P., THAMM, D. \& PRASAD, A. 2016. Changes in cell shape are correlated with metastatic potential in murine and human osteosarcomas. Biol Open, 5, 289-99.

MACHESKY, L. M. 2008. Lamellipodia and filopodia in metastasis and invasion. FEBS Lett, 582, 2102-11.

MAIZELS, Y., ELBAZ, A., HERNANDEZ-VICENS, R., SANDRUSY, O., ROSENBERG, A. \& GERLITZ, G. 2017. Increased chromatin plasticity supports enhanced metastatic potential of mouse melanoma cells. Exp Cell Res, 357, 282-290.

MARCHAL, C., SIMA, J. \& GILBERT, D. M. 2019. Control of DNA replication timing in the 3D genome. Nat Rev Mol Cell Biol.

MIRNY, L. A., IMAKAEV, M. \& ABDENNUR, N. 2019. Two major mechanisms of chromosome organization. Curr Opin Cell Biol, 58, 142-152.

MIROSHNIKOVA, Y. A., NAVA, M. M. \& WICKSTROM, S. A. 2017. Emerging roles of mechanical forces in chromatin regulation. J Cell Sci, 130, 2243-2250.

NAVA, M. M., MIROSHNIKOVA, Y. A., BIGGS, L. C., WHITEFIELD, D. B., METGE, F., BOUCAS, J., VIHINEN, H., JOKITALO, E., LI, X., GARCIA ARCOS, J. M., HOFFMANN, B., MERKEL, R., NIESSEN, C. M., DAHL, K. N. \& WICKSTROM, S. A. 2020. Heterochromatin-Driven Nuclear Softening Protects the Genome against Mechanical Stress-Induced Damage. Cell, 181, 800-817 e22.

NUEBLER, J., FUDENBERG, G., IMAKAEV, M., ABDENNUR, N. \& MIRNY, L. A. 2018. Chromatin organization by an interplay of loop extrusion and compartmental segregation. Proc Natl Acad Sci U S A, 115, E6697-E6706.

OPPENHEIMER, S. B. 2006. Cellular basis of cancer metastasis: A review of fundamentals and new advances. Acta Histochem, 108, 327-34. 
PANAGIOTAKOPOULOU, M., BERGERT, M., TAUBENBERGER, A., GUCK, J., POULIKAKOS, D. \& FERRARI, A. 2016. A Nanoprinted Model of Interstitial Cancer Migration Reveals a Link between Cell Deformability and Proliferation. ACS Nano, 10, 6437-48.

POMBO, A. \& DILLON, N. 2015. Three-dimensional genome architecture: players and mechanisms. Nat Rev Mol Cell Biol, 16, 245-57.

QUINLAN, A. R. \& HALL, I. M. 2010. BEDTools: a flexible suite of utilities for comparing genomic features. Bioinformatics, 26, 841-2.

RAAB, M., GENTILI, M., DE BELLY, H., THIAM, H. R., VARGAS, P., JIMENEZ, A. J., LAUTENSCHLAEGER, F., VOITURIEZ, R., LENNON-DUMENIL, A. M., MANEL, N. \& PIEL, M. 2016. ESCRT III repairs nuclear envelope ruptures during cell migration to limit DNA damage and cell death. Science, 352, 35962.

RAMASWAMY, S., ROSS, K. N., LANDER, E. S. \& GOLUB, T. R. 2003. A molecular signature of metastasis in primary solid tumors. Nat Genet, 33, 49-54.

ROWAT, A. C., JAALOUK, D. E., ZWERGER, M., UNG, W. L., EYDELNANT, I. A., OLINS, D. E., OLINS, A. L., HERRMANN, H., WEITZ, D. A. \& LAMMERDING, J. 2013. Nuclear envelope composition determines the ability of neutrophil-type cells to passage through micron-scale constrictions. $J$ Biol Chem, 288, 8610-8.

ROWLEY, M. J. \& CORCES, V. G. 2018. Organizational principles of 3D genome architecture. Nat Rev Genet, 19, 789-800.

ROWLEY, M. J., NICHOLS, M. H., LYU, X., ANDO-KURI, M., RIVERA, I. S. M., HERMETZ, K., WANG, P., RUAN, Y. \& CORCES, V. G. 2017. Evolutionarily Conserved Principles Predict 3D Chromatin Organization. Mol Cell, 67, 837-852 e7.

SCHWARZER, W., ABDENNUR, N., GOLOBORODKO, A., PEKOWSKA, A., FUDENBERG, G., LOE-MIE, Y., FONSECA, N. A., HUBER, W., HAERING, C. H., MIRNY, L. \& SPITZ, F. 2017. Two independent modes of chromatin organization revealed by cohesin removal. Nature, 551, 51-56.

SEGAL, T., SALMON-DIVON, M. \& GERLITZ, G. 2018. The Heterochromatin Landscape in Migrating Cells and the Importance of H3K27me3 for Associated Transcriptome Alterations. Cells, 7.

SERVANT, N., VAROQUAUX, N., HEARD, E., BARILLOT, E. \& VERT, J. P. 2018. Effective normalization for copy number variation in Hi-C data. BMC Bioinformatics, 19, 313.

SHIVASHANKAR, G. V. 2019. Mechanical regulation of genome architecture and cell-fate decisions. Curr Opin Cell Biol, 56, 115-121.

SPIELMANN, M., LUPIANEZ, D. G. \& MUNDLOS, S. 2018. Structural variation in the 3D genome. Nat Rev Genet, 19, 453-467.

STEPHENS, A. D., BANIGAN, E. J., ADAM, S. A., GOLDMAN, R. D. \& MARKO, J. F. 2017. Chromatin and lamin A determine two different mechanical response regimes of the cell nucleus. Mol Biol Cell, 28, 1984-1996.

STEPHENS, A. D., LIU, P. Z., BANIGAN, E. J., ALMASSALHA, L. M., BACKMAN, V., ADAM, S. A., GOLDMAN, R. D. \& MARKO, J. F. 2018. Chromatin histone modifications and rigidity affect nuclear morphology independent of lamins. Mol Biol Cell, 29, 220-233.

STROM, A. R., EMELYANOV, A. V., MIR, M., FYODOROV, D. V., DARZACQ, X. \& KARPEN, G. H. 2017. Phase separation drives heterochromatin domain formation. Nature, 547, 241-245.

SWIFT, J., IVANOVSKA, I. L., BUXBOIM, A., HARADA, T., DINGAL, P. C., PINTER, J., PAJEROWSKI, J. D., SPINLER, K. R., SHIN, J. W., TEWARI, M., REHFELDT, F., SPEICHER, D. W. \& DISCHER, D. E. 2013. Nuclear lamin-A scales with tissue stiffness and enhances matrix-directed differentiation. Science, 341, 1240104.

TABERLAY, P. C., ACHINGER-KAWECKA, J., LUN, A. T., BUSKE, F. A., SABIR, K., GOULD, C. M., ZOTENKO, E., BERT, S. A., GILES, K. A., BAUER, D. C., SMYTH, G. K., STIRZAKER, C., O'DONOGHUE, S. I. \& CLARK, S. J. 2016. Three-dimensional disorganization of the cancer genome occurs coincident with longrange genetic and epigenetic alterations. Genome Res, 26, 719-31. 
TAJIK, A., ZHANG, Y., WEI, F., SUN, J., JIA, Q., ZHOU, W., SINGH, R., KHANNA, N., BELMONT, A. S. \& WANG, N. 2016. Transcription upregulation via force-induced direct stretching of chromatin. Nat Mater, 15, 1287-1296.

TORVALDSON, E., KOCHIN, V. \& ERIKSSON, J. E. 2015. Phosphorylation of lamins determine their structural properties and signaling functions. Nucleus, 6, 166-71.

VAN STEENSEL, B. \& BELMONT, A. S. 2017. Lamina-Associated Domains: Links with Chromosome Architecture, Heterochromatin, and Gene Repression. Cell, 169, 780-791.

VENABLES, R. S., MCLEAN, S., LUNY, D., MOTELEB, E., MORLEY, S., QUINLAN, R. A., LANE, E. B. \& HUTCHISON, C. J. 2001. Expression of individual lamins in basal cell carcinomas of the skin. $\mathrm{Br} J$ Cancer, 84, 512-9.

WAZIR, U., AHMED, M. H., BRIDGER, J. M., HARVEY, A., JIANG, W. G., SHARMA, A. K. \& MOKBEL, K. 2013. The clinicopathological significance of lamin $A / C$, lamin $B 1$ and lamin $B$ receptor $m R N A$ expression in human breast cancer. Cell Mol Biol Lett, 18, 595-611.

WILLIS, N. D., COX, T. R., RAHMAN-CASANS, S. F., SMITS, K., PRZYBORSKI, S. A., VAN DEN BRANDT, P., VAN ENGELAND, M., WEIJENBERG, M., WILSON, R. G., DE BRUINE, A. \& HUTCHISON, C. J. 2008. Lamin A/C is a risk biomarker in colorectal cancer. PLoS One, 3, e2988.

WOLF, K., TE LINDERT, M., KRAUSE, M., ALEXANDER, S., TE RIET, J., WILLIS, A. L., HOFFMAN, R. M., FIGDOR, C. G., WEISS, S. J. \& FRIEDL, P. 2013. Physical limits of cell migration: control by ECM space and nuclear deformation and tuning by proteolysis and traction force. J Cell Biol, 201, 1069-84.

YANKASKAS, C. L., THOMPSON, K. N., PAUL, C. D., VITOLO, M. I., MISTRIOTIS, P., MAHENDRA, A., BAJPAI, V. K., SHEA, D. J., MANTO, K. M., CHAI, A. C., VARADARAJAN, N., KONTROGIANNIKONSTANTOPOULOS, A., MARTIN, S. S. \& KONSTANTOPOULOS, K. 2019. A microfluidic assay for the quantification of the metastatic propensity of breast cancer specimens. Nat Biomed Eng, 3 , 452-465.

ZHANG, D., HUANG, P., SHARMA, M., KELLER, C. A., GIARDINE, B., ZHANG, H., GILGENAST, T. G., PHILLIPS-CREMINS, J. E., HARDISON, R. C. \& BLOBEL, G. A. 2020. Alteration of genome folding via contact domain boundary insertion. Nat Genet, 52, 1076-1087.

ZHANG, Y., LIU, T., MEYER, C. A., EECKHOUTE, J., JOHNSON, D. S., BERNSTEIN, B. E., NUSBAUM, C., MYERS, R. M., BROWN, M., LI, W. \& LIU, X. S. 2008. Model-based analysis of ChIP-Seq (MACS). Genome Biol, 9, R137.

ZHANG, Y., MCCORD, R. P., HO, Y. J., LAJOIE, B. R., HILDEBRAND, D. G., SIMON, A. C., BECKER, M. S., ALT, F. W. \& DEKKER, J. 2012. Spatial organization of the mouse genome and its role in recurrent chromosomal translocations. Cell, 148, 908-21.

ZHOU, Y., GERRARD, D. L., WANG, J., LI, T., YANG, Y., FRITZ, A. J., RAJENDRAN, M., FU, X., SCHIFF, R., LIN, S., FRIETZE, S. \& JIN, V. X. 2019. Temporal dynamic reorganization of 3D chromatin architecture in hormone-induced breast cancer and endocrine resistance. Nat Commun, 10, 1522. 